\title{
Teachers' perceptions of the goals of secondary schools physical education in state of Kuwait
}

\author{
Obaid Alshammari \\ West Virginia University
}

Follow this and additional works at: https://researchrepository.wvu.edu/etd

\section{Recommended Citation}

Alshammari, Obaid, "Teachers' perceptions of the goals of secondary schools physical education in state of Kuwait" (2004). Graduate Theses, Dissertations, and Problem Reports. 2548.

https://researchrepository.wvu.edu/etd/2548

This Dissertation is protected by copyright and/or related rights. It has been brought to you by the The Research Repository @ WVU with permission from the rights-holder(s). You are free to use this Dissertation in any way that is permitted by the copyright and related rights legislation that applies to your use. For other uses you must obtain permission from the rights-holder(s) directly, unless additional rights are indicated by a Creative Commons license in the record and/ or on the work itself. This Dissertation has been accepted for inclusion in WVU Graduate Theses, Dissertations, and Problem Reports collection by an authorized administrator of The Research Repository @ WVU.

For more information, please contact researchrepository@mail.wvu.edu. 
Teachers' Perceptions of the Goals of Secondary Schools Physical Education in State of Kuwait

\author{
Obaid Alshammari \\ Dissertation submitted to the \\ College of Human Resources and Education \\ at West Virginia University \\ in partial fulfillment of the requirements \\ for the degree of
}

Doctor of Education

in

Curriculum and Instruction

Perry Phillips, Ed.D., Chair

C. Kenneth Murray, Ph.D.

Ernest R. Goeres, Ph.D.

W. Scott Bower, Ph.D.

William Phillips, Ph.D.

Department of Curriculum and I nstruction

Morgantown, West Virginia

2004

Keywords: Physical Education Goals, Teacher's Perception, Secondary Education 


\title{
ABSTRACT \\ Teachers' Perceptions of the Goals of Secondary Schools Physical Education in State of Kuwait
}

\author{
Obaid Alshammari
}

The purpose of this study was to investigate the perceptions of the Kuwait physical education teachers relevant to the goals of the physical education program for secondary schools. Data were collected from a sample consisting of $200 \quad(n=200)$ physical education teachers teaching in six provinces in Kuwait. For data collection, a five-point Likert scale questionnaire, named "Kuwaiti Physical Education Goals" (KPEG) was designed. The instrument asked the participants to indicate the level of agreement with four categories of physical education goals. In addition, differences in teachers based on gender between physical education teachers' perceptions were investigated. An examination was also made to see if there were differences in teachers' perception of the physical education goals based on the number of years of teaching. Research questions were analyzed using descriptive and inferential analyses. The results established that affective $(M=2.71)$ and psychomotor domain goals $(M=2.76)$ were perceived positively while the cognitive $(M=3.34)$ and health domains $(M=3.09)$ were perceived negatively. Also, the result showed that female and male physical educators differ to a certain extent in their perceptions relevant to the goals presented in the KPEG items. Further, it was established that the psychomotor domain goals were perceived positively at the top (52.2\%), followed by affective domain goals $(51.8 \%)$, then health related $(46.0 \%)$ and finally, cognitive domain goals $(41.4 \%)$. Significant differences $(p=.014)$ ware found between group 1-5 and 11-15. A major conclusion made was that the significant differences found between male and female teachers suggest that there are cultural and gender influences on teaching physical education in Kuwait. Similarly, years of teaching do not have significant influence on teachers' perception of physical education goals. Finally, physical education program in Kuwait can be said to be effective in attaining only the psychomotor and affective domain goals. Major implications for this study were that physical educators in Kuwait need professional development to assist them in applying the concepts of the cognitive and health-related fitness domain to their students. Similarly, teachers should provide their students with information regarding the needs and values of practicing heath-related fitness exercises. 


\section{DEDI CATI ON}

To my late valuable and precious father, Mohammad Obaid Al-Shammari, may Allah accept you among the forgiven, my dear beloved mother whom I shall always be grateful to for her relentless support and supplication, my dear wife for being there for me at all times, my dearest children, Nouf, Mohammad, Abdullah, Abdul-Rahman, Fatima, Arwa, and beloved brothers. 


\section{ACKNOWLEDGEMENTS}

All praises and thanks are due to Allah (God), the Most Gracious the Most Merciful, for giving me the strength and ability to complete this dissertation. I would like to express my deepest gratitude and appreciation to my academic advisor Dr. Perry Phillips for his assistance, advice, guidance, criticism, feedback, valuable comments, noble conduct, and insistence on taking this study to success.

I would also like to thank my committee members, Dr. Kenneth Murray, Dr. Ernest Goeres, Dr. Scott Bower, and Dr. William Phillips, for their valuable support, suggestions, and remarks that significantly improved the quality of this dissertation.

Special thanks go to Dr. Abdul-Rahman Al-Gahtany, Dr. Saleh Al-Abdul-Kareem, and Dr. Maher Al-Ghanem for their guidance, continuous support, and kind reception. In addition, I cannot forget my dear friends and brothers Abdullah Al-Shammari, Fahad Kanan, and Nayef Al-Shammari.

Last but not least, I express my appreciation to my dear family including my late father, Mohammad Obaid Al-Shammari, mother, wife, children, and brothers who were most patient, loving, and offered me lots of supplication. 
TABLE OF CONTENTS

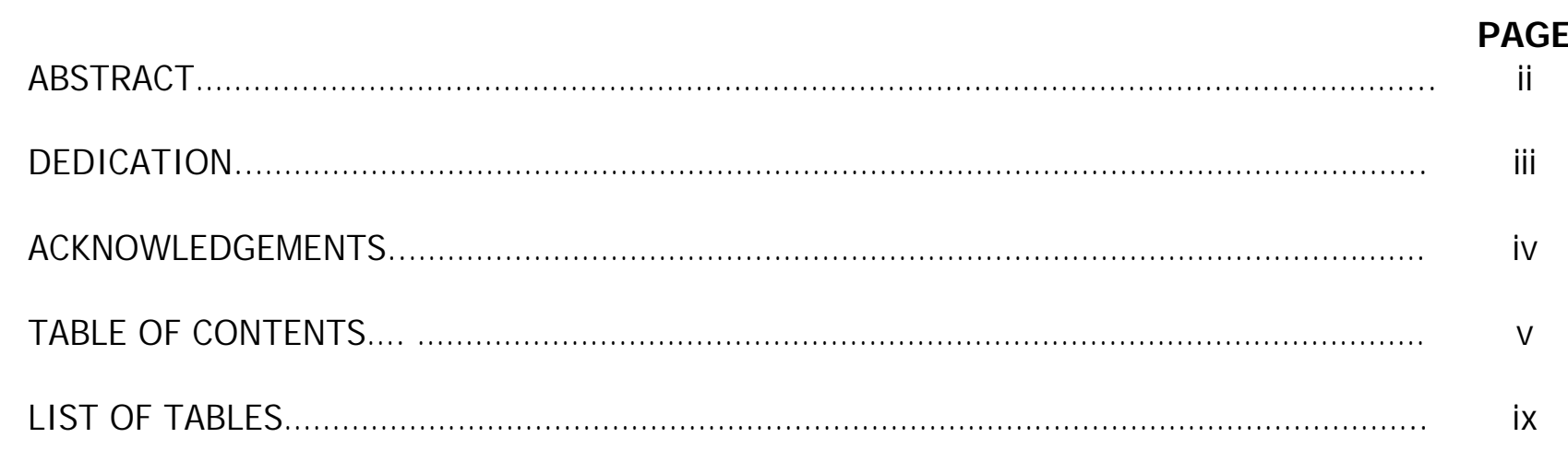

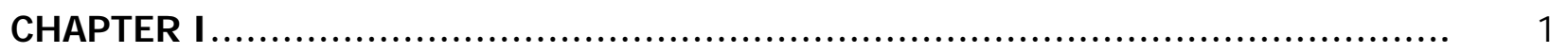

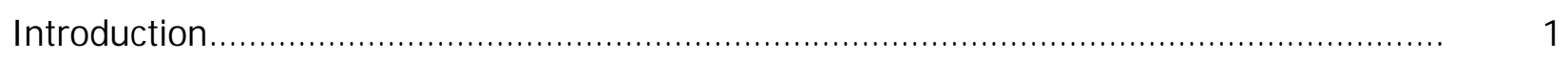

Background of the Problem...................................................................................

Statement of the Problem......................................................................................

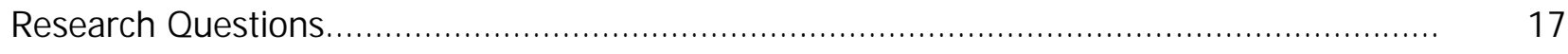

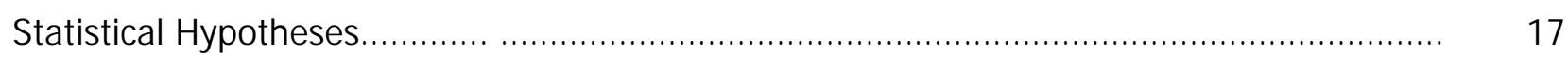

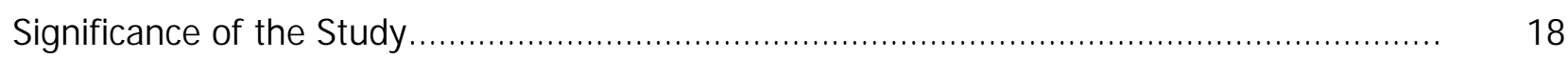

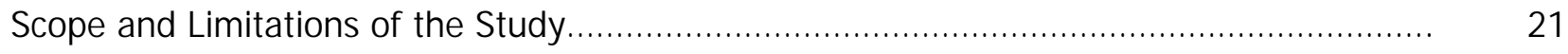

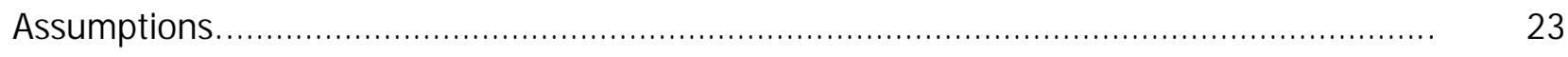

Summary of Research Methodology ....................................................................... 24

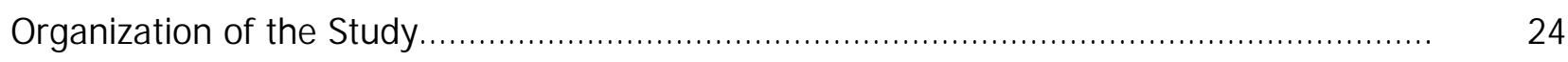

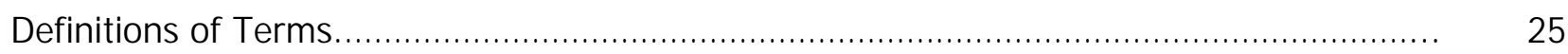

CHAPTER II .......................................................................................

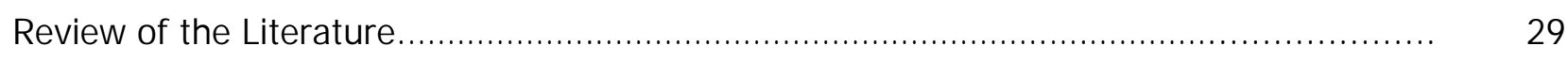

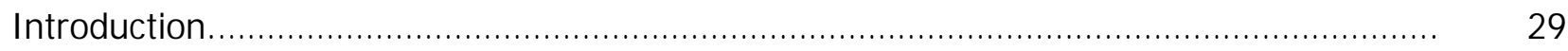




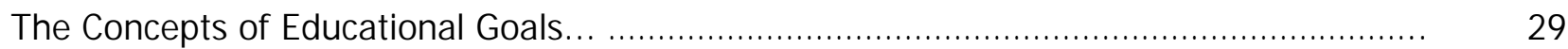

The Learning Domains in Physical Education.................................................... 31

The Four Basic Components of Health-Related Fitness............................................. 52

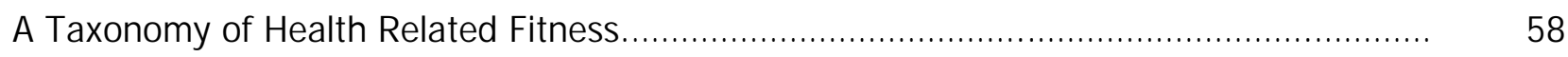

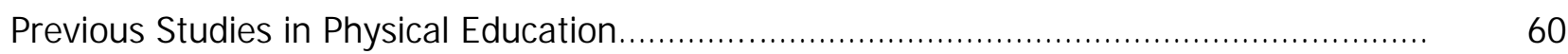

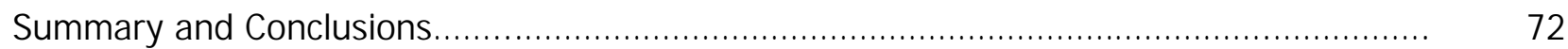

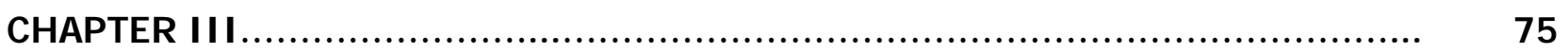

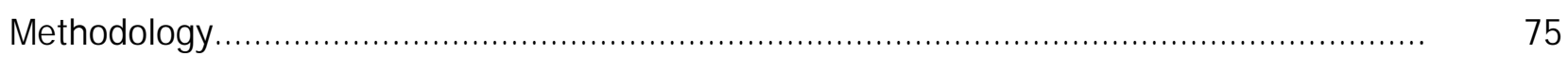

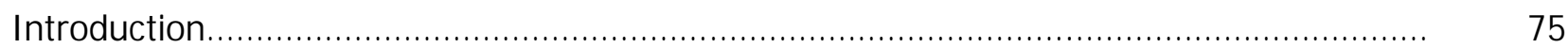

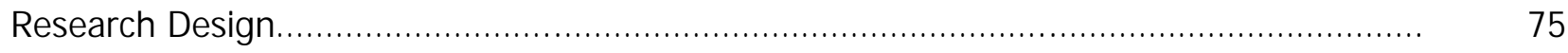

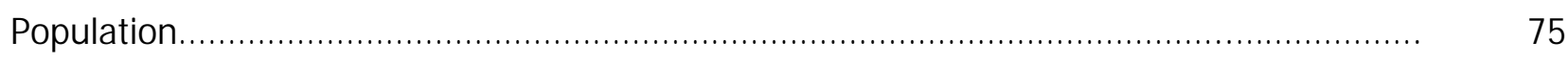

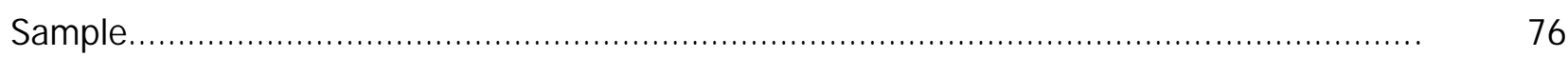

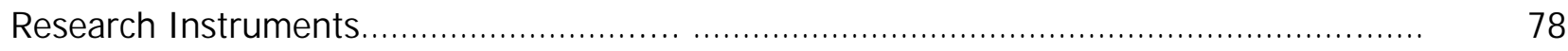

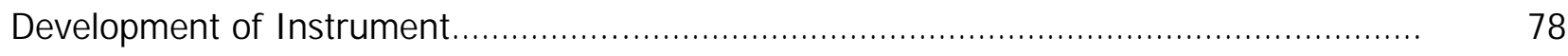

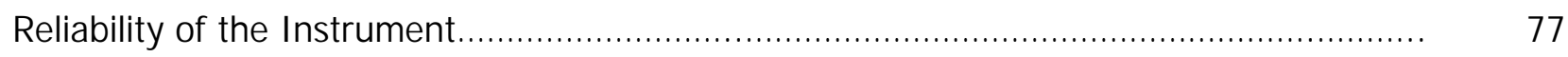

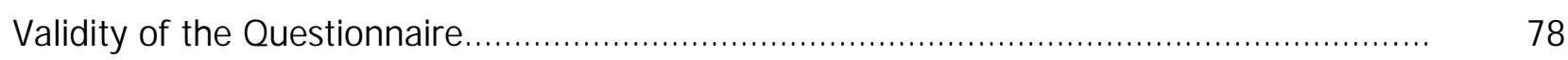

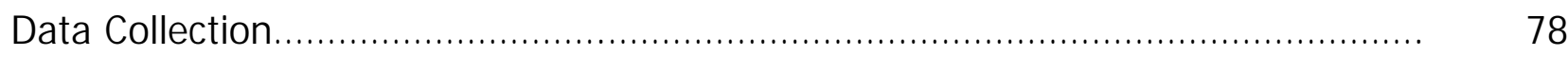

Data Analysis Procedures............................................................... 78

CHAPTER IV......................................................................... 84

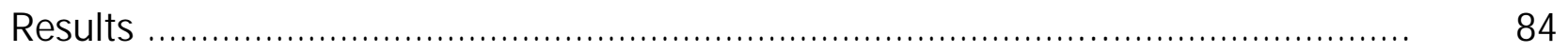




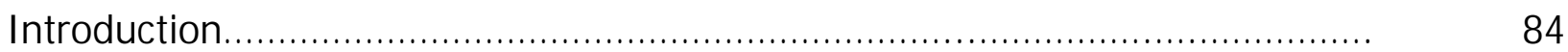

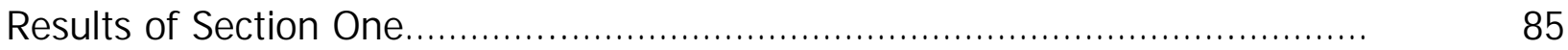

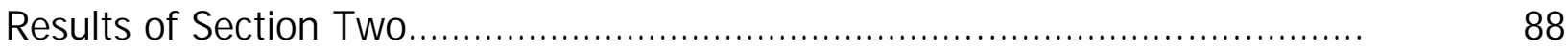

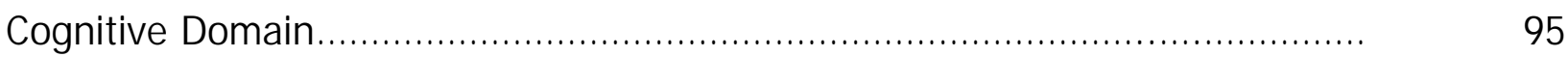

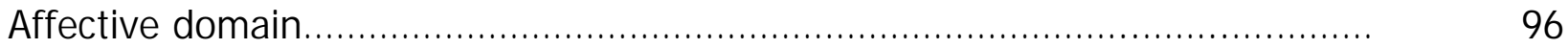

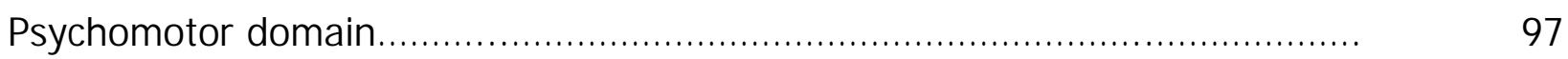

Health-Related Fitness Domain................................................................. 99

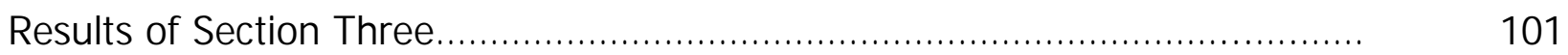

Perception of Males and Females to Cognitive Domain Goals......................... 102

Perception of Males and Females to Affective Domain Goals.......................... 104

Perception of Males and Females to Psychomotor Domain Goals.................... 107

Perception of Males and Females to Health-Related Fitness Domain Goals...... $\quad 110$

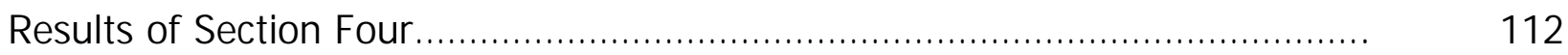

Cognitive Responses and Experience. ...................................................... 113

Affective Responses and Experience....................................................... 117

Psychomotor Responses and Experience.................................................. 120

Health-Related Fitness and Experiences.................................................. 125

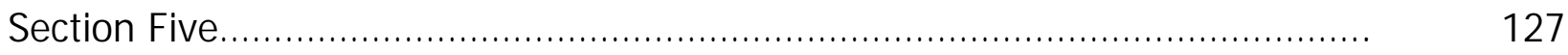

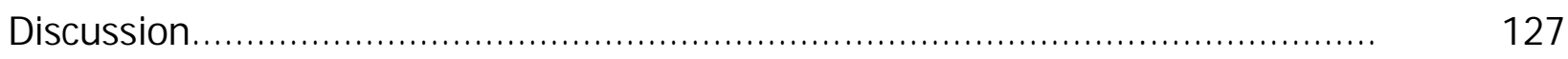

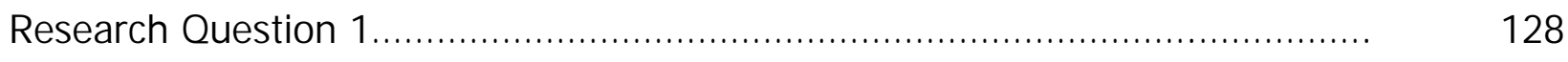

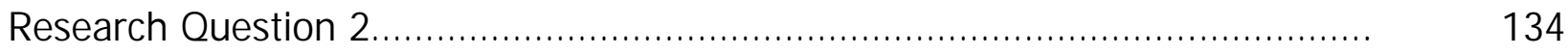


TABLE OF CONTENTS (Continued)



CHAPTER V......................................................................... 142

Summary, Findings, Conclusions, and Recommendations............................. 142

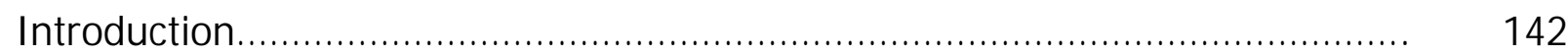

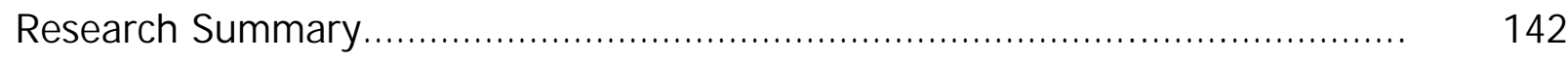

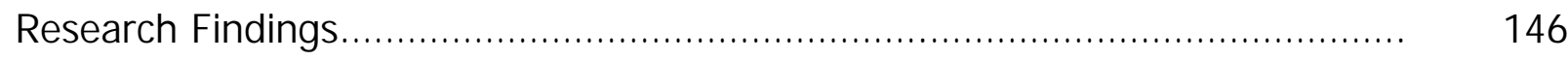

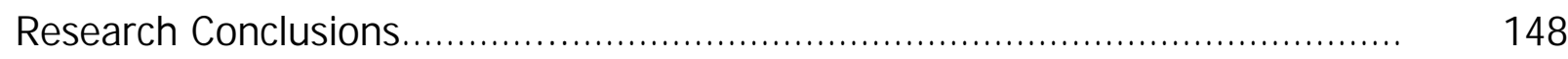

Recommendations and Implications of the Study...................................... 150

REFERENCES........................................................................... 153

APPENDI CES.............................................................................. 165

CURRI CULUM VITAE...................................................................... 173 


\section{LIST OF TABLES}

TABLE

PAGE

1. Distribution of Male and Female Physical Educators on Province........... 76

2. Number of Years' Teaching Experience............................................... 77

3. Factor Analysis and Cronbach's Alpha of the KPEG............................... 86

4. Means and Standard Deviations of Responses for KPEG Items............ 89

5. Physical Education Goals: Frequencies and Percentage of Responses.... 91

6. Cognitive Domain: Significant and Non-significant Goals................... 94

7. Affective Domain: Significant and Non-significant Goals.................... 96

8. Psychomotor Domain: Significant and Non-significant Goals................ 97

9. Health-Related Fitness Domain: Significant and Non-significant Goal.... 99

10. Comparisons of Males' and Females' Perception on Cognitive Goals....... 101

11. Comparison between Males' and Females' Perception........................ 102

12. Perceptions of Male and Female Toward Affective Goals...................... 104

13. Comparison on Males and Females Perception on Affective Domain....... 105

14. Perceptions of Male and Female Groups toward Psychomotor Goals...... 107

15. Comparison between Males' and Females' Perception toward Psychomotor Domain

16. Perception of Male and Female toward Health-Related Fitness Goal....... 109

17. Comparisons between Males and Females on Health-related Fitness Domain 
18. Number of Years' Teaching Experience of the Sample........................... 113

19. Years of Teaching Experience and Cognitive Goals Responses.............. 114

20. Analysis of Variance among the effect of experience on the Perception of the Three Groups toward Cognitive Goals.........................................

21. Years of Teaching Experience and Responses and Affective Goals Response.

22. Analysis of Variance among the effect of experience on the Perception

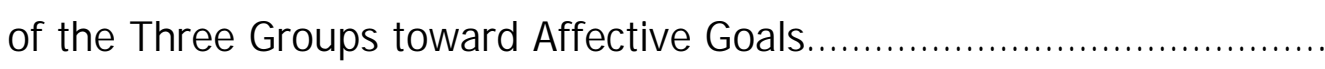

23. Teaching Experience and Psychomotor Frequencies and Percentages...

24. Analysis of Variance among the effect of experience on the Perception of the Three Groups toward Psychomotor Goals.................................

25. Years of Teaching Experience and Health-Related Fitness Frequencies.

26. Analysis of Variance among the effect of experience on Perception of the Three Groups Toward Health-Related Fitness Goals 


\section{CHAPTER I}

\section{I ntroduction}

\section{Background of the problem}

Man has spent thousands of years emerging from his primitive state. In his confrontation with the world around him, primitive man relies heavily on his body. Vigorous physical activity is not only the clue to his survival, it also serves to integrate his life and make it meaningful. At the root of his existence are the functional, goal-oriented movements with which man responds to the challenges of every day life: running, jumping, climbing, and throwing that assist him to be a great hunter. Weather and topography around him are not only a clue in determining types of man's physical activities, but also his motor skills. Thus, primitive man educated himself through his experience, at the same time, played the role of a teacher in educating others. In this respect, Van Dalen \& Bennett (1971) stated: “To a large extent, general education was physical education in early societies, for the environment made great demands on the physical education of man" (p. 4).

Ancient man (Egyptian, Assyrian, Persian, Greek, Roman) created great civilizations with his human mind and body, and his ability to produce goaloriented movements. On the other hand, modern man with his scientific discoveries is transforming the life of the individual, on a scale hard to comprehend. The modern scientific and technological revolution alters the 
character and conditions of work and man's role in the system of production. Complex mechanization, automation and comprehensive intensification of production processes, characteristic of the scientific and technological revolution, make the raising of the level of physical education essential for those who engaged in production. Additionally, the great jump in the new electronics technologies is shaping everyday life for all ages through the popular media, television, video, computer, video game, play station, just to mention a few.

However, automation and the new electronic technologies have advantages and also disadvantages on man's life and health. Scientific and technological progress changes the character of man. Automation increasingly relieves man from direct production efforts, leaving him to control the production process, while self-programming and adjusting mechanisms free him from monotonous and tiring operations. Thus, modern man has greater freedom of action and opportunity for creative activity. In addition, automation lessens the danger to his health and reduces injuries.

Coates (1981) concluded that automation and the intensification of work connected with it, makes new requirements for man's mental and physical abilities. The share of physical work decreases and the entire work process becomes lighter. Care of automatic devices, adjustments and repairs, which require high qualifications, contain elements of physical work combined with mental work. However, the share of physical work, which remains, is too 
insignificant and cannot ensure a sufficient measure of physical activity necessary for the normal functioning of man's health.

Bucher \& Wust (1987) indicated that the development of technology entails the appearance of new implements for people and new professions. However, the more modern and complex the technology, the higher the training level has to be, because even with the highest development of technology people are still the main productive force of society.

The technological progress also alters the character of mental work. As a result, a huge amount of nervous energy is saved, the time expended cut down, and the accuracy of the results of many kinds of mental work and its efficiency increases. Technical devices and computers take over a considerable share of mental work. The human brain is freed from monotonous, stereotyped and tiring mental operations, which waste an enormous amount of time and nervous energy. Therefore, mental work becomes more creative (Zeigler, 1988). On the other hand, Stillwell \& Willgoose (1997) pointed out that the drop in muscles activity owing to the development of technology is accompanied by an increase in the strain on the nervous system and results in greater fatigue.

Today, man has to carry out these functions in ever more diverse and tense conditions, since controlled processes take place at increasingly greater speeds, demanding quick reactions in the processing of information as well as maximum concentration and observance of a variety of control instruments. This requires greater professional, physiological, and psychological abilities. Swift 
motor reactions, physical coordination, and visual observance are also required. That's where versatile physical training and the comprehensive development of physical abilities become the most important ways of raising the body's work activity (Black, 1986). Thus, to overcome the industrial automation and the high electronics technology inventions on man's health, the only solution is at the hands of the physical education profession (i.e. scholars and physical educators).

Physical education (including sports) is an integrated and sophisticated dynamic structure, a diversified social phenomenon with a definite structure. The important indicators of its place in a society are its mass nature, the level of health and of the all-around development of people's physical abilities, the acceptance and the extent to which it is used as a means in education, in production, in everyday life, in leisure time, as well as the level of sport achievements (Zeigler, 1988).

Many specific humanitarian and biological sciences study the problems of physical education on the basis of its philosophy and varied connection with other human sciences. Specialized branches of scientific knowledge studying the process of physical education and sport have been formed in the process of the development of scientific research and the practice of physical education. These branches include: psychology, sociology, history, organization and management, theory and methodology of physical education and sports; sports education; specialized sections of anatomy, morphology, physiology, biochemistry, biomechanics, biophysics, medicine, and hygiene. 
In this respect, Sadovsky (2001) asserted that physical education is the factor that normalizes functions, alters or relieves fatigue and strengthens the body's vital forces. Control functions, which include collection and processing of information and issuing control commands, which require highly developed sensory and motor functions, change with the development of technology.

Throughout history, physical activity has been considered an important component of the educational process and in diverse ways has been a significant element in all cultures. Formal education institutional form, "physical education", has enjoyed a continuing presence. The sustained presence as Van Dalen \& Bennett (1971) describe, implies that it has passed the 'test' of time. However, as the new millennium draws near, physical education as a significant sphere of human activity appears to be under threat in countries in all continental regions of the world.

Physical education and sports have had their place in the school curriculum justified on the basis of, among other things, their value in the development of desirable social habits and attitudes. This is usually under the rubric of general objectives. Hughes, et al. (1984) believed that "physical education and athletics should offer children and youth the opportunity to develop desirable citizenship traits through harmonious and cooperative participation in group activities. They should lead to attainment of sportsmanship, leadership, self-discipline, sociability, and social cooperation" (p.4). 
Stroot \& Morton (1989) saw "physical education as contributing toward the attainment of personal social attitudes and adjustment is more than any other subject in the curriculum, physical education is organized to deal specifically with elements of proper social behavior" (p. 65).

In the school curriculum physical education is justified on the basis of, among other subjects, their value in the development of desirable social habits and attitudes. Hughes et al. (1984) viewed "physical education as contributing toward the attainment of personal social attitudes and adjustment. Haywood (1991) went further to state, "More than any other subject in the curriculum, physical education is organized to deal specifically with elements of proper social behavior" (p. 151).

Increasingly in recent years, physical educators have repeatedly been called to justify the inclusion of physical education as part of the school curriculum. In many countries physical education is not accepted on par with seemingly superior academics concerned with developing a child's intellect. Moreover, as curricula content in schools is extended through the inclusion of 'new' subject areas, competition increases between subjects, often resulting in reduction of the number of classes or time allocation for physical education.

Many commentators have argued that physical education has been pushed into a defensive position, which it is suffering from reductions in curriculum time allocation, declining status, budgetary controls leading to inadequate financial, material and personnel resources, erosion of quality 
standards and instability. In this respect, Riley (1992) has written, "What now appears to be the international dilemma regarding physical education school curriculum subject, certainly, is far from accepting idealistic documentary. Therefore, the 'truth of fact' should be questioned" (p. 11).

The National Association for Sport and Physical Education (NASPE) report, "Shape of the Nation", (2001), as well as a large body of research suggests quite clearly that today's children are less physically active and more overweight/obese than those of previous generations.

Evidence from the recent studies indicates that children became less active and more obese than ever before (Hill \& Trowbridge, 1998). The most popular activities among children and teenagers are watching television and playing video games (Lupker, 1999). It is actually noted that children watch an average of 25 to 27 hours of television a week (Dietz \& Gortmaker, 1985). In contrast, they spend only 14 minutes a day engaged in physical activity (Fry, 1999). While schools have historically provided opportunities for physical activity, cutbacks in space and funding have drastically reduced the number of pupils who participate in daily physical education classes. Additionally, during physical education classes and recess, children actually spend very little time engaged in physical activity. Other important environmental barriers include lack of access to play space and concerns about physical safety (Simons, Morten , Taylor, Snider, 1994). 
A report by Meyer (1997) as well as The American J ournal of Public Health (1993), point out that students exercised vigorously for $9 \%$ of the physical education class time (about four min.), and $70 \%$ of the time stood in line (about 30 min.). What are the implications of these findings? According to the Center for Disease Control and Prevention, a sedentary lifestyle almost doubles one's risk for coronary heart disease and increases risks for diabetes, certain cancers, high blood pressure, depression, and osteoporosis. In this respect Arnold (1991) stated, "I think we've made a serious error by not requiring physical education" (p. 123).

Accordingly, physical education programs, methods of teaching, as well as the thoughts and philosophy of scholars of physical education must be reformed and developed to face the scientific and technological revolution. It appears that physical education is in a period of theoretical transition, and it is still difficult to determine the exact direction in which it will move.

Physical education has been transformed from "the education-of-thephysical viewpoint, to the "education-through-the-physical. However, it may appear that education-through-the-physical, as traditionally formulated, has reached its peak as the primary theoretical concept underlying programs of physical education and it is presently being challenged on several fronts. In this regard, Preboth (2000) stated that "It might be that the concept has sufficient strength and merit to prevail as the major theory all over the world, but it will probably have to undergo some modification if it is to retain its position" (p. 2). 
Theoretically, education-through-the-physical is a very useful concept in many ways. This idea as J ewett (1994) mentioned, "solidifies a young profession that needed solidarity in order to grow both in breadth and in depth" (p. 57). To achieve this general concept, Siedentop, et al (1994) specified that physical education should adopt the four domain objectives first proposed by Clark Hetherington in 1910. These were: organic development, psychomotor development, character development, and intellectual development. These four objectives left a firm mark upon physical education, not only upon American physical education, but also all over the world. Number and type of domains depend on and reflect the philosophy of the long-term instructional objectives as expected learning outcomes in terms of the student behavior.

\section{Secondary School Physical Education Program in Kuwait}

Physical education and sports in our current time have become two of the fields that have expanded greatly in the last two decades after the increase in public maturity in health-, psychological-, and upbringing- related aspects; such factors have become human aspects in the minds of people of all ages, intellect, and living standards.

Physical education and sports in advanced countries represents a pronounced position in education curricula, since it is an essential part of an integrated education system, which can be achieved by studying physical education and its complimentary activities. Although such education is purely 
motional in its exterior, it is, however, also mental, spiritual, social, psychological, and ethical in its goals and relations.

Physical education in the ministry of education is directed into dealing with approximately a third of the Kuwaiti population in all levels of education. Programs of physical education and sports are required to achieve fitness, in addition to motional, health, ethical, and knowledge, etc. skills for students.

Thus, teacher goals have not anymore been limited to the conventional role known to all. Such goals have demanded creativity and innovation to encourage students into sports activities, and to perform them in a positive fashion. This challenges the vast amount of computer games, videotapes, and satellite channels that broadcast material, which draws the attention of students due to its captivating thrills, and recreation in air-conditioned rooms that do not involve any physical activity, and no concern about weather conditions.

It has thus become an obligation upon all workers in the field of physical education and sports to engage in the process of improvement and innovation in order to achieve what can be used to challenge the advent of technology in our societies, which has been associated with the development of laziness in students. This will also used to resist the tides of corruption and chaos that has been infused amongst students, as well as taking advantage of our kids' free time, instead of surrendering to the audio, video technologies and their negative, and corruptive effects. We have, thus, integrated such changes and innovations 
in our curricula, in addition to the practical and educational requirements that match those of the educational policies.

Physical education in Kuwait is one of the subjects taught in public schools. Students in the secondary schools have to attend two-class meetings per week with a total of 66 class hours for each grade level (based on thirty four week school year). Such classes are 40 minutes in length with 20 to 25 students. Time in each class session (40 min.) is divided into: (a) five minutes for putting on the sport uniform and roll call, and (b) ten minutes for warming up and fitness exercises, and (c) twenty minutes for playing the required sport activities, and (d) five minutes for cooling down and collecting the equipment, (Manual Book for Secondary School Physical Education, 2000).

The manual book for the secondary physical education for boys and girls (separate schools for boys and girls) classifies the required sport activities for boys: soccer, basketball, volleyball, handball, track and field, and gymnastics. Girls are also required to practice the same activities except soccer, which is replaced by modern gymnastics.

\section{General Goal and Objectives of Physical Education in Kuwait}

The general goal of physical education for all school levels in Kuwait is to provide students with opportunities to develop their physical, mental, emotional and social growth through the following objectives:

1. Paying attention to general health and special care of posture. 
2. Realizing high level of physical and motor fitness through developing physical qualities and suitable skills.

3. Paying attention to general physical development as preparation for defending the homeland and increasing the production in all areas of life requirements.

4. Learning and enhancing motor skills for sport activities in accordance with obtainable sport equipments and students' physical and skill levels.

5. Paying attention to sportsmanship and correct behavior while practicing sport activities.

6. Discovering sport gifted and high capabilities students.

7. Directing and encouraging students to practice sports as a hobby in free time.

\section{Domains of Physical Education for Secondary Schools in Kuwait}

The secondary school program in Kuwait is regulated to assist each student in the physical education domains' goals as follows:

The Cognitive Domain: is manifested in realizing the following goals through improving the ability of the students to:

1. Acquire knowledge and information regarding motor skills through the learning process.

2. Teach student acceptable behavior through different situations. 
3. Acquire sufficient knowledge regarding security and safety.

4. Obtain information and develop an understanding of some basic factors that affect health and physical activity.

5. Obtain information and develop an understanding of some basic factors that develop physical characteristics.

The Affective Domain: is manifested in realizing the following goals through improving the ability of the students to:

1. Develop an appreciation of and feelings toward physical education and sports.

2. Appreciates the value of learning motor skills and strive to reach high level of performance.

3. Recognize verbally and practically the importance of good moral, ideal behavior.

4. Respect varied abilities and attitudes, and believe in individual differences.

5. Comply with discipline; carry out responsibility and understand its value.

The psychomotor domain is manifested in realizing the following goals through improving the ability of the students to:

1. Integrate sport-specific skills through active participation in individual and 
team sports.

2. Integrate spatial awareness as defensive or offensive position in selected individual and team sports.

3. Demonstrate competency in many movement forms and proficiency in a few movement forms, to give him/her the opportunity to participate in interscholastic teams.

4. Acquire the fundamental sport skills for the participation in competitions.

The Health Related Fitness Domain is manifested in realizing the following goals through improving the ability of the students to:

1. Exhibit a physically active lifestyle.

2. Achieve and maintains a health-enhancing level of physical fitness.

3. Demonstrate understanding of physical fitness values.

4. Integrate physical fitness components into the learning and development of motor skills.

\section{Statement of the Problem}

In light of the secondary school physical education program, the time and number of class meetings, goals of the four domains, and the available facilities, in addition to the teenager problems, it is hard to believe that physical education teachers can realize all these goals. Some judgments are needed, however, 
concerning the degree to which we should expect the cognitive, affective, psychomotor, and health related fitness goals to occur, given the circumstances within which this program normally operates.

A case can be made which suggests that a multi-activity program carried on within a learning environment such as the one described above has little chance, if any, of producing significant and meaningful degrees of skill acquisition.

Moreover, physical education does not have its proper status in the school curricula in Kuwait. Physical education has been considered to be "enrichment" or "frill" unworthy of high priority. The main goal of school administrators is to improve academic performance. The program of secondary physical education in schools has become less important than other subjects such as Arabic, English, and mathematics. The decreasing importance of physical education is manifested in several ways:

The goals of physical education in Kuwait are ambiguous and imbalanced. In addition, the same goals have been applied for elementary, intermediate, and secondary schools. A study conducted by the Educational Office of the Arab Gulf Countries (1980) shows all the Arab Gulf countries give emphasis to a large extent to one aspect of the goals, which is the affective domain, followed by the psychomotor domain, while there are only a few goals related to the cognitive domain. However, this study did not include the goals of the health-related fitness domain. 
This study will be achieved through examining the goals of physical education that are of current importance in terms of their real or potential influence on programs of physical education in schools.

In summary, the problems encountered in the realization of the educational domain goals of physical education in Kuwait are as follows:

1. Less time is allocated to physical education in the school year. It is only two classes per week for about eight months per year.

2. Physical education is not a required subject, therefore it is not considered in student's rating.

3. Physical education classes are canceled in order to create more time for other subjects, especially at the end of the school year.

Thus, the primary purpose of this study was to identify the most important physical education goals perceived by the physical education teachers in Kuwait.

The second purpose of this study was to compare the differences, if any, between male and female teachers' perceptions relevant to each domain goals. The third purpose of this study was to investigate differences existing between teachers' perceptions of each of the domain goals according to number of years teaching experiences in secondary schools. 


\section{$\underline{\text { Research Questions }}$}

This study was conducted to answer the following questions:

1. How do Kuwaiti physical education teachers perceive the domain goals of the physical education program?

2. Do Female and male teachers differ significantly in their perceptions relevant to the cognitive, affective, psychomotor, health-related fitness domain goals?

3. Is there any significant difference among teachers' perceptions regarding number of years' teaching experience toward: (a) cognitive, (b) affective, (c) psychomotor, and health-related fitness domains?

\section{Statistical Hypotheses}

In light of the research questions, the following statistical hypotheses were established except for the first question, which describes the overall responses of the sample for this study. The null hypothesis is adapted in comparing the results between the two subgroups comprising gender, and among the three groups forming years' of teaching experience as follows:

HO1: Null Hypothesis: There is no significant difference between the means of the female and male teachers' perceptions toward the importance of the cognitive, affective, psychomotor, health-related fitness domain goals. 
HO2: Null Hypothesis: There are no significant differences between teachers' perceptions toward the importance of the cognitive, affective, psychomotor, health-related fitness domain goals and number of years of teaching experience.

\section{Significance of the study}

A great amount of research has related physical traits to the total effectiveness of the individual physically, mentally, psychologically, and socially. Medical authorities have stressed the need for physical activities for organic soundness throughout the life span. Leading nutritionists have shown the role of exercise in weight control. Renowned psychologists have reported that strong boys tend to be adjusted socially and psychologically, while weak boys show tendencies toward social deficiencies, feeling of inferiority, and other personal maladjustments.

Physical education has stressed the totality of the individual through realizing all the above vital aspects. Their major aim through numerous studies and the application of the results in physical education programs is developing in all students an enthusiasm for physical activity and to maintain and encourage that enthusiasm so that they become committed to pursuing an active lifestyle, in conjunction with the goals of the cognitive, affective, psychomotor domains which constitute the totality of the man.

It is becoming increasingly important for physical educators to examine program goals and program content in order to determine the basic ideas and concepts that form the basis the program. The physical educator should be able 
to make judgments about the relative merits of the various ideas and concepts that he encounters.

It is important to recognize that all goals are not of equal value. The goal should be able to analyze ideas and the programs that reflect these ideas on the basis of the best current research evidence, the logic of the ideas, and the consistency with which the programs reflect these ideas.

There are many problems in applying goals into practice. Realizing ambiguous goals or too many educational goals may hinder goal-achievements. Therefore, the primary purpose of this study was addressed by examining in detail four determinants reflecting educational domains (psychomotor domain, cognitive domain, affective domain, and health-related fitness domain). These four educational domains had been considered prior to planning the physical education program for secondary schools for girls and boys. However, it should be noted that secondary schools girls and boys are living their adolescence period of life.

Physical education program emphasis is mostly on the qualities of how physical educators approach the learners and subject matter with improved attitudes, concepts, knowledge, purposes, and instructional methods. Physical educators are presently required to view the physical education programs as adaptive (to meet the various needs of diverse student populations) and futureoriented (providing students with knowledge and skills for dealing with society and shaping their adult lives). 
Thus, in order to have a general view of the importance of goal achievement relevant to the physical education program for secondary schools for boys and girls, male and female physical education teachers were asked to weigh the importance of the goals relevant to each domain. In addition, differences between male and female teachers' perceptions were investigated. Additionally, the relationship between teacher experience and perceptions of these goals was also examined.

Therefore, it is expected that the present investigation would provide valued information since it deals with those who play a crucial role in applying the physical education program for secondary school for boys and girls in Kuwait. Thus result of the present study will help:

\section{A. Teachers of physical education}

To assist physical educators in the secondary school in Kuwait, as follows:

1. To give them the opportunity to report their perspectives towards goals of the physical education program.

2. To educate them toward scope of goals in their profession and how to communicate these goals to realize them.

\section{B. Ministry of Education}

To provide the teachers with knowledgeable about the actual results of their effort. To enable those who are in charge of developing the physical education program in the Ministry of Education in Kuwait as follows: 
1. Develop a cohesive strategy for the acceptance and rejection of the physical education goals when determining programs for physical education classes.

2. Modify and moderate the current goals of physical education.

\section{Future Teachers}

Results of this study may benefit those who are in charge of teacher preparation in the College of Physical Education in Kuwait as follows:

1. Give much more effort in the actual preparation of curriculum materials in teacher training.

2. Support research in the physical education teaching area for improving educational practices in order to meet the challenges of the scientific and social revolution.

\section{Scope and Limitations of the Study}

The purpose of this study was to investigate the importance of selected physical education goals as perceived by secondary school physical education teachers from both sexes.

Physical education teachers were asked to participate in this study. Each participant should hold a bachelor's degree (four years of study) in physical education. Also, each participant should be currently teaching in a high school in Kuwait. 
A questionnaire (Kuwaiti Physical Education Program; briefly, KPEP) was used to examine the perceptions of physical education teachers. This questionnaire consists of 24 items derived by the researcher from the Outcomes Committee (1992), and goals of the four domains of the secondary physical education curricula in Kuwait.

Male and female physical education teachers were used as subjects in this study. Two independent variables were studied in this research (gender, and years of experience) in order to determine their effects on the dependent variables, which are the goals of physical education program for secondary schools in Kuwait.

\section{Limitations of the Study}

Although the results of the present study provided significant insights on the importance of selected physical education goals as perceived by secondary school physical education teachers from both sexes, the findings should be interpreted with an awareness of certain methodological limitations.

\section{(1) Drawing Generalizations}

The selected population of this study was limited to a small sample of 200 respondents who represented only $34.3 \%$ of the target population. The results therefore cannot be generalized to all secondary teachers teaching in Kuwait. It should also be noted that the participating schools were not equal in size, infrastructure, and number of teachers, therefore, making any generalizations without considering these factors is not only inappropriate but also misleading. 
In reality, the social and academic contexts in which this research was conducted were not similar, as it varied in one way or the other.

(2) Sample size and selection

A significant limitation of the present study is that only a small sample size returned the survey. A low sample size may have significantly affected the "power of statistical test". In the present study, the small sample size cannot be said to have sufficient statistical power that could guarantee the absence of Type II error. Though sampling error may have affected the statistical power, repeating similar study with a large sample would increase the statistical power, thus, making the findings more representative and conclusive.

\section{Assumptions}

A number of assumptions are formulated as a basis for the study:

1. The items of the KPEP derived from the Outcomes Committee (1992), and physical education curricula for the secondary in Kuwait are clear and coincide with the physical education profession.

2. The KPEP actually measures the perception of the physical education teachers toward the goals of each of the four physical education domains (cognitive, affective, psychomotor, and health related fitness).

3. The respondents as physical education teachers are conversant with the curricula of physical education in general and the goals of the programs in 
particular, by virtue of their educational background and teaching experience.

4. The respondents are truthful in expressing their opinions about each statement in the KPEP.

\section{Summary of Research Methodology}

The purpose of this investigation was to weigh selected physical education goals as perceived by physical education teachers in Kuwait. Physical educators, in general and in schools in particular, aim to emphasize the physical and spiritual principles to the students and improve them. They are considered the most significant factors in the educational process. Therefore, physical education teachers were chosen to participate as subjects in this study.

The questionnaire was titled "Kuwaiti Physical Education Program"; briefly; "KPEP". The aim of the KPEP was to detail the perceptions of Kuwaiti physical education teachers toward goals of physical education. The items of the questionnaire were divided into four areas: cognitive, affective, psychomotor, and health-related fitness. Each participant was asked to weigh his perceptions of the importance of each goal by using a 5-point rating scale.

\section{Organization of the Study}

The study was organized into five chapters. Chapter 1 introduces the nature and the objectives of the study. Chapter 2 presents a review of related literature that deals with the goals of physical education. Chapter 3 describes the 
research design and methodology. Chapter 4 presents the findings of the study and answers the research questions. Chapter 5 summarizes the findings of the investigation and develops conclusions and recommendations based on the findings. Appendixes and the list of reference materials follow.

\section{Definitions of Terms}

A number of terms were of special importance for the study. They were defined as follows for the purpose of this study.

\section{Acquisition in the psychomotor domain}

Attainment of those practice-related capabilities contributing to the increased likelihood of goal achievement (Graham, 1991, p. 353).

\section{Affective Domain}

The affective domain refers to one of the educational objectives that deals with attitudes, values, interests, and emotional aspects of learning.

\section{Bachelor's Degree}

The degree received after four years of successful study in a university program.

\section{Cognitive Domain}

The cognitive domain refers to one of the educational objectives that deals with content and processes and are intellectual in nature. 
5. Domain

A Domain refers to the set of current values, goals, and principles that give physical education curricula individual and recognizable character. Domain stresses currency or prevailing mode (J ewett \& Mullan, 1977).

\section{Health-related Fitness Domain}

The health-related fitness domain refers to the physiological efficiency of the body.

\section{Physical Education}

An educational process that has as its aim the improvement of human performance through the medium of physical activities selected to realize this outcome" (Buche \& Wuest, 1987, p. 9).

\section{The Health and Physical Education}

The health and physical education refers to an area focusing on a holistic concept of health. It recognizes the physical, mental, emotional, social and spiritual dimensions of the health of the individual. It examines the impact of interactions between the individual, the family, the wider community and the environment of health of populations (Curriculum Framework, Health and Physical Education, Definition and Rational, p. 1, 2000).

\section{Student's Health and Physical Education}

Health and physical education encourages students to plan, act and reflect in order to develop the essential knowledge and understandings, attitudes, 
values and skills which promote health practices, encourage participation in regular and physical activity and support the maintenance of a healthy lifestyle (Curriculum Framework, Health and Physical Education, Definition and Rational, 2000).

\section{Physical Education Program}

The term "physical education program" refers to a plan for instructional action based on a set of decisions intended to reflect in the actions of learners (J ewett \& Mullan, 1977). In this study the term refers to all the physical education activities that students participate in at school to realize the educational goals of the secondary school curriculum in Kuwait.

\section{Psychomotor Domain}

The psychomotor domain refers to motor skills related to physical education and sports.

\section{Secondary school}

Secondary school is the third stage of the schools' educational system in

Kuwait. It is equivalent to the $9^{\text {th }}-12^{\text {th }}$ grades in the United States of America.

13. Skill in the psychomotor domain

Ability acts to allow a domain's goal to be achieved as a result of practice (Graham, 1991, p. 353). 


\section{Teachers' Perceptions of Physical Education Goals}

Perception refers to what Kuwaiti physical education teachers believe relevant to the importance of the physical education goals. 


\section{CHAPTER I I}

Review of the Literature

$\underline{\text { Introduction }}$

In order to accomplish the goals of this study, it was necessary to carry out a methodical review of the related studies. The nature of the study required that the reporting of this search be organized in several sections and subsections. This chapter reports the literature related to this study as follows:

1. The Concept of Educational Goals.

2. The Learning Domains in Physical Education.

3. Previous Studies in Physical Education.

4. Summary.

\section{The Concepts of Educational Goals}

Through the educational system both individuals and society are most likely to be quickly changed. Thus, a school curriculum should provide students with sufficient opportunities to obtain and use subject matter in school and in the society. Therefore, as Beauchamp (1969) asserted, a school's curriculum should point out the relationships among its elements by directing its development, its use, and its evaluation.

Jewett (1994) defined a curriculum's theory as "a set of related statements that gives meaning to a school curriculum by pointing out the relationships among its elements and by directing its development, it uses, and 
its evaluation" (p. 66). Theory in curriculum becomes the rationale for defining purpose, selecting objectives, and determining content organization. Therefore, each curriculum area should have its valuable content for students to acquire. This means, as Bain (1985) indicates, "theory should be interrelated with practice so that both aspects of the curriculum process can contribute to a quality educational process" (p. 145).

The major problem of education, as Flintoff (2000) indicates, is currently engaged in a struggle over conflicting conceptions of what should be the goals, content, and organization of curriculum. In this regard Ornstein and Hunkinis (1993) state that:

If there were only one philosophy, only one way of viewing reality or interpreting societal needs, the tasks of curriculum specialists would indeed be easy. However, such is not the case. Because of the numerous philosophical positions, there are myriad ways to conceptualize and deliver curricula. Whether curricularists view the outcomes of schooling as fixed terminal points or as points in a never-ending series of points, the curriculum is influenced by their philosophies. (p. 209)

Bucher \& Wuest (1987) mention that physical education, however, is not spared from this controversy and may in fact experience more argument in the process of defining its purpose, substance, and order. Evidence of such trouble is apparent in physical education literature and in conferences and workshops 
where numerous approaches to curriculum can be observed. As Harrison et al. (1996) indicated, a goal in education describes an outcome of what students should know and be able to do.

In education, goals are long-term purposes measured through the attainment of a series of objectives. Sound and Everett (1981) defined an objective as "the means used to achieve a goal while objectives are the observable, measurable, and quantifiable statements that guide the teacher to select appropriate educational strategies that help students attain their goals" ( $p$. 16). The same authors also indicate that establishing objectives is the first step in designing any educational program. If they are realistic and well considered, such objectives can ensure direction and consistency in a curriculum.

The Education Office of the Arab Gulf Countries (1980) stated that the whole goal of education is to help the individual gain proper experiences by which he/she can achieve the ultimate development; emotionally, morally, physically, cognitively, and socially, to become a good citizen and a happy person in this life and in the hereafter.

\section{The Learning Domains in Physical Education}

One approach to curriculum planning is to use a taxonomy for classifying objectives. Medin (2000) stated "taxonomy permits classification of objectives from low to high order. Low order objectives are not unimportant; they are simply fundamental or prerequisite to meeting higher order objectives. Once lower objectives have been met (or are in the process of being met), higher 
order objectives can be emphasized" (p. 3). In this regard, Melograno (1996) mentioned that, "one shouldn't assume that the higher, complex levels are more valuable. Although knowledge is lower than application, it is just as valuable" ( $p$. 69). The reason is that the lower level constructs the basis for the complex levels. For example, one needs to know the rules of a game before he can apply them.

The taxonomies of educational objectives fall into three major domains: the cognitive, the affective, and the psychomotor (Bloom 1956, Krawthwohl, et al., 1964, J ewett, 1994). However Bloom and his associates proposed classifying educational objectives into these three categories, they believe in man's totality. They emphasize that "human behavior is not exclusively of any one domain, rather it is a complicated melding of the three domains" (p. 103). The purpose of classifying the three taxonomy domains are to motivate teachers when they design their instruction program, as well as enhancing the educational research area to emphasize the learning out come of their students.

Harrison et al (1996) noticed that the purpose of the three taxonomy domains are to motivate physical education teachers when designing their instruction program to provide a progression of learning outcomes. That means the learning process moves from those lower on the taxonomy through the higher order objectives listed at the top of each taxonomy. They state, "the taxonomy can be used as a check-list to ensure the entire range of behaviors is included in the curriculum or learning situation" (p. 104). 
Corbin \& Pate (1981) listed three common errors that result in failure to include the entire range of behaviors in the taxonomies. These errors are: "(1) trying to teach advanced skills and information without teaching essential prerequisites, (2) overemphasizing lower-order objectives, and (3) sacrificing higher-order objectives in the process of achieving lower-order objectives" ( $p$. 12).

Good physical health is necessary for people to achieve as optimally as possible in school and in society. Physical education in schools can do much in these cases and situations. The idea of strengthening and raising the level of public health permeates the entire system of physical education. This principle presupposes the availability of permanent medical control as well as that of instructors over the fulfillment of physical exercises.

These three domains do not reflect the subject matter we want the learner to acquire. Therefore, the researcher's agrees that learning of any subject matter fall into these three educational domains, in addition to the type of the subject to be learned. The type of the subject matter, on one hand, has its commitment toward the nature of this subject, and on the other hand, the learning process of this subject has also its commitment to the three educational domains. Accordingly, physical education should fall into three major educational domains (the cognitive, the affective, and the psychomotor) in addition to the health-related fitness domain. However, it should be noted that health is 
interrelated in any physical action with the other domains. Therefore, in the field of physical education the four domains are inseparable.

\section{Cognitive Domain}

Many cognitive psychologists restrict the definition of cognition to the higher mental processes such as knowledge, intelligence, thinking, acquisition of new meaning, generating plans, strategies, reasoning and problem solving. Many behaviorists, on the other hand, would restrict the term to conditioning, rote verbal learning and other procedures or processes consistent with their approach to learning. Still other schools of thought have their specific and varied definition that generally implies the gaining of knowledge.

Newcomb \& Treftz (1987) described cognition to include the processes of perception, thinking, reasoning, understanding problem solving and remembering. Page et al. (1980) and Johnson \& Thomas (1992) referred to cognition as an umbrella term for the process of perception, discovery, recognition, imagining, judging, memorizing, learning and thinking by which the individual obtains knowledge and conceptual understanding or explanation.

According to Mohr (1971), cognition included dimensions common to all types of knowing such as feelings, relationships, ideas, and the processes of imagining, judging, remembering, understanding, problem solving, and reasoning. Flavel (1977) argued that humans are cognitive beings and carry out a variety of mental operations to achieve a number of mental products. These operations, according to him, can be said to be cognitive. 
Bloom (1956) has developed a classification system; he specifies that the cognitive domain consist of categories built upon a hierarchy from simple to complex, ranging from knowledge, comprehension, application, analysis, synthesis, and evaluation. Newcomb \& Treftz (1987) consolidated Bloom's taxonomy to include the four categories of remembering, processing, creating and evaluating.

Sefert (1991) asserted that cognitive domain should include objectives that deal with content, actions related to knowledge, and understanding about each sport activity such as rules, strategies, technique, and concepts of healthrelated fitness in physical education.

Joyce and Weil (1996) explained that cognition has implications for learning and teaching physical education, students learn by acquiring and organizing knowledge. This process sometimes produces immediate or obvious changes in their behavior, but more often merely sets the stage for such changes by making them more flexible in their choice of responses and courses of action. Such a view of learning assumes that human beings are more than just their actions: that they also think, remember, perceive, and become motivated.

Mohr (1971) pointed out the cognitive learning goals of physical education as a center on helping the learner to become more effective multi sensory learners and active learners. As such, movement is a viable medium for both perceptual-motor and cognitive concept learning. 
The cognitive domain deals with intellectual skills that move from simple to complex. These skills as Bloom (1956) determined are:

1. The knowledge level deals with specific facts and terminology. Thus, this level is referred to as memorization or rote learning. In physical education the knowledge that can be fit into this level includes the rules and strategies of various sports, the name of body systems, the history of sport, etc.

2. The comprehension level deals with translation and interpretation of information. Students must understand what they have learned. This level goes beyond memorizing facts and strategies. In physical education, students at this level must understand the effects of exercise, the benefits of exercise, and factors affecting people to participation in sport activity.

3. The application level deals with the use of abstract ideas in particular situations. That means the students ate able to apply the information in new problems and situations. For example, in physical education the student must apply game rules and strategies in actual situations.

4. The analysis level deals with breaking a whole into parts and seeing their relationships. Students at this level are able to organize, classify, distinguish and clarify information by determining the relationships among ideas. In physical education students can 
analyze an article about physical fitness and determine the accuracy of information.

5. The synthesis level deals with gathering parts in order to create new forms, that is, students are able to arrange or combine elements into new patterns. In physical education, a student can create his or her own exercise program to attain physical fitness.

6. The evaluation level deals with making judgments based on evidence. It includes both qualitative and quantitative measurements. In physical education, a student can measure and writes his record by himself, or cooperate with one or more of his friends.

Norman (1980) mentioned many reasons why cognitive concept learning can be effectively taught through movement. Among these is the fact that active participation is fun. Movement often meets the needs and interests of children more than less active classroom activities. Active participation in a game in which academic concepts are being taught makes it difficult for the child's attention to be diverted by extraneous stimuli. Also, many of today's children undervalue academic achievement but highly regard physical performance.

Concerning cognitive transaction in adolescence, El-Nagger et al (1991) mentioned that adolescents are more likely than children to see things as relative, rather than absolute. Children tend to see things in absolute terms in black and white. Adolescents, in contrast tend to see things as relative. They are 
more likely to question others' assertions and less likely to accept "facts" as absolute truths. This increase in relativism can be particularly exasperating to parents, who may feel that their adolescent children question everything just for the sake of argument. Difficulties often arise, for example, when adolescents begin seeing their parents' values as excessively relative.

\section{Cognitive learning}

Movement can be used to enhance the understanding and application of cognitive learning. With regard to movement, Hellison (1985) indicated that cognitive concept learning is a relatively permanent change in behavior brought about by meaningful movement experiences. Cognitive learning can, and does, occur in the gymnasium and on the playing field through the skill, movement, fitness, and activity concepts that are taught in the developmental physical education program.

\section{Physical Educators and Cognitive Learning}

Teachers can facilitate cognitive development among learners by using the instructional interventions and strategies recommended by Johnson \& Thomas (1992): (1) helping students organize their knowledge, (2) building on what students already know; (3) facilitating information processing and deep thinking through elaboration, and (4) making the thinking process explicit. They believe that teachers' behaviors will promote higher order thinking skills among students by using strategies such as: (1) requiring justification for ideas and probing for reasoning strategies, (2) confronting students with alternatives and 
thought provoking questions, (3) asking open ended questions, (4) requiring students to be accountable for class discussion and, (5) serving as a master of apprentices rather than a teacher of students, and using Socratic discussion techniques.

These strategies, as noted by Johnson \& Thomas (1992), help learners to move from basic skills and pure facts to linking new information with prior knowledge, from relying on a single authority to recognizing multiple sources of knowledge, and to moving from novice-like to expert-like problem solving abilities.

Jewett (1980) indicated that physical educators can use the following objectives to enhance cognitive learning, such as describe, investigate, analyze, portray, explain, interpret, develop, differentiate, evaluate, relate, distinguish, select, discriminate, choose, determine, and apply. These are:

1. Learning of knowledge of facts: parts, names, law order concepts, or information.

2. Understandings: comprehension, principles, generalizations, high order concepts, or the use of information and ideas.

3. Processes: transformational skills used in learning, communicating, using the knowledge of understanding in solving problems synthesizing, associating, conceptualizing, creating, perceiving, evaluating, analyzing, etc. 


\section{$\underline{\text { Affective Domain }}$}

The affective domain includes objectives dealing with emotion and social objectives. Noddings (1992) stated that the "affective domain stresses the individual value system and philosophy that are basic to maturity" (p. 61). Moreover, Woodford (1979) indicated, "the affective domain is best viewed as a way of person feels (not thinks) concerning a given phenomenon" (p. 286).

Noddings (1992) pointed out the potential nature of a physical activity program by arguing that, "The physical self is only part of the self, and clearly these are not discrete. We separate and label them for convenience in discussion but it may be a mistake to separate them sharply in curriculum" (p. 48).

Also in this regard Figley (1984) stated, "Individuals do not come to physical education with just their bodies. They bring their total self, their bodies, minds, and feelings, attitudes and values" (p. 94).

The affective development forms the important program strands that are woven throughout each skill theme. The unique contribution of developmental physical education is in the realm of motor development in which progressive change in one's movement behavior brought about by interaction of the individual with the environment and the task (Bain, 1985).

According to Hellison (1993) the objectives of the affective domain include:

1. Attitudes: Feelings, values, mood, acceptance of rejection of ideas or a person. 
2. Appreciation: Perception of a worth or value to something, recognition of esthetic value of something.

3. Interests: Desires, curiosity, attentiveness to something, manifested.

4. Voluntary participation, involvement, and degree of involvement.

Asci (2001) indicated that affective behavior is often referred to as "socialemotional development" and is vitally important to adolescents. A good or poor, an affluent or culturally deprived environment, and the quality and quantity of stimulation largely determine whether adolescents view their world as one that they can control or as one that controls them.

Krawthwohl et al. (1964) represented a unique taxonomy of affective objectives that consists of five major categories:

1. Receiving refers to passive attention to the activity or event. It includes three sublevels: awareness, willingness to receive, and attention. For example, a person becomes first aware of what physical fitness is, then he or she begins to be concerned about issues relating to physical fitness. And lastly, in this level, a person selects and reads articles about fitness rather than other reading materials.

2. Responding refers to the learner's active attention to certain stimuli. In other words, when a person does something about the activity it is called responding, which includes three sublevels: acquiescence, willingness to 
respond, and satisfaction in response. For example, a person at this level responds to information regarding physical fitness by forming his or her opinion about physical fitness and participates voluntarily in a fitness program and feels some satisfaction in doing so.

3. Valuing is considered with the learner's beliefs and attitudes of worth held by the learner about something. It includes three sublevels, namely. Acceptance of values. Preference for a value, and commitment. In this level a person not only participates in physical fitness, but also tries to convince his or her friends of the importance of a fitness program.

4. Organization, which is concerned with building a value system, includes two sub-levels: conceptualization of a value and organization of a value system. This level requires comparing and contrasting among many values that are held by the person in order to develop a philosophy of life. In this level a person is ready to place the value of physical fitness into his / her hierarchy of values.

5. Characterization: refers to the consistency of a person acting. It includes two sub-levels: generalized set and characterization. In this level a person is not only committed to the importance of physical fitness. But also he or she may decide to choose a career in the fitness area (Krathwhol et al, 1964; Ornstein \& Hunkins, 1993; Woodford, 1979)

According to Hellison (1993), the affective domain is not receiving enough attention in today's schools because students are facing more personal and social 
problems than ever before. Thus, Hellison (1993) suggested that the affective goals in physical education should include: (1) Social conventions such as: appropriate dress and language, (2) appreciation and affection for physical activity and its benefits, (3) psychological constructs such as self-esteem, selfefficacy, courage, motivation, and independence; (4) moral qualities such as respect for rights of others, compassion, and justice; and (5) aesthetic qualities such as play- fullness and gracefulness. (p.127)

A survey research finding reported by Ford, et al. (1989) indicated that both adults and adolescents believe that social responsibility is the most important goal for young people to have attained by age 18. Hellison (1985) presented a model for teaching social and personal responsibility through physical activity. It consists of five levels in progression:

Level 0: Irresponsibility describes students who are unmotivated and undisciplined.

Level 1: Self-control characterizes students who may or may not participate in the day's activity or display much mastery or betterment, but are able to control their behavior.

Level 2: Involvement describes students who demonstrate self-control and are involved in the activity. 
Level 3: Self-direction describes students who can recognize their own needs and interests and can start to design and carry out their own physical education program.

Level 4: Caring describes students who are motivated to lengthen their sense of responsibility by cooperating, giving support, showing concern, and helping others.

\section{Affective Learning}

Affective learning is the "learning that increases the ability of learners to act, interact, and react effectively with other people as well as with themselves" (Magill \& Ash, 1979, p. 167). An important outcome of any quality physical education program is enhancement in the affective domain.

The movement experiences engaged in by learners play an important role in how they view themselves as individuals and how they relate to their peers and use their free time. Thus, regardless of the skills or knowledge the student learns, the student feels it will influence his behavior in the future. Thus, as Woodford (1979) mentions, it is necessary to develop positive affective learning among students in order to assure their participation in the future. Moreover, Hellison (1993) indicated that both motivation and behavior are important factors in human learning because:

What we believe and what intend to do provide the motivation and direction for how we actually behave. Our actual behavior does not always reveal our intent. 
Yet our attitude toward doing or not doing something provides the motivation to keep trying (p. 5).

Griffey (1987) indicated that during adolescence, important shifts occur in the way individuals think about and characterize themselves--that is, in their selfconceptions. As individuals mature intellectually and undergo the sorts of cognitive changes described earlier, they come to perceive themselves in more sophisticated and differentiated ways. Compared with children, who tend to describe themselves in relatively simple, concrete terms, adolescents are more likely to employ complex, abstract, and psychological self-characterizations. As individuals' self-conceptions become more abstract and as they become more able to see themselves in psychological terms, they become more interested in understanding their own personalities and why they behave the way they do.

Hedlund (1985) showed that affective behavior also explores adolescent's self-esteem and their socialization and examines how this information may be incorporated into the physical education program. Conventional wisdom holds that adolescents have low self-esteem that they are more insecure and selfcritical than children or adults but most research indicates otherwise. Wood Ford (1979) indicated that teenagers' feelings about themselves may fluctuate, especially during early adolescence. However, their self-esteem remains fairly stable from about age 13 on. Self-esteem increases over the course of middle and late adolescence. 
Concerning the role of the physical educators, Schurr (1985) described the characteristics of an astute teacher that strengthen students' emotional and social development as follows: (1) recognizes the vital importance of balanced social-emotional development, (2) understands the affective development of his students, and (3) incorporates this knowledge into the physical education program in order to: (a) enhance their self-esteem, (b) improve positive socialization, (c) to encourage and structure meaningful movement experiences.

In dealing with adolescents Asci (2001) indicated that students should acquire solving problems and knowing facts such as skills perfected and values and attitudes developed. The highest reward of teaching comes when in some measure the answer to the adolescent's question is definitive, and when he gains knowledge, skills, attitudes and values.

\section{$\underline{\text { The Psychomotor Domain }}$}

The psychomotor domain is often termed perceptual-motor domain, or motor domain. This domain includes objectives dealing with movement skills and movement processes. The psychomotor objectives are related to the neuromuscular as well as to motor development and to realize primarily the attainment of skills through participation in physical education programs.

Nixon and Jewett (1984) proposed the movement process categories, which form the basis for the taxonomy of the psychomotor domain:

1. Generic Movement: Those movement operations or processes, which facilitate the development of characteristic and effective motor patterns. 
They are typically exploratory operations in which the learner receives or "takes in" data as he or she moves.

2. Perceiving, awareness of movement positions, postures, patterns, and skills. This awareness may be evidenced by motor acts such as imitating a position or skill; they may be sensory in that the mover feels a posture when the limbs are manipulated; or they may be evidenced cognitively through identification, recognition, or distinction.

3. Patterning arrangement and use of body parts in successive and harmonious ways to achieve a movement pattern or skill. This level is dependent on recall and performance of a movement previously demonstrated or experienced.

4. Co-ordinate Movement: The processes of organizing, refining and performing skillful movement. The processes involved are directed toward the organization of perceptual-motor abilities with a view to solving particular movement tasks or requirements.

5. Adapting modification of a patterned movement to meet externally imposed task demands. This would include modification of a particular movement to perform it under different conditions.

6. Refining: Acquisition of smooth, efficient control in performing a movement pattern or skill by mastery of spatial and temporal relations. This process deals with the achievement of precision in motor 
performance and habituation of performance under more complex conditions.

Creative Movement: Those motor performances, which include the processes of inventing or creating skillful movement, which will serve the personal and individual purposes of the learner. The processes employed are directed toward discovery, integration, abstraction, idealization emotional objectification and composition.

A. Varying: Invention or construction of unique or novel options in motor performance. These options are limited to different ways of performing specific movements; they are of an immediate situational nature and lack any pre-determined goal or outcome that has externally imposed on the mover.

B. Improvising: Extemporaneous origination or initiation of novel movements or combinations of movements. The processes involved may be stimulated by a situation externally structured, but pre-planning on the part of the performer is not usually required.

C. Composing: Combination of learned movements into unique motor designs or the creation of movements new to the performer. The performer creates his own motor response in terms of his own interpretation of a movement situation.

The categories are described as processes. Obviously they are in a hierarchy of difficulty, yet all can be sought and achieved at any age level in the context of 
the stage of learning by the learner; i.e., one must have tools (basic skills) in order to create. The creative product can be very simple.

\section{Psychomotor Learning}

Learning is a process involving both maturation and experience. Not all children entering school are at the same ability level. Although little can be done to speed up the maturational component of this process, parents and teachers can influence the experiential component. Perceptual-motor learning involves the establishment and refinement of sensory sensitivity to one's world through movement (Magill \& Ash, 1979). This sensory sensitivity involves developing and refining an adequate spatial and temporal world. All movement occurs in space and involves an element of time.

Developing these structures is basic to efficient functioning in a variety of other areas. It is possible to enhance children's knowledge of their spatial world by involving them in movement activities that contribute to their body awareness, directional awareness, and spatial awareness. Corbin \& Pate (1981) indicates that children's awareness of their temporal world may be increased through activities that focus on the synchrony, rhythm, and the sequencing of movements. Selected visual, auditory, and tactile abilities may also be reinforced through movement in carefully selected activities.

\section{Health-Related Fitness Domain}

Health is the normal development and functioning of all organs and systems of the human body which ensure its creative activity under specific historical 
conditions such as the social system, work, everyday life, rest, nutrition, housing conditions, culture, the medical service, just to mention a few (National Center for Health, 2000).

In 1997 AAHPERD changed the term "Performance Physical Fitness" (also known as physical fitness) to "Health-Related Physical Fitness" (also known as skill-related, or motor, fitness). A newly developed test has been constructed to conform to the assignments of this new term. The major differences between health related and performance related fitness lie in the degree to which each component must be developed within the two areas. Distinction between the two terms is important to explain the importance of the new one in school physical education programs.

Physical fitness has been considered to be the ability to perform daily tasks without undue fatigue and to possess ample reserves of energy for recreational pursuits and emergency needs. Muscular strength, muscular endurance, cardiovascular endurance, and joint flexibility are universally considered to be health-related fitness components. Body composition is also considered by many to be a health-related component.

However, physical fitness includes those qualities of function that provide the individual with the ability to participate in sport activities with greater power, strength, endurance, skill, etc., than would otherwise be the case. The ultimate example of a person with this type of fitness would be an athlete or professional athlete. 
The concept of performance-related fitness (physical fitness) is an elusive term that has been studied extensively over the past several years and is classified by some experts as an aspect of physical fitness. Balance, coordination, agility, speed of movement and power are among the most frequently cited components of performance-related fitness. The generality and specificity of these components have been debated and researched for years, with the bulk of evidence in favor of their specificity.

Health related-fitness refers to those aspects of physiological and psychological functioning, which are believed to offer the individual some protection against degenerative type diseases such as coronary heart disease, obesity, and various musculo-skeletal disorders (AAHPERD, 1997). The basic health-related fitness components, on the other hand, are measured in the new AAHPERD test by the one-mile or nine-minute run, sum of sub scapular and triceps skin folds, one-minute timed sit-up, and sit and reach, respectively (AAHPERD, 1997).

Thus, the general difference between the two terms, the old term might be specific to the athletic field, while the new term relates to the general health of the people. Thus, an individual might be high in certain components of performance-related fitness but low in health-related fitness and vice versa. An example would be baseball players who train only for their sport. Although these athletes are often very strong, usually exhibit high levels of skill in throwing, catching, and batting, and may possess exceptional sprinting speed. They are 
not necessarily high in other components of fitness, such as maximal oxygen consumption and low percentage body fat, both of which are important measures of health related fitness (Mack, 2001). As a matter of fact, each sport required the performer to be fit to perform only for his sport in an athletic sense but not fit in the health context.

\section{$\underline{\text { The Four Basic Components of Health-Related Fitness }}$}

The four Basic components of health related fitness is: cardiovascular function, body composition, strength, and flexibility.

\section{Cardiovascular Function}

Cardiovascular function is the most important component in the health-related fitness area. Although the evidence accumulated thus far is not undeniable, many cardiologists, physiologists, physical educators, and other health professionals are convinced that physical activity at levels sufficiently high enough to promote improved cardiovascular function is a potent factor in either preventing circulatory disease altogether or reducing its effect if it does occur (Target, 2002).

Another side of cardiovascular function that should not be overlooked is its impact on physical working capacity. The oxygen delivered to working muscles is critical to the energy transformation that occurs within them, especially when they are called upon to work for any significant length of time. A heart and circulatory system functioning at a higher level (delivering more blood) is also 
making more oxygen available to the muscles. This increases the individual's ability to work and/or exercise at a greater intensity and/or a longer period of time. The fatigue prevention aspect of this quality is very important (Preboth, 2000). In this regard, Lavie et al. (1993) states that:

The criterion for cardiovascular fitness and physical working capacity is the relative level of functioning within the heart and circulatory system. In order to evaluate cardiovascular function, it must be measured. Valid and reliable procedures are available, and as educators we must make use of them (p. 168).

\section{Body Composition}

Novac, et al. (1998) defines body composition as "the relative percentages of fat and fat-free body mass" (p.1331). It is an important correlate to cardiovascular function as far as health related fitness is concerned. Excess amounts of body fat take the form of "excess baggage" when it becomes necessary to move the body from one place to another. Therefore, for any given amount of work as Novak et al. (1998) and also Sadovesky (2001) indicated, the energy expenditure is increased in the obese. The greater demand for energy causes the circulation to work harder. Also, an obese person usually consumes a diet high in saturated fats and cholesterol. The resulting greater level of circulating blood fats increases the probability of developing arteriosclerosis - an important precursor to coronary heart disease. 
The problem of obesity is widespread all over the world. For example, National Institutes of Health (1995) has estimated that over $50 \%$ of all adults can be considered overweight, and surveys among school children indicate that a similar problem exists for at least $40 \%$ of that population. Lavie \& Milani (1993) indicated that retention of body fat at any age is a health problem of considerable concern, but it is especially significant in children and adolescents because obese individuals in those age ranges are much more likely to become fat adults than are their non-fat peers.

In addition to an increased incidence of coronary heart disease among obese persons, certain other health problems are prevalent. These, as Sadovesky (2001) described, include greater risk of developing and suffering from hypertension, diabetes mellitus, gall bladder disease, degenerative arthritis, kidney disease, adverse postural changes, delayed puberty in children, and decreased endurance and work capacity. It has been estimated that if all deaths from cancer were eliminated, two years would be added to the life span, and if all the deaths related to obesity were removed, the life span would increase five years! Indeed, most medical authorities recommend that one of the best personal preventive and rehabilitative health practices available to an individual are the reduction or prevention of excess body fat.

\section{Strength}

A third important component of health related fitness is muscular strength. Strength is usually defined as a muscle or muscle group's relative 
capacity for exerting force against some external resistance. The importance of strength to high-level performance in sport activities is rather obvious to most persons. Everything else being equal, higher levels of strength usually enable the possessor to jump higher, throw farther, push harder, and resist the efforts of an opponent to a greater degree.

Mack (2001) indicates that the importance of strength in general health is perhaps less readily apparent. However, stronger muscles better protect the joints that they cross. As a result, the individual is less susceptible to strains, sprains, and pulls that sometimes occur when one participates in physical activity. In addition, better tone in the muscles of the trunk aids in preventing some of the more common postural problems that plague us (e.g., sagging abnormal abdominal organs, round shoulders, and low back pain.)

The strength of the abdominal musculature is of critical importance in the etiology of the low back syndrome, one of the most prevalent health problems. Medical reports indicate that low back pain is experienced by approximately $80 \%$ of the population at some point in their lifetimes. Physical fitness experts, physical therapists, and orthopedic surgeons link the high incidence of low back problems with a corresponding lack of exercise. The general logic is that muscles that are easily fatigued and/ or strained can not support the spine in proper alignment. Weak abdominal and inflexible posterior thigh muscles, in particular, allow the pelvis to tilt forward causing a concurrent and abnormal arch in the low back. Shortened, inflexible muscles thus result in decreased mobility and 
increased possibilities of strain, spasm, and pain. The end result is the "low back syndrome" (Mack, 2001).

In addition to protection from the problems described, persons possessing optimum levels of strength development are likely to derive more satisfaction from recreational sports participation. They should be more successful in the execution of sport skills and less susceptible to fatigue. Because of this success, they are more likely to engage in recreational sport activities and derive the major benefits of cardiovascular conditioning, weight control, and tension relief (Mack, 2001).

\section{Flexibility}

The fourth important component of health related fitness is flexibility. In the physical education and sport context, flexibility refers to the degree to which a joint may move through its maximum possible normal range of motion. The determining factor in joint range of motion is the extensibility of the associated connective tissue (tendons and ligaments) in and around the joint. Any restriction in the normal extensibility of a joint's connective tissue defines a flexibility problem.

Mark et al. (2000) indicated that loss of joint flexibility often contributes to postural problems. These usually result from the adaptive shortening of connective tissue on one side of a joint concurrent with a loss of tone in the muscles on the opposite side of the joint. Examples are: (1) the condition of round shoulders in which shortened tendons and ligaments in the upper chest 
area allow the associated muscles to draw the shoulders forward; and (2) the common adult problem of an inability to bend forward and touch the toes with the hands while keeping the knees fully extended. A primary cause of the latter problem is adaptive shortening of the connective tissue in the lower back and the posterior thigh areas. The implications for adequate levels of both flexibility and strength in the prevention of back problems are obvious.

Adequate flexibility is also an important factor in the performance of many sport skills (both recreational and at higher competitive levels). If an individual suffers from a loss of flexibility, even high levels of development in other fitness components such as strength and endurance may be of decreased benefit. If there is decreased range of motion in a joint, the individual will be less effective in expressing whatever strength quality is present within the muscles acting over that joint. Also, the reduced range of motion may prevent the individual from observing proper mechanical principles in the execution of a skilled movement, lowering the level of performance. Any resulting misalignment of body segments and/or compensations within other joints can increase the possibility of joint or muscle injury.

Adequate levels of cardiovascular function, body composition, strength (especially abdominal), and flexibility (especially low back and posterior thigh) must form a base for all other components of physiological functioning. These are the components that have been shown by research and/or clinical practice to be significantly related to health. Adequate function in these components can 
have a positive effect on one's quality of life throughout childhood and adult years (Mark et al., 2000).

\section{A Taxonomy of Health Related Fitness}

The critical fitness objectives of developmental physical education focus on enhancing the ability and motivation of children to function in an environment that both requires and promotes the development of fitness. Physical fitness may be viewed as possessing the elements of both health-related fitness and performance-related fitness. Agreement on a suitable definition of physical fitness is often difficult, and the term is generally broadly described because the level of fitness required of one individual may not be the same as that required of another. Hence, a generic definition of "girls" and "boys" need to learn about the importance of health related physical fitness and to become aware of their own status.

For the purpose of this investigation, the physical fitness taxonomy outlined by Corbin and Pate (1981) would be a promotion of health through maintenance of health related fitness as a traditional domain of physical education. The taxonomy objective level is as follows:

1. Health Related Fitness Vocabulary.

2. Exercising.

3. Achieving Physical Fitness

4. Establishing Regular Exercise Patterns. 
5. Physical Fitness Evaluation.

6. Physical Fitness Problem Solving.

It would seem from the arrangement of the objectives that low order objectives are teachers oriented while higher order objectives are student or learner oriented.

Perhaps the most overt manifestation of the physical education profession's reaffirmation of the importance of health fitness is the development and adoption of the AAHPERD Health Related Physical Fitness Test (HRPFT). It seems likely that this new test will serve as the catalyst for a fundamental reorientation of the approach to fitness taken in many physical education programs. They also can learn the distinction between health related and skill related components.

As health and physical educators, our major claim to a position in the educational world is the contribution learning in our fields can make to an improved quality of life. Therefore, a basic emphasis, as educators, should be placed on health- related fitness that is important to everyone. However, the basic components of health related fitness, the "essentials of fitness," are also important components of performance related fitness in many sports, and the fundamental principles of development and maintenance of the components are common to the two areas. The major differences lie in the degree to which each component must be developed. 
The National Association for Sport and Physical Education (NASPE) (1992) indicates that physical educators play the central role in promoting the health of children and, ultimately, adults. The NASPE design the following seven standards of health-related physical fitness to help physical educators in evaluating the fitness of their students:

1. Demonstrates competency in many movement forms and proficiency in a few movement forms.

2. Applies movement concepts and principles to the learning and development of motor skills.

3. Exhibits a physically active lifestyle.

4. Achieves and maintains a health-enhancing level of physical fitness.

5. Demonstrates responsible personal and social behavior in physical activity settings.

6. Demonstrates understanding and respect for differences among people in physical activity settings.

7. Understands that physical activity provides opportunities for enjoyment, challenge, self-expression, and social interaction.

\section{Previous Studies in Physical Education}

Lambdin \& Steinthardt (1991) studied the perceptions of the elementary and secondary physical educator's relevant to their goals, expertise, curriculum, and students' achievement. Sixty physical education teachers completed a questionnaire that assessed their level of agreement 
with 14 commonly identified goals for physical education by using a 5-point Likert scale. These goals included: (1) the development of basic motor skills, (2) lifetime sports skills, and (3) physical fitness. For each goal, the teachers assessed their commitment to the goal, their expertise in content related to the goal, whether they taught this goal, and their students' achievements of the goals.

The results indicated that teachers do not perceive their level of expertise as a limiting factor. However, they showed a relationship with the teacher's commitment, his or her expertise, what was taught, and what was learned. They also concluded that teachers have a wide range of goals for teaching and they rate what is taught lower than their commitment to the goals. This result indicates that barriers exist that prevent them from teaching what they would like and what they feel prepared to teach.

Parker (1995) studied the beliefs of both teachers and students about physical education, and how these beliefs were translated into action in a class setting. Three eleventh-grade students in the same physical education class served as subjects. Interviews were field and observational field notes were collected on each subject. Results showed that personal relationships influenced the belief held by both the physical educator and the students. All agreed that learning to interact with others was important.

However, the teacher's and the students' beliefs differed significantly concerning the importance of physical education. While, the teacher believed 
that physical education was an essential component in the overall school curriculum, the students perceived physical education as a recreational break. These students placed less importance on physical education and further indicated that including this in the curriculum would not contribute to their future success.

Jewell (1995) investigated the perceptions of physical education teachers towards the goals of a high school physical education program. He utilized the National Association for Sport and Physical Education definition (1992) concerning the physically educated student. These definitions consist of 20 goals of secondary school physical education. The sample of this survey consisted of 105 physical education teachers.

According to Jewell's study, results showed that seventeen out of twenty goals received an average score, indicating that those goals should be included in the high school programs. The level of consensus for these seventeen goals ranged from $81 \%-90 \%$. The respondents did not decide whether or not the three remaining goals should be included as part of high school physical education programs. The highest rated goal by the respondents confirmed that regular participation in physical activity should be at least three times per week. The lowest rated goal was concerned with students being able to demonstrate proficiency in few forms of physical activity. Gender and years of teaching experience have no significance on teachers' perception toward the goals of the programs. 
Jensen (1975) investigated the relationship between physical education purposes and program implementation in Wisconsin schools. The sample consisted of three groups (physical education teachers, physical education teacher educators, and principals). They were asked to rank seven stated purposes. Rankings were reported by individual purposes and by the seven major purpose categories for each of the three groups of educators.

The results indicated that physiological efficiency was the first rated purpose, object manipulation the second rated- purpose, spatial orientation the third and group interaction the fourth with psychic equilibrium fifth, communication sixth, and cultural involvement seventh.

Chou (1989) investigated the importance of 22 purposes for present and future physical educators in Taiwan. Three groups served as a sample: educators in Taiwan (undergraduate majors, secondary school teachers, and college-university professors). He found the top five purposes for the present ranked by all three groups were circular-respiratory efficiency, teamwork, and neuromuscular efficiency. The same three groups of physical educators ranked circulo-respiratory efficiency, joy of movement, teamwork, neuromuscular efficiency, and leadership as the five most important future purposes for the people in Taiwan. However, leadership and competition were not ranked in the same order of priority. The areas identified as important for the future for the Taiwanese were individual development and social interaction. 
Williams (1984) conducted a study in New Zealand using a questionnaire that consisted of a set of physical education goals. Sample of the study consisted of 121 teachers, teaching either elementary or secondary schools. The investigator asked the teachers to rank eleven physical education goals from the most important (1) to the least important (11). The goals were emotional stability, self-realization, leisure activities, social competence, moral development, tolerance to exercise, motor skills, aesthetic appreciation, cognitive development, health education, and enjoyment and satisfaction.

Teachers at both levels ranked enjoyment and satisfaction as number one. Self-realization was ranked second by elementary teachers and third by secondary teachers, while health education was ranked third elementary teachers and second by secondary teachers. Leisure activities were ranked fifth by elementary teachers and fourth by secondary teachers, while motor skills were ranked filth by elementary teachers and fourth by secondary teachers. Teachers at both levels ranked the last six goals, tolerance to exercise, social competence, emotional stability, moral developmental, cognitive development, and aesthetic appreciation as less important.

Jerome and Geraldine (1996) studied perceptions of the values of basic physical education activity programs at historically black colleges and universities. In addition, they studied whether there were differences between African American females and males. 
The sample in this study consisted of 502 subjects; 300 (59.8\%) were females and $202(40.2 \%)$ were males. A questionnaire of 24 items was used to collect information from the subjects. By using factor analysis procedures, the 24 physical education values were reduced to five dimensions. These five dimensions were labeled: physical self-efficacy, commitment to lifelong participation, health related physical fitness, health aesthetic benefits, and social benefits. The five factors as a whole accounted for $56.5 \%$ of the variance in response to the 24 physical education values.

MANOVA was used to compare the vectors of the five factors mean scores between the African American male and female students. The results indicated that statistical significant differences existed in the mean vectors between the male and female students.

Univariate tests indicated that significant difference between male and female students existed in two factors. First, regarding the health aesthetic benefits factor, the African-American female students placed more emphasis on getting regular exercise and keeping weight under control than did African-American male students. Second, in the social benefits factor, AfricanAmerican male students placed more importance on having fun and making new friends than did the African-American female students.

Speakman (1987) used a Delphi technique to conduct a cross-cultural comparison of the 22 purposes identified in the Purpose Process Curriculum Framework to determine if the purposes were true and appropriate for 
different cultures. Fifty physical educators were involved in this study. Twenty respondents in England, 20 in the United States, and 10 in Japan completed three rounds of a questionnaire. Each respondent was requested to rate the importance of each of the 22 statements as a valued outcome for individuals in physical education for both the present and the future. He found that for the present in the United States, circular-respiratory efficiency, joy of movement, and participation for individuals participating in physical education as the top three valued outcomes. In Japan, the top three desired present outcomes were mechanical efficiency, catharsis, and teamwork. In England, respondents chose joy of movement, teamwork, and neuromuscular efficiency as the top three valued present outcomes.

For the future, United States respondents rated respiratory efficiency, joy of movement, and participation as valued outcomes of physical education, the same as for the present. Japanese respondents rated respiratory efficiency, joy of movement, and catharsis as valued future outcomes. English respondents rated teamwork, respiratory efficiency, and joy of movement as the valued future outcomes.

Martin (1992) ascertained the educational value orientations of selected physical educators, their perceived value orientations, and the relationship of their stated goals for physical education to those value orientations. His data were collected from 134 physical education teachers in a large Midwest metropolitan urban school district. The Physical Education 
Inventory was used to collect the data; Part I was developed to determine or assess the five educational value orientations, while Part II was designed by the researcher to determine the teacher's goals for physical education. Differences in value orientations and goals were examined in relation to gender, age, years of teaching experience, and grade level assignment. While the highest score of strong value orientations was for the orientation of disciplinary mastery, the largest percentage of teachers was found to have meta-orientations. No wide differences were found in relative positions of the three most important physical education goals. These three goals were fitness, enjoyment, and group interaction. Small differences in importance were found between priority rankings of the seven physical education goals. Although some differences were found in ranking of goals according to gender, age, teaching experience, and grade level assignment, none of these differences appeared to be major or meaningful.

Hedlund (1985) investigated the importance of the goals of physical education. He described and analyzed the beliefs of Kansas's secondary school physical educators about these goals. Data were collected from 216 physical education teachers randomly selected in Kansas. A questionnaire was used as the instrumentation to collect the data. The statistical tests used by the researcher were the Kendall coefficient of concordance, the MannWhitney U test, the Wilcoxon matched-pairs test, and Kendall rank correlation coefficient. 
The result indicated that Kansas's secondary school physical educators agree on the relative importance of both the outcomes within goal areas and the goal areas within varied physical education settings. Their rankings were consistent; the Kansas educators believe that lifelong use and implementation of motor skill and physical fitness are the primary outcomes of physical education at the secondary level. They believe that lifetime physical fitness is the most important overall outcome of physical education at the secondary level that "have improved self-concept and self-understanding" is the most important of the four outcomes in the affective goal area; that "know and understand the relationship between activity/fitness and health" is the most important of the four outcomes in the cognitive goal area; that 'desire to achieve and maintain a level of physical fitness necessary for health" is the most important of the four outcomes in the physical fitness goal area; and that "feel competent to participate in recreation situations" is the most important of the four outcomes in the motor skill goal area. Few significant differences in the priority orders exist in the rankings of the physical education goal areas and outcome statements regarding sex, amount of teaching experience, and number of memberships in professional organizations. However, differences in the priority order for the goal areas were found between elementary school and secondary school.

The Educational Office of the Arab Gulf Countries (1980) conducted a study titled "Evaluation of the Current Physical education Curriculum in Arab 
Gulf Countries According to Their Goal Setting." The intent of this study was to compare the curriculum of physical education in all levels (elementary, middle, and high school) among the Arab Gulf countries. The goals included:

1. Identifying physical education goals in each school level in each country.

2. Evaluating the teaching methods that have been used according to the goals of the program.

3. Evaluating the content of physical education in each school level according to the goals of the program.

4. Evaluating the facilities and equipment.

5. Evaluating the supervision in physical education according to the goals of the program.

To answer those questions the Office analyzed the documents and information regarding physical education that had been received from all the countries. The study revealed the following results:

1. There was no balance in the goals of physical education. The goals emphasized the affective domain to a large degree, then the psychomotor domain, whereas the cognitive domain was very weak.

2. The goals of physical education in Bahrain were most compatible with the general goals of education, followed by Qatar and Saudi Arabia. 
3. There was a large variance among countries regarding the number of physical education classes, and this variance was not compatible with the goals of physical education.

E1-Naggar, et. al (1991) investigated the merits and weaknesses of physical education in the developmental high schools in Saudi Arabia and proposed an integrated program for improving physical education in these schools. The study was divided into three parts dealing with the importance of physical education, the actual situation of physical education in schools, and ways of improving it.

In the first part, evidence was brought showing the importance of physical education in the integrated development of individuals. The second part a survey study was conducted in 13 secondary schools that applied the developmental system. The study showed that the ratio of the registered physical education hours to the total available registered hours was $67 \%$, which is lower than traditional system. Also it appeared that there was neither a specified program nor a known evaluation system for physical education in the schools, or at least it was unclear and unused by the teachers in the schools. In the third part, a physical education program was proposed for improving physical education in the developmental secondary schools. This program included purposes, theoretical and practical aspects and activities, methods of teaching and an evaluation system for physical education. 
Alsagheir (1993) evaluated the intermediate physical education goals from the teachers' and supervisors' points of view in Riyadh city in Saudi Arabia. The sample of the study included all the population of 100 teachers and 9 supervisors. The study answered the following questions:

1. To what extent are the physical education goals clear?

2. To what extent do the current physical education goals take into consideration the development of the psychomotor domain?

3. To what extent do the current physical education goals take into consideration the improvement of the cognitive domain?

4. To what extent do the current physical education goals take into consideration the development of the affective domain'?

5. Are there any differences in teachers' and supervisors' points of view towards the evaluation of physical education goals according to their job, qualification, and experience'?

The results of the study revealed the following:

1. The current goals of physical education at the intermediate level are not clear according to the teachers' points of view.

2. Few goals are concerned with the cognitive and psychomotor domain, while the affective goals appear to be acceptable.

3. The current goats of physical education are not concerned with the individual differences among students. 
4. The current goals of physical education are not concerned with the talented and disabled students.

5. The goals and objectives of the intermediate physical education are overlapping and not clearly stated.

6. No significant difference was found regarding job and experience in evaluating the current goals of the intermediate physical education goals, while significant differences were found regarding qualification.

\section{Summary and Conclusions}

Studies reviewed in this chapter have pointed to the importance of identifying specific goals for physical education programs. The emphasis of most of these studies was focused on the cognitive, affective, and psychomotor domains. However, few studies added the health- related fitness.

The Purpose Process Curriculum Framework (PPCF), a conceptual framework of physical education curricular decision-making is the result of the work of J ewett and Mullan (1977). The rational base of the PPCF is that the ways in which an individual participant may seek personal meaning through physical activity can be viewed as potential goals of the physical education curriculum. 
The PPCF consists of three key concepts and major curriculum orientations: (a) individual development, (b) environmental coping, and (c) social interaction. These three concepts are comprised of seven major purposes: psychological efficiency, psychic equilibrium, spatial orientation, object manipulation, communication, group interaction, and cultural involvement. Finally, from these key concepts and major purposes, 22 purpose elements were developed.

The executive committee of the National Association for Sport and Physical Education formed the Outcomes Committee in 1986. Its major responsibility was to define the physically educated person. After extensive work the committee delineated twenty major outcomes for a physically educated person under five categories that represent the three learning domains (psychomotor, cognitive, and affective) in physical education (Outcomes Committee, 1992). The definition of a physically educated person provided by the NASPE National Association for Sport and Physical Education (1992) can be used as a framework to guide a physical education program.

The conclusions that can be made from the above-mentioned studies in this chapter are as follows:

1. All studies are concerned with physical education curriculum in general and the goals of physical education in particular. Thus, these studies are important and relevant to the present study. 
2. Most of these studies used questionnaires as an instrument to collect the data. The present study will use also a questionnaire, since it is a proper technique in collecting data in such studies.

3. Most of these studies used teachers as a sample because the researchers realized that teachers are the most significant factor in the educational process. Accordingly, the present study also utilizes teachers.

4. Some studies declare the need to balance the three learning domains of physical education: cognitive, affective, and psychomotor.

5. The studies that were conducted in Saudi Arabia revealed that the goals of physical education were ambiguous, and in some cases, there were no specific goals for the programs.

The present study will extend the existing research regarding the goals of physical education by using physical education teachers in Kuwait and focusing on their perceptions toward the four selected domains of physical education (cognitive, affective, psychomotor, and health related fitness). 


\section{CHAPTER I I}

\section{METHODOLOGY}

\section{Introduction}

The major aim of this study was to investigate the perceptions of the Kuwaiti physical education teachers relevant to the goals of the physical education program for secondary schools. Physical education teachers were asked to indicate the level of agreement with physical education goals that are categorized into four areas: cognitive, psychomotor, affective and health-related fitness. In addition, differences in teachers are based on gender between physical education teachers' perceptions are investigated. An examination was also made to see if there were differences in teachers' perception of the physical education goals based on the number of years of teaching experience.

\section{$\underline{\text { Research Design }}$}

\section{Population}

Kuwait consists of six provinces: Hawly, Mubarak, Alasema, Al-Frawania, Alahmadi, and AlGahra. Information relevant to the number of female and male secondary schools teachers in each province was obtained from Ministry of Education in Kuwait.

Complete information about the population of this study was obtained from the Ministry of Education in Kuwait (see Table 1). The total number of secondary schools is 116 (57 school for males, and 59 for females). The total 
number of physical educators in the secondary schools is 570 . This total includes 289 females and 281 males. Secondary schools are dispersed into six Educational Provinces. These provinces are: Hawly (17 schools), Mubarak (17 schools), Alasema (22 schools), Al-Frawania (18 schools), Al-Ahmadi (29 schools), and Al-Gahra (13 schools).

Table (1)

Distribution of Male and Female Physical Educators on Provinces

\begin{tabular}{|l|c|c|c|c|}
\hline \multirow{2}{*}{ Province } & \multicolumn{3}{|c|}{ Males } & \multicolumn{3}{c|}{ Females } \\
\cline { 2 - 5 } & No. Schools & No. Teachers & No. Schools & No. Teachers \\
\hline Hawly & 9 & 45 & 8 & 44 \\
\hline Mubarak & 9 & 41 & 8 & 39 \\
\hline Al-Asema & 11 & 60 & 11 & 58 \\
\hline Farwania & 8 & 49 & 10 & 48 \\
\hline Ahmadi & 14 & 55 & 15 & 54 \\
\hline Gahra & 6 & 39 & 7 & 38 \\
\hline Total & 57 & 289 & 59 & 281 \\
\hline
\end{tabular}

\section{Sample}

Data were collected from a sample consisting of $200(n=200)$ physical education teachers ( 100 women $\& 100$ men). In order to have a representative sample of the six Educational Provinces, the number of sub-samples in each province for either males or females was determined according to what percentage it represented of the total population. Additionally, copies of the 
questionnaire were distributed to ensure that each school in the defined population had a chance of being selected as a member of the sample. Table (1) shows number of the respondent males and females in each province as well as their sums and percentages.

Table 2

Sample Distribution

\begin{tabular}{|c|c|c|c|c|c|}
\hline Source & Exp. & $\mathrm{N}$ & $\mathrm{N}$ & Mean & SD \\
\hline Female & \multirow{2}{*}{$1-5$} & \multirow{2}{*}{43} & 19 & 2.53 & 1.43 \\
\hline Male & & & 34 & 2.76 & 1.30 \\
\hline Female & \multirow{2}{*}{$6-10$} & \multirow{2}{*}{68} & 36 & 8.53 & 1.42 \\
\hline Male & & & 32 & 7.94 & 1.68 \\
\hline Female & \multirow{2}{*}{$11-15$} & \multirow{2}{*}{79} & 45 & 13.62 & 2.26 \\
\hline Male & & & 34 & 12.78 & 2.19 \\
\hline Total & & 200 & 200 & & \\
\hline
\end{tabular}

The total number of secondary school physical education teachers in Kuwait at the time the KPEPG had been distributed was 583. The sample of the present study consisted of 200 representing $34.3 \%$ of the population with equal number of female and male secondary school physical education teachers. Data were collected from six provinces that constitute Kuwait. Based on number of physical educators in each province, table (1) shows number and percentage of the sample from each province. 


\section{$\underline{\text { Research Instruments }}$}

According to the secondary school physical education program in Kuwait, this study investigated the following domains' goals: (1) cognitive, (2) affective, (3) psychomotor, and (4) health-related fitness.

In order to determine the current status of physical education in the secondary schools in Kuwait, an evaluation instrument was developed according to the objectives of the physical education program. Four developmental objectives were, therefore, accepted as the basis for physical education programs. These objectives are similar, if not identical, to those identified and accepted by many authorities in the field. They follow: (a) Neuromuscular development--skillful, graceful, and aesthetic performance in sport and other large muscle movements; (b) Organic development -- muscle strength and endurance, and cardiovascular endurance; (c) Interpretive development-knowledge of sport and fitness and the ability to use this knowledge effectively;

and (d) Affective development--use of emotions and attitudes to motivate participation in activities and to live a happy and productive life.

\section{Development of Instrument}

The format of the instrument utilized in this study was determined after a careful analysis of survey theory. A 24-item questionnaire derived from the Kuwaiti physical education program's goals for secondary schools was designed to provide information about Kuwait teachers' perceptions of the goals of physical education. Best and Kahn (1998) noted that the advantages of using a 
questionnaire are: reaching a large number of subjects, saving time, and reducing the expense of the research.

The questionnaire was composed of two sections. The first section obtained the participants' demographic information. The demographic information included sex, qualification, and years of experience. Section two, was designed to collect information about the goals of physical education. A series of closed-ended positive statements were designed to collect information about teachers' perceptions regarding the level of realization of selected physical education goals. These items covered all four domains of physical education goals. These domains were (a) cognitive, (b) affective, (c) psychomotor, and (d) health-related fitness.

The questionnaire asked teachers to rate the level of realizing each goal to them as individuals. The opinions were measured on a 5-point rating scale: (strongly agree) 1, (agree) 2, (uncertain) 3, (disagree) 4, (strongly disagree) and 5. (The questionnaire can be found in Appendix C).

At the end of the questionnaire an opportunity was given to the respondents to list any opinion regarding any important problems they face in realizing the required goals in the physical education program, and to report any opinion not included in the questionnaire.

A group of five Arabs PhD holders that work in the College of Education, the Department of Linguistics at Al-Kuwait University, were given the two versions of the questionnaire for comparison and commentary. 
Using the Arabic version allowed the researcher to check the weaknesses and strengths of the questionnaire in order to avoid the former and support the latter. Similarly, a panel consisting of 10 teachers in physical education then reviewed this initial list of items for clarity. As a result of their review, a preliminary instrument was developed. The instrument included 24 items evaluating four domain goals of physical education: cognitive, affective, psychomotor, and health-related fitness. Some statements were reworded and the final draft of the instrument was made.

\section{Pilot Study}

In order to achieve reliability for this study, a pilot study was conducted. The researcher selected 60 teachers not included in the sample of the present study. The reliability of the instrument was established by internal consistency (stability of items). The coefficient alpha (Cronbach's alpha) was computed to examine internal consistency for each of the four dimensions: cognitive, affective, psychomotor, and health-related fitness (Table 3).

\section{Reliability of the Instrument}

Reliability refers to the degree to which the instrument measures phenomena in a consistent manner (Oosterhof, 1994). In order to have reliability for this study, 60 teachers, not included in the sample of this study, were administered the questionnaire to provide data for the determining the reliability and validity of the instrument. Reliability was established by internal consistency (stability of items). The coefficient alpha (Cronbach's alpha) was computed to 
examine internal consistency for each of the four dimensions: cognitive, affective, psychomotor, and health-related fitness (Table 3).

The selection of this technique of reliability is related to the goals of the present study. Since the rationale of reliability of such instrument is to examine the consistency of physical education teachers' responses to different goals of physical education on the same questionnaire at the same time, according to Light, et al. (1990) the best way to estimate reliability is by internal consistency.

\section{Validity of the Questionnaire}

Validity refers to the degree that the instrument measures what it is supposed to measure (Light et al. 1990). Construct validity was conducted by using the factor analysis procedure (Table 3).

\section{Data Collection}

After the researcher's committee approved the research, the researcher traveled to Kuwait during the summer and part of fall periods of 2003. The Ministry of Education was contacted to request permission to conduct research in all secondary for girls and boys. Upon receiving approval, the researcher contacted the six educational provinces in Kuwait.

The final revised version of the Arabic form of the questionnaire was distributed to the sample of this study through the six Educational provinces. Follow-up was done to encourage the physical education teachers chosen as the sample of this study to respond as soon as possible. Three weeks later the data was collected. 


\section{Data Analysis Procedures}

All Data were coded for computer handling, and was analyzed using the program Statistical Package for the Social Sciences (SPSS) version 11. Types of analyses used to in this study were as follows:

1. Cronbach's alpha reliability test was used for items measuring the dependent variables.

2. Factor analysis was employed to examine the validity of the KPEG.

3. Descriptive statistics were reported for the variables of the study (frequencies, percentages, means, and standard deviations).

4. Chi-square-test was used to determine if the frequencies observed are different from the frequencies that would be expected by chance. This test was used to determine the significant level of agreement or disagreement of the sample toward each of the four domains as well as each of the six statement goals comprising that domain.

5. T-test for "independent-samples" was used to test differences in responses between males and females participates in this study toward each domain and each goal. The 0.05 level of significance was utilized as the lowest level of acceptance.

6. One-way analysis of variance for unequal group sizes was employed, to find out the effect, if any, of years' of teaching 
experience $(1-5,6-10,11-15$ years) upon the perception of each of the four domain's goals. In case of significance at the 0.05 level, multiple comparisons (Gabriel) was employed. 


\section{CHAPTER IV}

\section{RESULTS}

\section{Introduction}

In order to provide answers to the three questions of the present study, a 5-points Likert scale questionnaire named "Kuwaiti Physical Education Goals", briefly, "KPEG" was designed. The KPEG contained items with a 5-point format (1=strongly agree, 2 =agree, $3=$ uncertain, $5=$ disagree, and $5=$ strongly disagree). All items were positively worded statements (see Appendix). The content of questionnaire items represented the four educational domains in physical education: (a) cognitive domain, (b) affective domain, (c) psychomotor domain, and (d) health related fitness domain. Each domain consisted of six stated goals.

A sample of 200 physical educators ( $n=200$ ) was asked to reply to the 24 statements of the KPEG, and to write any additional opinion related to the subject of this investigation. The sample was internally divided into two groups representing males $(n=100)$ and females $(n=100)$, as well as three groups relevant to years' of teaching experience: $1-5$ years $(n=53), 6-10$ years $(n=68)$, and $11-15$ years $(n=79)$.

In this chapter, the results of the responses of the sample and groups (gender, and experience) toward the (KPEG) statements are presented. For 
clarity, this chapter is organized into four major sections. These sections included:

1. Section one: Reliability and validity of the KPEG.

2. Section two: Descriptive Analysis of the responses toward the 24 statement goals forming the KPEG.

3. Section three: Comparisons between female and male groups.

4. Section four: Comparisons among the three groups of years' teaching experience.

5. Section 5: Discussion of the results.

\section{Results of Section One}

The reliability and validity of the KPEG were measured by coefficient of reliability (Cronbach's alpha) and factor analysis, respectively. Cronbach's alpha was computed for the total items, as well as each of the four domains. Factor analysis was computed for each item as well as each of the four domains. The results of the factor analysis, Cronbach's alpha, and Eigenvalues are summarized in Table 3. 


\section{Table 3}

\section{Factor Analysis and Cronbach's Alpha of the KPEG}

\begin{tabular}{|c|c|c|}
\hline \multicolumn{2}{|r|}{ Factors and physical education goals } & $\begin{array}{l}\text { Factor } \\
\text { loading }\end{array}$ \\
\hline \# & COGNITIVE & \\
\hline 1 & $\begin{array}{l}\text { Knowing the benefits, costs and obligations associated with regular participation in } \\
\text { physical activity. }\end{array}$ & .660 \\
\hline 2 & $\begin{array}{l}\text { Recognizing the risk and safety factors associated with regular participation in physical } \\
\text { activity. }\end{array}$ & .932 \\
\hline 3 & Applying concepts and principles to the development of motor skills. & .736 \\
\hline 4 & Knowing the rules, strategies and appropriate behaviors for selected physical activities. & .685 \\
\hline 5 & $\begin{array}{l}\text { Understanding that physical activity provides the opportunity for enjoyment, self- } \\
\text { expression, and communication. }\end{array}$ & .776 \\
\hline 6 & Realizing activities that can continue outside of school. & .844 \\
\hline \multicolumn{2}{|c|}{ Cronbach's Alpha } & .863 \\
\hline \multicolumn{2}{|c|}{ Variance explained (Eigenvalues) } & $19.79 \%$ \\
\hline \# & AFFECTIVE & \\
\hline 7 & Improving self-confidence. & .684 \\
\hline 8 & Releasing tension and frustration. & .667 \\
\hline 9 & Developing emotional stability. & .729 \\
\hline 10 & $\begin{array}{l}\text { Appreciating the relationships with others that result from participation in physical } \\
\text { activity. }\end{array}$ & .851 \\
\hline 11 & Cooperating with others to achieve common goals. & .685 \\
\hline 12 & Appreciating the role of exercise in healthful living. & .765 \\
\hline \multicolumn{2}{|c|}{ Cronbach's Alpha } & .610 \\
\hline \multicolumn{2}{|c|}{ Variance explained (Eigenvalues) } & $16.63 \%$ \\
\hline
\end{tabular}




\begin{tabular}{|l|l|l|}
\hline$\#$ & \multicolumn{1}{|c|}{ PSYCHOMOTOR } & \\
\hline 13 & Moving using concepts of body awareness, space awareness, effort, and relationship. & .729 \\
\hline 14 & $\begin{array}{l}\text { Demonstrating competence in a variety of manipulative, locomotors and non- } \\
\text { locomotors skills performed individually and with others. }\end{array}$ & .645 \\
\hline 15 & Demonstrating competence in many different forms of physical activity. & .808 \\
\hline 16 & Demonstrating proficiency in a few forms of physical activity. & .847 \\
\hline 17 & Learning how to learn new skills. & .693 \\
\hline 18 & Physical education program helps students develop skills in various sports. & .879 \\
\hline Cronbach's Alpha & .693 \\
\hline Variance explained (Eigenvalues) & $17.16 \%$ \\
\hline$\#$ & & \\
\hline 19 & Keeping weight controlled. & .863 \\
\hline 20 & Assessing, achieve, and maintaining physical fitness. & .618 \\
\hline 21 & $\begin{array}{l}\text { Designing safe, personal fitness programs in accordance with principles of training and } \\
\text { conditioning. }\end{array}$ & .844 \\
\hline 22 & Participating in health enhancing physical activity at least three times a week. & .822 \\
\hline 23 & $\begin{array}{l}\text { Selecting and regularly participating in physical activities now and throughout their adult } \\
\text { years. }\end{array}$ & .873 \\
\hline 24 & Keeping in good health and physical condition & .691 \\
\hline Cronbach's Alpha & .921 \\
\hline Variance explained (Eigenvalues) & $17.43 \%$ \\
\hline Total: Cronbach's Alpha & .815 \\
\hline Total: Variance explained (Eigenvalues) & $71.01 \%$ \\
\hline
\end{tabular}

Results of Table (3) indicated that the value of the overall standardized alpha was 0.815 . This value is greater than the suggested accepted value in the literature (0.70.). For each of the four domains the coefficient was as follows: cognitive domain, 0.863; affective domain, 0.610; psychomotor domain 0.693; and health-related fitness domain, 0.921. Factor analysis for the total KPEG ranged between $0.610-0.932$. For each of the four domains the range of these values was: cognitive domain: $0.660-0.932$, affective domain: $0.610-0.851$; 
psychomotor domain: 0.645. - 0.879, health-related fitness domain: 0.618 0.873 .

\section{Results of Section Two}

Section Two presents frequencies and percentages of the responses, and descriptive statistics (means and standard deviations), regarding: KPEG as statements, domains, and total responses of the sample. In addition, it presents comparisons between agreement and disagreement responses using Chi-Square.

Table 4 presents sum, mean, and standard deviation of the frequencies of the responses regarding:

1. Each of the 24 statements' goals.

2. Each of the four domain statements' goals (cognitive, affective, psychomotor, and health, related fitness".

3. Total statements' goals of the KPEG. 
Table 4.

Means and Standard Deviations of Responses for KPEG I tems

\begin{tabular}{|c|c|c|c|c|}
\hline 1. & Cognitive DOMAIN & Mean & SD & Sum \\
\hline$\overline{1}$ & $\begin{array}{l}\text { Knowing the benefits, costs and obligations associated with } \\
\text { regular participation in physical activity. }\end{array}$ & 3.47 & 1.31 & 694 \\
\hline 2 & $\begin{array}{l}\text { Recognizing the risk and safety factors associated with regular } \\
\text { participation in physical activity. }\end{array}$ & 3.28 & 1.43 & 655 \\
\hline 3 & $\begin{array}{l}\text { Applying concepts and principles to the development of motor } \\
\text { skills. }\end{array}$ & 2.75 & 1.42 & 549 \\
\hline 4 & $\begin{array}{l}\text { Knowing the rules, strategies and appropriate behaviors for } \\
\text { selected physical activities. }\end{array}$ & 3.41 & 1.44 & 682 \\
\hline 5 & $\begin{array}{l}\text { Understanding that physical activity provides the opportunity } \\
\text { for enjoyment, self-expression, and communication. }\end{array}$ & 2.70 & 1.43 & 539 \\
\hline 6 & Realizing activities that can continue outside of school. & 2.95 & 1.41 & 589 \\
\hline \multicolumn{2}{|c|}{ Cognitive Goals - Mean and SD } & 3.09 & 1.10 & \\
\hline$\underline{11}$ & $\underline{\text { Affective Domain }}$ & Mean & SD & Sum \\
\hline 7 & Improving self-confidence. & 2.64 & 1.38 & 527 \\
\hline 8 & Releasing tension and frustration. & 2.96 & 1.47 & 591 \\
\hline 9 & Developing emotional stability. & 3.03 & 1.45 & 605 \\
\hline 10 & $\begin{array}{l}\text { Appreciating the relationships with others that result from } \\
\text { participation in physical activity. }\end{array}$ & 2.55 & 1.48 & 510 \\
\hline 11 & Cooperating with others to achieve common goals. & 2.58 & 1.37 & 515 \\
\hline 12 & Appreciating the role of exercise in healthful living. & 2.88 & 1.40 & 576 \\
\hline \multicolumn{2}{|r|}{ Affective Goals - Mean and SD } & 2.76 & 0.65 & \\
\hline$\underline{111}$ & Psychomotor Domain & Mean & SD & Sum \\
\hline 13 & $\begin{array}{l}\text { Moving using concepts of body awareness, space awareness, } \\
\text { effort, and relationship. }\end{array}$ & 2.65 & 1.43 & 529 \\
\hline 14 & $\begin{array}{l}\text { Demonstrating competence in a variety of manipulative, } \\
\text { locomotors and non- locomotors skills performed individually } \\
\text { and with others. }\end{array}$ & 2.13 & 1.23 & 426 \\
\hline 15 & $\begin{array}{l}\text { Demonstrating competence in many different forms of } \\
\text { physical activity. }\end{array}$ & 2.97 & 1.52 & 593 \\
\hline 16 & Demonstrating proficiency in few forms of physical activity. & 3.14 & 1.48 & 628 \\
\hline 17 & Learning how to learn new skills. & 2.91 & 1.37 & 581 \\
\hline 18 & $\begin{array}{l}\text { Physical education program helps students develop skills in } \\
\text { various sports. }\end{array}$ & 2.99 & 1.44 & 597 \\
\hline \multicolumn{2}{|r|}{ Psychomotor Goals - Mean and SD. } & 2.71 & 0.95 & \\
\hline
\end{tabular}




\begin{tabular}{|l|l|l|l|l|}
\hline IV & Health- Related Fitness Domain & Mean & SD & Sum \\
\hline 19 & Keeping weight controlled. & 2.91 & 1.46 & 581 \\
\hline 20 & Assessing, achieving, and maintaining physical fitness. & 2.65 & 1.46 & 529 \\
\hline 21 & $\begin{array}{l}\text { Designing safe, personal fitness programs in accordance with } \\
\text { principles of training and conditioning. }\end{array}$ & 3.65 & 1.31 & 729 \\
\hline 22 & $\begin{array}{l}\text { Participating in health enhancing physical activity at least } \\
\text { three times a week. }\end{array}$ & 3.92 & 1.35 & 783 \\
\hline 23 & $\begin{array}{l}\text { Selecting and regularly participating in physical activities now } \\
\text { and throughout their adult years. }\end{array}$ & 3.13 & 1.44 & 725 \\
\hline 24 & Keeping in good health and physical condition. & 3.29 & 1.36 & 658 \\
\hline & Mean and SD - Health-related fitness goals & 3.34 & 1.22 & \\
\hline KPEG - Mean and SD & 2.97 & 0.86 & \\
\hline
\end{tabular}

Table 4 indicated that total mean and standard deviation of the sample's responses toward the 24 statements comprising the KPEG were 2.97, and 0.86 , respectively. It may be noticed that the mean value is slightly less than the average point of the scale (3), and the value of the standard deviation is low indicating that variability among the sample's responses would be accepted.

Concerning the four domains, means of the affective domain (2.76) and the psychomotor domain (2.71) were less than the average point of the scale, while means of the health-related fitness domain (3.34) and the cognitive domain (3.09) were slightly higher than the average point of the scale.

Table 5 presents frequencies and percentages of the responses toward:

1. Each of the 24 statements' goals.

2. Each of the four domain statements' goals (cognitive, affective, psychomotor, and health-related fitness.

3. Total statement goals of the KPEG. 
Table 5

Physical Education Goals: Frequencies and Percentage of Responses $(N=200)$

\begin{tabular}{|c|c|c|c|c|c|c|c|c|c|c|}
\hline Item & 1 & $\%$ & 2 & $\%$ & 3 & $\%$ & 4 & $\%$ & 5 & $\%$ \\
\hline 1 & \multicolumn{10}{|c|}{ COGNITIVE GOALS } \\
\hline 1 & 21 & 10.5 & 30 & 15.0 & 35 & 17.5 & 62 & 31.0 & 52 & 36.0 \\
\hline 2 & 32 & 16.0 & 36 & 18.0 & 29 & 14.5 & 51 & 25.5 & 52 & 26.0 \\
\hline 3 & 49 & 24.5 & 57 & 28.5 & 18 & 9.0 & 48 & 24.0 & 28 & 14.0 \\
\hline 4 & 29 & 14.5 & 35 & 17.5 & 22 & 11.0 & 53 & 26.5 & 61 & 30.5 \\
\hline 5 & 44 & 22.0 & 72 & 36.0 & 23 & 11.5 & 23 & 11.5 & 38 & 19.0 \\
\hline 6 & 36 & 18.0 & 56 & 28.0 & 30 & 15.0 & 39 & 19.5 & 39 & 19.5 \\
\hline Sum \& \% & 211 & 17.6 & 286 & 23.8 & 157 & 13.1 & 276 & 23.0 & 270 & 22.5 \\
\hline$\underline{11}$ & \multicolumn{10}{|c|}{ AFFECTIVE GOALS } \\
\hline 7 & 50 & 25.0 & 62 & 31.0 & 26 & 13.0 & 35 & 17.5 & 27 & 13.5 \\
\hline 8 & 45 & 22.5 & 48 & 24.0 & 16 & 8.0 & 53 & 26.5 & 38 & 19.0 \\
\hline 9 & 39 & 19.5 & 48 & 24.0 & 23 & 11.5 & 49 & 24.5 & 41 & 20.5 \\
\hline 10 & 68 & 34.0 & 52 & 26.0 & 10 & 5.0 & 42 & 21.0 & 28 & 14.0 \\
\hline 11 & 57 & 28.5 & 56 & 28.0 & 23 & 11.5 & 43 & 21.5 & 21 & 10.5 \\
\hline 12 & 41 & 21.5 & 55 & 27.5 & 22 & 11.0 & 51 & 25.5 & 31 & 15.5 \\
\hline Sum \& \% & 300 & 25.0 & 321 & 26.8 & 120 & 10.0 & 273 & 22.7 & 186 & 15.5 \\
\hline$\underline{111}$ & \multicolumn{10}{|c|}{ PSYCHOMOTOR GOALS } \\
\hline$\overline{13}$ & 56 & 28.0 & 55 & $\overline{27.5}$ & 21 & 10.5 & 40 & 20.0 & 28. & 14.0 \\
\hline 14 & 76 & 38.0 & 71 & 35.5 & 18 & 9.0 & 21 & 10.5 & 14 & 7.0 \\
\hline 15 & 44 & 22.0 & 55 & 27.5 & 11 & 5.5 & 44 & 22.0 & 46 & 23.0 \\
\hline 16 & 38 & 19.0 & 44 & 22.0 & 17 & 8.5 & 54 & 27.0 & 47 & 23.5 \\
\hline 17 & 35 & 17.5 & 62 & 31.0 & 21 & 10.5 & 51 & 25.5 & 31 & 15.5 \\
\hline 18 & 41 & 22.5 & 49 & 42.5 & 19 & 9.5 & 54 & 27.0 & 37 & 18.5 \\
\hline Sum \& \% & 290 & 24.2 & 336 & 28.0 & \begin{tabular}{|l|}
107 \\
\end{tabular} & 8.9 & 264 & 22.0 & 203 & 16.9 \\
\hline IV & \multicolumn{10}{|c|}{ HEALTH-RELATED FITNESS } \\
\hline$\overline{19}$ & 45 & 22.5 & 51 & 25.5 & 19 & 9.5 & 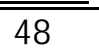 & 24.0 & 37 & 18.5 \\
\hline 20 & 50 & 25.0 & 73 & 36.5 & 13 & 6.5 & 26 & 13.0 & 38 & 19.0 \\
\hline 21 & 22 & 11.0 & 24 & 12.0 & 16 & 8.0 & 79 & 39.5 & 59 & 29.5 \\
\hline 22 & 15 & 7.5 & 28 & 14.0 & 17 & 8.5 & 39 & 19.5 & 101 & 50.5 \\
\hline 23 & 35 & 17.5 & 48 & 24.0 & 16 & 8.0 & 59 & 29.5 & 42 & 21.0 \\
\hline 24 & 26 & 13.0 & 45 & 22.5 & 15 & 7.5 & 73 & 36.5 & 41 & 20.5 \\
\hline Sum \& \% & 193 & 16.1 & 269 & 22.4 & 96 & 8.0 & 324 & 27.0 & 318 & 26.5 \\
\hline Total \& \% & 994 & 20.7 & 1212 & 25.3 & 480 & 10.0 & 1137 & 23.7 & 977 & 20.4 \\
\hline
\end{tabular}

$1=$ strongly agree $2=$ Agree $3=$ Uncertain $4=$ Disagree $5=$ strongly disagree 
Results of Table 5 indicated that total frequencies of the responses for each of the 5-points scale toward the KPEG 24 statements in ascending order were as follows:

(1) Agree $25.3 \%$, (2) Disagree $23.7 \%$, (3) Strongly Agree $20.7 \%$, (4) Strongly Disagree $20.4 \%$, and (5) Uncertain $10.0 \%$.

Regarding the four domain goals, results of Table 5 indicated the responses for each of the 5-points scale regarding the total responses of the KPEG (24 statements) in ascending order. These were as follows:

1. Strongly agree: (1) affective $25.0 \%$, (2) psychomotor $24.2 \%$, (3) health-related fitness $20.7 \%$, and (4) cognitive $17.6 \%$.

2. Agree: (1) psychomotor $28.0 \%$, (2) affective $26.8 \%$, (3) healthrelated fitness $25.3 \%$, and (4) cognitive $23.8 \%$.

3. Uncertain: (1) cognitive $13.1 \%$, (2) affective and health-related fitness $10.0 \%$, (3) psychomotor $8.9 \%$.

4. Disagree: (1) health-related fitness $23.7 \%$, (2) cognitive $23.0 \%$, (3) affective $22.7 \%$, and (4) psychomotor $22.0 \%$.

5. Strongly disagree: (1) cognitive $22.5 \%$, (2) health-related fitness $20.4 \%$, (3) psychomotor $16.9 \%$, and (4) affective $15.5 \%$.

As noted above, more details regarding the distribution of the sum of the responses toward KPEG along each of the 5-points of the utilized scale are found in table 5. The result asserted and explained the data obtained in Table 4. The sum of the distribution of the positive responses (strongly agree + agree) was slightly larger than the same value recorded for the negative responses (strongly disagree + disagree), $46.0 \%$ and $44.0 \%$, respectively. 
Results of each of the four domains (Table 5) relevant to the sum of the responses of the six items, comprising each of the four domain goals, along the 5-points scale in ascending order were as follows:

1. Cognitive goals: (1) $23.8 \%$ agree, (2) $23.0 \%$ disagree, (3) $22.5 \%$ strongly disagree, (4) $17.6 \%$ strongly agree, and $13.1 \%$ uncertain.

2. Affective goals: (1) $26.8 \%$ agree, (2) $25.0 \%$ strongly agree, (3) $22.7 \%$ disagree, (4) $15.5 \%$ strongly disagree, and (5) $10.0 \%$ uncertain.

3. Psychomotor goals: (1) $28.0 \%$ agree, (2) $24.2 \%$ strongly agree, (3) $22.0 \%$ disagree, (4) $16.9 \%$ strongly disagree, and (5) $8.9 \%$ uncertain.

4. Health-related fitness goals: (1) $25.3 \%$ agree, (2) $23.7 \%$ disagree, (3) $20.7 \%$ strongly agree, (4) $20.4 \%$ strongly disagree, and (5) $10.0 \%$ uncertain.

The preceding results provided a general indication concerning the distribution of the responses toward the total statements of the KPEG. These results also indicated that the total of the "uncertain" response conform only $10 \%$ of total responses. Since the percentage of the uncertain responses was small, its influence on the results of the present study would lead to a slight effect. Thus, in order to confirm the answer regarding the perception of the sample toward each statement, the researcher combined "strongly agree" 
responses with the "agree" to form a new variable; "agreement", and combined the "strongly disagree" responses with the "disagree" to form an opposite variable; "disagreement".

To obtain a measure of statistical significance between the agreement and disagreement variables for each of the six statements comprising each of the four domain goals, a Chi square test was used, and the 0.05 levels served as the minimum level of significant acceptance.

Table 6

Cognitive Domain: Significant and Non-significant Goals

\begin{tabular}{|c|c|c|c|c|c|c|c|}
\hline \# & Source & $\begin{array}{c}\text { Observed } \\
\mathbf{N}\end{array}$ & $\begin{array}{c}\text { Expected } \\
\mathbf{N}\end{array}$ & Residual & $\begin{array}{c}\text { Chi- } \\
\text { Square }\end{array}$ & Df & Sig. \\
\hline \multirow{2}{*}{1} & Agreement & 66 & \multirow{2}{*}{86.5} & -20.5 & \multirow{2}{*}{$9.717^{*}$} & \multirow{2}{*}{1} & \multirow{2}{*}{.002} \\
\hline & Disagreement & 107 & & 20.5 & & & \\
\hline \multirow{2}{*}{2} & Agreement & 68 & \multirow{2}{*}{85.5} & -17.5 & \multirow{2}{*}{ 7.164* } & \multirow{2}{*}{1} & \multirow{2}{*}{.007} \\
\hline & Disagreement & 103 & & 17.5 & & & \\
\hline \multirow{2}{*}{3} & Agreement & 94 & \multirow{2}{*}{91.5} & 2.5 & \multirow{2}{*}{0.137} & \multirow{2}{*}{1} & \multirow{2}{*}{.712} \\
\hline & Disagreement & 89 & & -2.5 & & & \\
\hline \multirow{2}{*}{4} & Agreement & 68 & \multirow{2}{*}{89.0} & -21.0 & \multirow{2}{*}{$9.910^{*}$} & \multirow{2}{*}{1} & \multirow{2}{*}{.002} \\
\hline & Disagreement & 110 & & 21.0 & & & \\
\hline \multirow{2}{*}{5} & Agreement & 116 & \multirow{2}{*}{88.5} & 27.5 & \multirow{2}{*}{$17.090 *$} & \multirow{2}{*}{1} & \multirow{2}{*}{.001} \\
\hline & Disagreement & 61 & & -27.5 & & & \\
\hline \multirow{2}{*}{6} & Agreement & 92 & \multirow{2}{*}{85.0} & 7.0 & \multirow{2}{*}{1.153} & \multirow{2}{*}{1} & \multirow[t]{2}{*}{.238} \\
\hline & Disagreement & 78 & & -7.0 & & & \\
\hline
\end{tabular}

Tables 6-9 show the levels of significant agreements, disagreement, and non-significant responses of the sample for each domain's goals in the following order: Cognitive Domain, Affective Domain, Psychomotor Domain, and HealthRelated Fitness Domain. 


\section{$\underline{\text { Cognitive domain }}$}

Results of Table 6 indicated that four of the cognitive domain's goals reached the level of significance; one goal was at the agreement side, while three goals were at the disagreement side.

\section{Cognitive Goals: Significant Agreement Item}

The Physical education program helps students to understand that physical activity provides the opportunity for enjoyment, selfexpression, and communication (\# 5, p $<0.001$ ).

\section{Cognitive Goals: Significant Disagreement Items}

1. Physical education program helps students to know the benefits, costs and obligations associated with regular participation in physical activity $(\# 1, p<0.002)$.

2. Physical education program helps students to recognize the risk arid safety factors associated with regular participation in physical activity (\# $2, p<0.007)$.

3. Physical education program helps students to know the rules, strategies and appropriate behaviors for selected physical activities (\# 4, p < $0.002)$. 


\section{Cognitive Goals: Non-significant I tems}

Physical education program helps students to apply concepts and principles to the development of motor skills (\# 3).

Physical education program helps students to realize activities that can continue outside of school (\# 6).

\section{Affective domain}

Table 7

\begin{tabular}{|c|c|c|c|c|c|c|c|}
\hline \# & Source & Observed $\mathrm{N}$ & Expected $\mathrm{N}$ & Residual & Chi- Square & $\mathrm{df}$ & Sig. \\
\hline \multirow{2}{*}{7} & Agreement & 112 & \multirow{2}{*}{87.0} & 25.0 & \multirow{2}{*}{$14.368 *$} & \multirow{2}{*}{1} & \multirow{2}{*}{.001} \\
\hline & Disagreement & 62 & & -25.0 & & & \\
\hline \multirow{2}{*}{8} & Agreement & 93 & \multirow{2}{*}{92.0} & 1.0 & \multirow{2}{*}{0.022} & \multirow{2}{*}{1} & \multirow{2}{*}{.883} \\
\hline & Disagreement & 91 & & -1.0 & & & \\
\hline \multirow[b]{2}{*}{9} & Agreement & 87 & \multirow{2}{*}{88.5} & -1.5 & \multirow{2}{*}{0.051} & \multirow{2}{*}{1} & \multirow[b]{2}{*}{882} \\
\hline & Disagreement & 90 & & 1.5 & & & \\
\hline \multirow{2}{*}{10} & Agreement & 119 & \multirow{2}{*}{95.0} & 24.0 & \multirow{2}{*}{$12.126 *$} & \multirow{2}{*}{1} & \multirow{2}{*}{.001} \\
\hline & Disagreement & 71 & & -24.0 & & & \\
\hline \multirow{2}{*}{11} & Agreement & 121 & \multirow{2}{*}{89.0} & 32.0 & \multirow{2}{*}{$23.011^{*}$} & \multirow{2}{*}{1} & \multirow{2}{*}{.001} \\
\hline & Disagreement & 57 & & -32.0 & & & \\
\hline \multirow{2}{*}{12} & Agreement & 95 & \multirow{2}{*}{89.0} & 6.0 & \multirow{2}{*}{0.809} & \multirow{2}{*}{1} & \multirow{2}{*}{.368} \\
\hline & Disagreement & 83 & & -6.0 & & & \\
\hline
\end{tabular}

Affective Domain: Significant and Non-significant Goals

Results of Table 7 indicated that three of the affective domain's goals reached the significant level of agreement, while the other three goals were nonsignificant. 


\section{Affective domain: Significant Agreement goals}

1. Physical education program helps students to Improving self-confidence $(\# 7, p<0.001)$.

2. Physical education program helps students to appreciate the relationships with others that result from participation in physical activity $(\# 10, p<0.001)$.

3. Physical education program helps students to cooperate with others to achieve common goals (\# 11, $p<0.001$ ).

\section{Affective Domain: Significant Disagreement Goals}

None.

Table 8

Psychomotor Domain: Significant and Non-significant Goals

\begin{tabular}{|c|c|c|c|c|c|c|c|}
\hline \# & Source & Observed N & Expected $\mathrm{N}$ & Residual & Chi- Square & $\overline{D f}$ & Sig. \\
\hline \multirow{2}{*}{13} & Agreement & 111 & \multirow{2}{*}{89.5} & 21.5 & \multirow{2}{*}{$10.330 *$} & \multirow{2}{*}{1} & \multirow{2}{*}{.001} \\
\hline & Disagreement & 68 & & -21.5 & & & \\
\hline \multirow{2}{*}{14} & Agreement & 147 & \multirow{2}{*}{91.0} & 56.0 & \multirow{2}{*}{$68.923 *$} & \multirow{2}{*}{1} & \multirow{2}{*}{.001} \\
\hline & Disagreement & 35 & & -56.0 & & & \\
\hline \multirow{2}{*}{15} & Agreement & 99 & \multirow{2}{*}{94.5} & 4.5 & \multirow{2}{*}{0.429} & \multirow{2}{*}{1} & \\
\hline & Disagreement & 90 & & -4.5 & & & \\
\hline \multirow{2}{*}{16} & Agreement & 82 & \multirow{2}{*}{91.5} & -9.5 & \multirow{2}{*}{1.973} & \multirow{2}{*}{1} & \\
\hline & Disagreement & 101 & & 9.5 & & & \\
\hline \multirow{2}{*}{17} & Agreement & 138 & \multirow{2}{*}{92.5} & 45.5 & \multirow{2}{*}{$44.762 *$} & \multirow{2}{*}{1} & \multirow{2}{*}{.001} \\
\hline & Disagreement & 47 & & -45.5 & & & \\
\hline \multirow{2}{*}{18} & Agreement & 90 & \multirow{2}{*}{90.5} & -.5 & \multirow{2}{*}{0.006} & \multirow{2}{*}{1} & \\
\hline & Disagreement & 91 & & .5 & & & \\
\hline
\end{tabular}




\section{$\underline{\text { Non-Significant Goals }}$}

1. Physical education program helps students to realize tension and frustration (\# 8).

2. Physical education program helps students to develop emotional stability (\# 9).

3. Physical education program helps students to appreciate the role of exercise in healthful living (\# 12).

\section{Psychomotor Domain}

Results of Table 8 indicated that three of the psychomotor domain goals reached the significant level of agreement, while three goals were nonsignificant.

\section{Psychomotor Domain: Significant agreement Goals}

1. Physical education program helps students to move using concepts of body awareness, space awareness, effort, and relationship (\# 13, p $<0.001)$.

2. Physical education program helps students to demonstrate competence in a variety of manipulative, locomotors and non locomotors skills performed individually and with others (\# 14, p < $0.001)$.

3. Physical education program helps students to learn how to learn new skills (\# 17, p < 0.001). 
Psychomotor Domain: Significant Disagreement Goals: None.

\section{Psychomotor Domain: Non-Significant Goals}

1. Physical education program helps students to demonstrate competence in many different forms of physical activity (\# 15).

2. Physical education program helps students to demonstrate proficiency in few forms of physical activity (\#16).

3. Physical education program helps students to move using concepts of body awareness, space awareness, effort, and relationship (\# 18).

Health-Related Fitness Domain

Table 9

Health-Related Fitness Domain: Significant and Non-significant Goals

\begin{tabular}{|c|c|c|c|c|c|c|c|}
\hline \# & Source & Observed $\mathrm{N}$ & Expected $\mathrm{N}$ & Residual & Chi- Square & $\overline{D f}$ & Sig. \\
\hline \multirow{2}{*}{19} & Agreement & 96 & \multirow{2}{*}{90.5} & 5.5 & \multirow[b]{2}{*}{0.669} & \multirow[b]{2}{*}{1} & \\
\hline & Disagreement & 85 & & -5.5 & & & \\
\hline \multirow{2}{*}{20} & Agreement & 93 & \multirow{2}{*}{93.0} & 0.0 & \multirow[b]{2}{*}{0.000} & \multirow[b]{2}{*}{1} & \\
\hline & Disagreement & 93 & & 0.0 & & & \\
\hline \multirow{2}{*}{21} & Agreement & 46 & \multirow{2}{*}{92.0} & -46.0 & \multirow{2}{*}{$46.000 *$} & \multirow[b]{2}{*}{1} & \multirow{2}{*}{.001} \\
\hline & Disagreement & 138 & & 46.0 & & & \\
\hline \multirow{2}{*}{22} & Agreement & 43 & \multirow{2}{*}{91.5} & -48.5 & \multirow[b]{2}{*}{$51.415^{*}$} & \multirow[b]{2}{*}{1} & \multirow[b]{2}{*}{.001} \\
\hline & Disagreement & 140 & & 48.5 & & & \\
\hline \multirow[b]{2}{*}{23} & Agreement & 79 & \multirow[b]{2}{*}{92.5} & -13.5 & \multirow[b]{2}{*}{$3.941 *$} & \multirow[b]{2}{*}{1} & \multirow[b]{2}{*}{.047} \\
\hline & Disagreement & 106 & & 13.5 & & & \\
\hline \multirow{2}{*}{24} & Agreement & 71 & \multirow{2}{*}{92.5} & -21.5 & \multirow{2}{*}{ 9.995* } & \multirow[b]{2}{*}{1} & \multirow[b]{2}{*}{.002} \\
\hline & Disagreement & 114 & & 21.5 & & & \\
\hline
\end{tabular}


Results of Table 9 indicated that four out of the six health-related fitness domain goals reached the significant level, but all were at the side of disagreement.

Health-Related Fitness Domain: Significant Agreement Goals: None.

$\underline{\text { Health-Related Fitness Domain: Significant Disagreement Goals }}$

1. Physical education program helps students to design safe, personal fitness programs in accordance with principles of training and conditioning (\# 21, p < 0.001).

2. Physical education program helps students to participate in health enhancing physical activity at least three times a week (\# 22, $p<0.001)$.

3. Physical education program helps students to select and regularly participate in physical activities now and throughout their adult years $(\# 23, p<0.047)$.

4. Physical education program helps students to keep in good health and physical condition (\# 24, $\mathrm{p}<0.002$ ).

Health-Related Fitness Domain: Non-Significant Goals

1. Physical education program helps students to keep weight controlled (\# 19).

2. Physical education program helps students to assess, achieve, and maintaining physical fitness (\# 20). 


\section{Results of Section Three}

Section three deals with differences that existed, if any, between males' and females' perception toward the KPEG. To assess these differences between the two groups regarding each of the four the KPEG domains (cognitive, affective, psychomotor, and health-related fitness), frequencies and percentage of responses, as well as t-Test for independent groups were computed.

\section{Table 10}

\section{Comparisons between Males' and Females' Perception toward Cognitive Goals}

\begin{tabular}{|c|c|c|c|c|c|c|c|}
\hline \multirow{2}{*}{ \# } & \multirow{2}{*}{ Cognitive Goals } & \multirow{2}{*}{ Gender } & \multicolumn{5}{|c|}{ Frequency \& \% } \\
\hline & & & 1 & 2 & 3 & 4 & 5 \\
\hline \multirow{2}{*}{1} & \multirow{2}{*}{$\begin{array}{l}\text { Knowing the benefits, costs and obligations } \\
\text { associated with regular participation in } \\
\text { physical activity. }\end{array}$} & $M$ & 11 & 11 & 18 & 36 & 24 \\
\hline & & $\mathrm{F}$ & 10 & 19 & 17 & 26 & 28 \\
\hline \multirow{2}{*}{2} & \multirow{2}{*}{$\begin{array}{l}\text { Recognizing the risk and safety factors } \\
\text { associated with regular participation in } \\
\text { physical activity. }\end{array}$} & $M$ & 12 & 21 & 14 & 28 & 25 \\
\hline & & $\mathrm{F}$ & 20 & 15 & 15 & 23 & 27 \\
\hline \multirow{2}{*}{3} & \multirow{2}{*}{$\begin{array}{l}\text { Applying concepts and principles to the } \\
\text { development of motor skills. }\end{array}$} & $M$ & 22 & 25 & 10 & 26 & 17 \\
\hline & & $\mathrm{F}$ & 27 & 32 & 8 & 22 & 11 \\
\hline \multirow{2}{*}{4} & \multirow{2}{*}{$\begin{array}{l}\text { Knowing the rules, strategies and appropriate } \\
\text { behaviors for selected physical activities. }\end{array}$} & $M$ & 13 & 8 & 14 & 33 & 32 \\
\hline & & $\mathrm{F}$ & 16 & 27 & 8 & 20 & 29 \\
\hline \multirow{2}{*}{5} & \multirow{2}{*}{$\begin{array}{l}\text { Understanding that physical activity provides } \\
\text { the opportunity for enjoyment, self- } \\
\text { expression, and communication. }\end{array}$} & $M$ & 14 & 39 & 17 & 14 & 16 \\
\hline & & $\mathrm{F}$ & 30 & 33 & 6 & 9 & 22 \\
\hline \multirow{2}{*}{6} & \multirow{2}{*}{$\begin{array}{l}\text { Realizing activities that can continue outside } \\
\text { of school. }\end{array}$} & M & 22 & 18 & 14 & 23 & 23 \\
\hline & & $\mathrm{F}$ & 14 & 38 & 16 & 16 & 16 \\
\hline \multirow{2}{*}{\multicolumn{2}{|c|}{ SUM }} & $M$ & 94 & 122 & 87 & 160 & 137 \\
\hline & & $\mathrm{F}$ & 117 & 164 & 70 & 116 & 133 \\
\hline \multirow{2}{*}{\multicolumn{2}{|c|}{ Percentage }} & $M \%$ & 15.7 & 20.3 & 14.5 & 26.7 & 22.8 \\
\hline & & F \% & 19.5 & 27.3 & 11.7 & 19.3 & 22.2 \\
\hline
\end{tabular}

$1=$ strongly agree $2=$ Agree $3=$ Uncertain $4=$ Disagree $5=$ strongly disagree 
Perception of Males and Females to Cognitive Domain Goals

Table 10 shows six statements comprising the goals of the cognitive domain in this study. The same table also presents frequencies of the five points of the scale, relevant to the males and females responses to each item, as well as total and percentage of responses comprising this domain.

\section{Table 11}

Cognitive Domain: Comparison between Males' and Females' Perception

\begin{tabular}{|c|c|c|c|c|c|c|}
\hline$\#$ & Gender & Mean & SD & Df & T & Sig \\
\hline \multirow{2}{*}{1} & Male & 3.510 & 1.275 & \multirow{2}{*}{198} & .432 & 0.666 \\
\cline { 2 - 4 } & Female & 3.430 & 1.343 & & & \\
\hline \multirow{2}{*}{2} & Male & 3.330 & 1.371 & \multirow{2}{*}{198} & .542 & 0.588 \\
\cline { 2 - 5 } & Female & 3.220 & 1.495 & & & \\
\hline \multirow{2}{*}{3} & Male & 2.910 & 1.443 & \multirow{2}{*}{198} & \multirow{2}{*}{1.653} & 0.100 \\
\cline { 2 - 4 } & Female & 2.580 & 1.379 & & & \\
\hline \multirow{2}{*}{4} & Male & 3.630 & 1.353 & \multirow{2}{*}{198} & $2.176 *$ & 0.031 \\
\cline { 2 - 4 } & Female & 3.190 & 1.502 & & & \\
\hline \multirow{2}{*}{5} & Male & 2.790 & 1.305 & \multirow{2}{*}{198} & .942 & 0.347 \\
\cline { 2 - 4 } & Female & 2.600 & 1.537 & & & \\
\hline \multirow{2}{*}{6} & Male & 3.070 & 1.492 & \multirow{2}{*}{198} & 1.258 & 0.210 \\
\cline { 2 - 4 } & Female & 2.820 & 1.313 & & & \\
\hline
\end{tabular}

Results of Table 10 indicated that females showed more positive agreement (strongly agree/ agree) relevant to the total of the six items comprising the cognitive domain. Percentage of the scale "strongly agree" (19.5) and "agree" (27.3) for females were higher than those of males (15.7 and 
20.3), respectively. In addition, percentages of the "uncertain" responses were slightly higher for males (14.5) than that for females (11.7).

Table 11 presents the means and standard deviations for male and female groups relevant to each of the six items of the cognitive domain. The computed "t" values and its significant level as a result of the comparisons between both sexes are also presented.

Results of Table 11 indicated that numbers of mean values under the average point of the utilized scale (3) were slightly toward the side of disagreement. Number of items scored under this level was three for females (\# 3, \# 5, and \# 6), and two for males (\# 3, and \# 5).

Comparisons between males and females relevant to the six items of the cognitive domain revealed no significant differences between males and females perception toward the items of this domain except for item number four $(p=$ 0.03). This item indicated that:

The Physical education program helps students to know the rules, strategies and appropriate behaviors for selected physical activities $(\# 4, p<0.031)$.

Males' response mean (3.630) for this item was found to be higher than that recorded by females (3.190). This result asserts the fact that the male group significantly perceived this goal in a more negative manner (Strongly Disagree and Disagree) compared to the female group. 


\section{Perception of Males and Females to Affective Domain Goals}

Table 12 shows six statements comprising the goals of the affective domain in this study. The same table also presents frequencies of the five points of the scale, relevant to the males and females responses to each item, as well as total and percentage of responses comprising this domain.

\section{Table 12}

Perceptions of Male and Female Toward Affective Goals

\begin{tabular}{|c|c|c|c|c|c|c|c|}
\hline \multirow{2}{*}{$\#$} & \multirow{2}{*}{$\begin{array}{c}\text { Goals } \\
\text { AFECTIVE }\end{array}$} & \multirow{2}{*}{ Gender } & \multicolumn{5}{|c|}{ Frequency \& \% } \\
\hline & & & 1 & 2 & 3 & 4 & 5 \\
\hline \multirow{2}{*}{7} & \multirow{2}{*}{ Improving self-confidence. } & M & 23 & 33 & 12 & 18 & 14 \\
\hline & & $\mathrm{F}$ & 27 & 29 & 14 & 17 & 13 \\
\hline \multirow{2}{*}{8} & \multirow{2}{*}{ Releasing tension and frustration. } & M & 17 & 27 & 8 & 26 & 22 \\
\hline & & $\mathrm{F}$ & 28 & 21 & 8 & 27 & 16 \\
\hline \multirow{2}{*}{9} & \multirow{2}{*}{ Developing emotional stability. } & $M$ & 16 & 22 & 11 & 30 & 21 \\
\hline & & $\mathrm{F}$ & 23 & 26 & 12 & 19 & 20 \\
\hline \multirow{2}{*}{10} & \multirow{2}{*}{$\begin{array}{l}\text { Appreciating the relationships } \\
\text { with others that result from } \\
\text { participation in physical activity. }\end{array}$} & $\bar{M}$ & 26 & 27 & 5 & 27 & 15 \\
\hline & & $\mathrm{F}$ & 42 & 25 & 5 & 15 & 13 \\
\hline \multirow{2}{*}{11} & \multirow{2}{*}{$\begin{array}{l}\text { Cooperating with others to } \\
\text { achieve common goals. }\end{array}$} & $M$ & 35 & 29 & 11 & 18 & 7 \\
\hline & & $\mathrm{F}$ & 22 & 27 & 12 & 25 & 14 \\
\hline \multirow{2}{*}{12} & \multirow{2}{*}{$\begin{array}{l}\text { Appreciating the role of exercise } \\
\text { in healthful living. }\end{array}$} & $M$ & 22 & 31 & 11 & 28 & 8 \\
\hline & & $\mathrm{F}$ & 19 & 24 & 11 & 23 & 23 \\
\hline & \multirow{2}{*}{ SUM } & $M$ & 139 & 169 & 58 & 147 & 87 \\
\hline & & $\mathrm{F}$ & 161 & 152 & 62 & 126 & 99 \\
\hline & \multirow{2}{*}{ Percentage } & M \% & 23.2 & 28.2 & 9.7 & 24.5 & 14.5 \\
\hline & & F \% & 26.8 & 25.3 & 10.3 & 21.0 & 16.5 \\
\hline
\end{tabular}


Concerning the total results of the affective domain, Table 12 indicated that females scored higher (26.8) in the scale point "Strongly Agree" than that by males (23.2), however, males scored higher (28.2) in the scale point "Agree" than that recording by females (25.3). In addition, percentages of the "uncertain" responses were slightly higher for females (10.3) than that for males (9.7). It may be concluded that males and females perceived the affective domain positively, and their agreement score (Strongly Agree + Agree) was relatively equal (males $=51.4 \&$ females $=52.1$ ).

Table 13 presents the means and standard deviations for male and female groups relevant to each of the six items of the affective domain. The same table also includes the computed " $\mathrm{t}$ " value and its significant level as a result of the comparisons between both sexes.

\section{Table 13}

Comparison between Males and Females Perception toward Affective Domain

\begin{tabular}{|c|c|c|c|c|c|c|}
\hline$\#$ & Gender & Mean & SD & df & T & Sig \\
\hline \multirow{2}{*}{7} & Male & 2.670 & 1.378 & \multirow{2}{*}{198} & 0.358 & .721 \\
\cline { 2 - 4 } & Female & 2.600 & 1.385 & & & \\
\hline \multirow{2}{*}{8} & Male & 3.090 & 1.450 & 198 & 1.297 & .196 \\
\cline { 2 - 4 } & Female & 2.820 & 1.493 & & & \\
\hline \multirow{2}{*}{9} & Male & 3.180 & 1.410 & \multirow{2}{*}{198} & 1.519 & .130 \\
\cline { 2 - 4 } & Female & 2.870 & 1.474 & & & \\
\hline \multirow{2}{*}{10} & Male & 2.780 & 1.467 & \multirow{2}{*}{198} & $2.215^{*}$ & .028 \\
\cline { 2 - 4 } & Female & 2.320 & 1.469 & & & \\
\hline \multirow{2}{*}{11} & Male & 2.330 & 1.311 & \multirow{2}{*}{198} & $-2.559^{*}$ & .011 \\
\cline { 2 - 4 } & Female & 2.820 & 1.395 & & & \\
\hline \multirow{2}{*}{12} & Male & 2.690 & 1.308 & \multirow{2}{*}{198} & $-1.930^{*}$ & .055 \\
\cline { 2 - 4 } & Female & 3.070 & 1.472 & & & \\
\hline
\end{tabular}


Table 13 indicated that 9 out of twelve means were under the point average of the utilized scale (3).

Comparisons between males and females relevant to the six items of the affective domain (Table 13 ) revealed that three (items 10, 11, and 12) items were found to be significant.

In item 10, the females' response mean (2.320) was found to be less than that recorded by males (2.780). This result asserts the fact that the female group significantly perceived this goal in a less positive manner compared to the male group. This item indicated:

The Physical education program helps students to appreciate the relationships with others that result from participation in physical activity (\# 12, p < 0.055).

The male group significantly agreed regarding items $11(p=0.01)$, and 12 $(p=0.05)$ in comparison to the females group. Mean values recorded by the male group were 2.330 (\# 11) and 2.690 (\# 12). The same values recorded by the females group were 2.820 and 3.070 , successively. This result asserts the fact that the males group significantly perceived this goal in a more positive manner comparing by the female group. These items indicate that:

1. The Physical education program helps students to cooperate with others to achieve common goals (\# 11). 
2. The Physical education program helps students to appreciate the role of exercise in healthful living (\# 12).

\section{Perception of Males and Females to Psychomotor Domain Goals}

Table 14 shows six statements comprising the goals of the psychomotor domain in this study. The same table also presents frequencies of the five points of the scale relevant to the males and females responses to each item, as well as total and percentage of responses comprising this domain.

Table 14: Perceptions of Male and Female Groups Toward Psychomotor Goals

\begin{tabular}{|c|c|c|c|c|c|c|c|}
\hline \multirow{2}{*}{ \# } & \multirow{2}{*}{ Goals } & \multirow{2}{*}{ Gender } & \multicolumn{5}{|c|}{ Frequency \& \% } \\
\hline & & & 1 & 2 & 3 & 4 & 5 \\
\hline \multirow{2}{*}{13} & \multirow{2}{*}{$\begin{array}{l}\text { Moving using concepts of body } \\
\text { awareness, space awareness, effort, and } \\
\text { relationship. }\end{array}$} & M & 26 & 24 & 9 & 21 & 20 \\
\hline & & $\mathrm{F}$ & 30 & 31 & 12 & 19 & 8 \\
\hline \multirow{2}{*}{14} & \multirow{2}{*}{$\begin{array}{l}\text { Demonstrating competence in a variety of } \\
\text { manipulative, locomotors and non- } \\
\text { locomotors skills performed individually } \\
\text { and with others. }\end{array}$} & M & 38 & 45 & 8 & 5 & 4 \\
\hline & & $\mathrm{F}$ & 38 & 26 & 10 & 16 & 10 \\
\hline \multirow{2}{*}{15} & \multirow{2}{*}{$\begin{array}{l}\text { Demonstrating competence in many } \\
\text { different forms of physical activity. }\end{array}$} & $\bar{M}$ & 26 & 31 & 5 & 18 & 20 \\
\hline & & $\mathrm{F}$ & 18 & 24 & 6 & 26 & 26 \\
\hline \multirow{2}{*}{16} & \multirow{2}{*}{$\begin{array}{l}\text { Demonstrating proficiency in few forms of } \\
\text { physical activity. }\end{array}$} & M & 17 & 20 & 7 & 31 & 25 \\
\hline & & $\mathrm{F}$ & 21 & 24 & 10 & 23 & 22 \\
\hline \multirow{2}{*}{17} & \multirow[t]{2}{*}{ Learning how to learn new skills. } & M & 18 & 31 & 11 & 23 & 17 \\
\hline & & $\bar{F}$ & 17 & 31 & 10 & 28 & 14 \\
\hline \multirow{2}{*}{18} & \multirow{2}{*}{$\begin{array}{l}\text { Physical education program helps } \\
\text { students develop skills in various sports. }\end{array}$} & M & 20 & 26 & 12 & 26 & 16 \\
\hline & & $F$ & 21 & 23 & 7 & 28 & 21 \\
\hline & \multirow{2}{*}{ SUM } & M & 145 & 177 & 52 & 124 & 102 \\
\hline & & $\mathrm{F}$ & 145 & 159 & 55 & 140 & 101 \\
\hline & \multirow{2}{*}{ PERCENTAGE } & M \% & 24.2 & 29.5 & 8.7 & 20.7 & 17.0 \\
\hline & & $F \%$ & 24.2 & 26.5 & 9.2 & 23.3 & 16.8 \\
\hline
\end{tabular}


In general, results of Table 14 indicated that males and females showed more positive agreement (strongly agree/ agree) in their total of the six responses of the psychomotor domain. Percentage of the scale's point "strongly agree" was equal for males and females (24.2). However, percentage of the scale's point "Agree" for the male group was higher (29.5) than that for females (26.5). In addition, percentages of the "uncertain" responses were slightly higher for females (9.2) than that for males (8.7).

Table 15 presents the means and standard deviations for male and female groups relevant to each of the six items of the psychomotor domain. The same table also includes the computed " $t$ " value and its significant level as a result of the comparisons between both sexes.

\section{Table 15}

Comparison between Males' and Females' Perception on Psychomotor Domain

\begin{tabular}{|c|c|c|c|c|c|c|}
\hline$\#$ & Gender & Mean & SD & Df & T & Sig. \\
\hline \multirow{2}{*}{13} & Male & 2.850 & 1.513 & \multirow{2}{*}{198} & $2.046^{*}$ & .042 \\
\cline { 2 - 4 } & Female & 2.440 & 1.313 & & & \\
\hline \multirow{2}{*}{14} & Male & 1.920 & 1.012 & \multirow{2}{*}{198} & $-2.446^{*}$ & .015 \\
\cline { 2 - 4 } & Female & 2.340 & 1.387 & & & \\
\hline \multirow{2}{*}{15} & Male & 2.750 & 1.513 & \multirow{2}{*}{198} & $-2.018^{*}$ & .045 \\
\cline { 2 - 4 } 16 & Female & 3.180 & 1.500 & & & \\
\cline { 2 - 4 } 16 & Male & 3.270 & 1.462 & \multirow{2}{*}{198} & 1.247 & .214 \\
\cline { 2 - 4 } 17 & Female & 3.010 & 1.487 & & & \\
\cline { 2 - 4 } & Memale & 2.900 & 1.396 & 198 & -0.051 & .959 \\
\hline \multirow{2}{*}{18} & Male & 2.910 & 1.357 & & & \\
\cline { 2 - 4 } & Female & 3.050 & 1.486 & & & \\
\hline
\end{tabular}


Results of table 15 indicated that number of mean values under the point average of the utilized scale (3) were slightly toward the side of agreement. Number of items scored under this level was five for males (\# 13, \# 14, \# 15, \# 17, and \# 18) and three for females (\# 13, \# 14 and \# 17).

Comparisons between males and females regarding the psychomotor domain (Table 13) revealed that three items (\# 13, \# 14, and \#15) out of six were found to be significant. These items were significant at the levels 0.042 , 0.015 , and 0.045 , respectively.

Table 16 Perceptions of Male and Female toward Health-Related Fitness Goals

\begin{tabular}{|c|c|c|c|c|c|c|c|}
\hline \multirow{2}{*}{$\#$} & Goals & \multicolumn{2}{|c|}{ Gender } & \multicolumn{4}{|c|}{ Frequency \& \% } \\
\hline & HEALTH RELATED FITNESS & & 1 & 2 & 3 & 4 & 5 \\
\hline \multirow{2}{*}{19} & \multirow{2}{*}{ Keeping weight controlled } & $M$ & 19 & 21 & 8 & 30 & 22 \\
\hline & & $F$ & 26 & 30 & 11 & 18 & 15 \\
\hline \multirow{2}{*}{20} & \multirow{2}{*}{$\begin{array}{l}\text { Assessing, achieving, and maintaining } \\
\text { physical fitness. }\end{array}$} & $M$ & 26 & 35 & 8 & 12 & 19 \\
\hline & & $\mathrm{F}$ & 24 & 38 & 5 & 14 & 19 \\
\hline \multirow[b]{2}{*}{21} & \multirow{2}{*}{$\begin{array}{l}\text { Designing safe, personal fitness in } \\
\text { accordance with principles of training and } \\
\text { conditioning. }\end{array}$} & $M$ & 11 & 11 & 6 & 38 & 34 \\
\hline & & $\mathrm{F}$ & 11 & 13 & 10 & 40 & 25 \\
\hline \multirow{2}{*}{22} & \multirow{2}{*}{$\begin{array}{l}\text { Participating in health enhancing physical } \\
\text { activity at least three times a week }\end{array}$} & $M$ & 7 & 15 & 7 & 16 & 55 \\
\hline & & $\mathrm{F}$ & 8 & 13 & 10 & 23 & 46 \\
\hline \multirow[b]{2}{*}{23} & \multirow{2}{*}{$\begin{array}{l}\text { Selecting and regularly participate in } \\
\text { physical activities now and throughout } \\
\text { their adult years. }\end{array}$} & $M$ & 17 & 22 & 6 & 35 & 20 \\
\hline & & $\mathrm{F}$ & 18 & 26 & 10 & 24 & 22 \\
\hline \multirow{2}{*}{24} & \multirow{2}{*}{$\begin{array}{l}\text { Keeping in good health and physical } \\
\text { condition. }\end{array}$} & M & 12 & 28 & 8 & 29 & 23 \\
\hline & & $\mathrm{F}$ & 14 & 17 & 7 & 44 & 18 \\
\hline & \multirow{2}{*}{ SUM } & $M$ & 145 & 159 & 55 & 140 & 101 \\
\hline & & $\mathrm{F}$ & 92 & 132 & 43 & 160 & 173 \\
\hline & \multirow{2}{*}{ PERCENTAGE } & $M \%$ & 24.2 & 26.5 & 9.2 & 23.3 & 16.8 \\
\hline & & $\mathrm{F} \%$ & 15.3 & 22.0 & 7.2 & 26.7 & 28.8 \\
\hline
\end{tabular}

$1=$ Strongly agree $2=$ Agree $3=$ Uncertain $4=$ Disagree $5=$ Strongly disagree 
In item 13, the females' response mean (2.440) was found to be less than that recorded by males (2.850). This result asserts the fact that the female group significantly perceived this goal in a more positive manner when compared to the male group. This item indicates:

The Physical education program helps students to move using concepts of body awareness, space awareness, effort, and relationship.

However, the male group significantly agreed regarding items $14(p=$ $0.015)$, and $3(p=0.045)$ in comparison to the females group. Mean values recorded by the male group were 1.92 (\# 14) and 2.750 (\# 15). The same values recorded by the females group were 2.340 and 3.180 , successively. This result asserts the fact that the male group significantly perceived these goals in a more positive manner when compared to the female group. These items indicate that:

1. The Physical education program helps students to demonstrate competence in a variety of manipulative, locomotors and nonlocomotors skills performed individually and with others (\# 14).

2. The Physical education program helps students to demonstrate competence in many different forms of physical activity (\# 15).

\section{Perception of Males and Females to Health-Related Fitness Domain Goals}

Table 16 shows six statements comprising the goals of the health-related fitness domain in this study. The same table also presents frequencies of each 
of the five points of the scale relevant to the males and females responses to each item, as well as total and percentage of responses comprising this domain.

Results of Table 16 indicated that males showed more positive agreement (strongly agree/ agree) in their total of the six responses of the health-related fitness domain. Percentage of the scale "strongly agree" (24.2) and "agree" (26.5) for males were higher than those of females recording 15.3 and 22.0 respectively. However, percentages of the "uncertain" responses were slightly higher for males (9.2) than that for females (7.2).

Table 17 presents the means and standard deviations for male and female groups relevant to each of the six items of the health-related fitness domain. The same table also includes the computed " $\mathrm{t}$ " value and its significant level as a result of the comparisons between both sexes.

\section{Table 17}

Comparisons between Males and Females on Health-related Fitness Domain

\begin{tabular}{|c|l|c|c|c|c|c|}
\hline$\#$ & Gender & Mean & SD & df & T & Sig. \\
\hline \multirow{2}{*}{19} & Male & 3.150 & 1.466 & \multirow{2}{*}{198} & \multirow{2}{*}{$2.389 *$} & .017 \\
\cline { 2 - 4 } & Female & 2.660 & 1.422 & & & \\
\hline \multirow{2}{*}{20} & Male & 2.630 & 1.468 & \multirow{2}{*}{198} & -0.145 & .885 \\
\cline { 2 - 4 } & Female & 2.660 & 1.465 & & & \\
\hline \multirow{2}{*}{21} & Male & 3.730 & 1.332 & \multirow{2}{*}{198} & 0.914 & .362 \\
\cline { 2 - 4 } & Female & 3.560 & 1.297 & & & \\
\hline \multirow{2}{*}{22} & Male & 3.970 & 1.367 & \multirow{2}{*}{198} & 0.574 & .566 \\
\cline { 2 - 4 } & Female & 3.860 & 1.341 & & & \\
\hline \multirow{2}{*}{23} & Male & 3.190 & 1.426 & \multirow{2}{*}{198} & 0.638 & .524 \\
\cline { 2 - 4 } & Female & 3.060 & 1.455 & & & \\
\hline \multirow{2}{*}{24} & Male & 3.230 & 1.392 & \multirow{2}{*}{198} & -0.622 & .535 \\
\cline { 2 - 4 } & Female & 3.350 & 1.336 & & & \\
\hline
\end{tabular}


Results of table 17 indicated that numbers of mean values under the point average of the utilized scale (3) were slightly toward the side of disagreement. Number of items scored under this level were only two for females (\# 1, and \# 2), and one for males (\# 2). Generally, this result may be considered as a negative perception (Strongly Disagree and Disagree) by both groups toward the health-related fitness domain.

Comparisons between males and females relevant to the six items of the health-related fitness revealed that no significant differences were found between males and females perception toward the goals of this domain except for item number 19. This item indicated that:

The Physical education program helps students to keep weight controlled.

Females' response mean (2.660) for this item was found to be less than that recorded by males (3.150). This result indicated that the female group significantly perceived this goal in a more positive manner compared to the male group.

\section{Results of Section Four}

To asses the effect, if any, between number of years of teaching experience on the perception of the KPEG responses, the sample of the present study ( $n=200$ ) was internally divided into three groups according to the years of teaching experience as follows: group one (1-5 years), group two (6-10 years), and group three (11-15 years). Obviously, this division would result in three 
unequal group sizes. The number of physical educators in these groups was 53, 86 , and 79 , respectively. Descriptive statistics for each of the three groups is presented in table 18.

Table 18

Number of Years' Teaching Experience of the Sample

\begin{tabular}{|c|c|c|c|c|c|c|c|}
\hline Source & Exp. & $\mathrm{N}$ & $\mathrm{N}$ & \multicolumn{2}{|c|}{ Mean } & \multicolumn{2}{|c|}{ SD } \\
\hline Female & \multirow{2}{*}{$\begin{array}{c}\text { Group } 1 \\
1-5\end{array}$} & \multirow{2}{*}{53} & 19 & 2.53 & \multirow{2}{*}{2.65} & 1.43 & \multirow{2}{*}{1.17} \\
\hline Male & & & 34 & 2.76 & & 1.30 & \\
\hline Female & \multirow{2}{*}{$\begin{array}{c}\text { Group } 2 \\
6-10\end{array}$} & \multirow{2}{*}{68} & 36 & 8.53 & \multirow{2}{*}{8.24} & 1.42 & \multirow{2}{*}{1.15} \\
\hline Male & & & 32 & 7.94 & & 1.68 & \\
\hline Female & \multirow{2}{*}{$\begin{array}{c}\text { Group } 3 \\
11-15\end{array}$} & \multirow{2}{*}{79} & 45 & 13.62 & \multirow{2}{*}{13.20} & 2.26 & \multirow{2}{*}{1.35} \\
\hline Male & & & 34 & 12.78 & & 2.19 & \\
\hline Total & & 200 & 200 & & & & \\
\hline
\end{tabular}

In this section, comparisons among the three groups are shown. The comparisons include frequencies and percentages and descriptive statistics. Also, one-way analysis of variance for unequal sample size was performed to determine whether or not there were any significant differences among the three groups. This analysis was performed relevant to the perception of each group toward each of the 6 goals comprising the KPEG domain goals.

\section{Cognitive Responses and Experience}

Table 19 presents six statements comprising the goals of the cognitive domain in this study. Regarding each of the 5 points of the scale, the table shows frequencies and percentages of the responses for the 3 groups. 
Results of the six statements comprising the cognitive goals of the KPEG

Table 19 indicated that responses of the agreement scales (Strongly Agree/ Agree) verses the disagreement scales (Strongly Disagree/ Disagree) might be summarized in descending order as follows:

1. Items 1: The three groups were in the side of disagreement scoring: group $3=63.2 \%$, group $1=54.7 \%$, and group $2=51.5 \%$.

Table 19:

Years of Teaching Experience and Cognitive Goals Responses

\begin{tabular}{|c|c|c|c|c|c|c|c|c|c|c|c|c|}
\hline$\#$ & Exp. & 1 & $\%$ & 2 & $\%$ & 3 & $\%$ & 4 & $\%$ & 5 & $\%$ & $\mathrm{~N}$ \\
\hline \multirow{3}{*}{1} & 1-5 & 11 & 20.8 & 4 & 7.5 & 9 & 17.0 & 20 & 37.7 & 9 & 17.0 & 53 \\
\hline & $6-10$ & 5 & 7.4 & 13 & 19.1 & 15 & 22.1 & 17 & 25.0 & 18 & 26.5 & 68 \\
\hline & 11-15 & 5 & 3 & 13 & 16.5 & 11 & 13.9 & 25 & 31.6 & 25 & 31.6 & 79 \\
\hline \multirow{3}{*}{2} & $1-5$ & 6 & 11.3 & 10 & 18.9 & $y$ & 17.0 & 15 & 28.3 & 13 & 24.5 & 53 \\
\hline & $6-10$ & 11 & 16.2 & 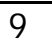 & 13.2 & 10 & 14.7 & 18 & 26.5 & 20 & 29.4 & 68 \\
\hline & 11-15 & 15 & .0 & 17 & 1.5 & 10 & 2.7 & 18 & 2.8 & 19 & 24.1 & 79 \\
\hline \multirow{3}{*}{3} & $1-5$ & 11 & .8 & P & 7.0 & & 15.1 & 14 & 6.4 & 11 & 20.8 & 53 \\
\hline & $6-10$ & 15 & 22.1 & 18 & 26.5 & 7 & 10.3 & 16 & 23.5 & 12 & 17.6 & 68 \\
\hline & 11-15 & 23 & 29.1 & 30 & 38.0 & 3 & 3.8 & 18 & 22.8 & 5 & 6.3 & 79 \\
\hline \multirow{3}{*}{4} & $1-5$ & 6 & 11.3 & 9 & 17.0 & 13 & 24.5 & 13 & 24.5 & 12 & 22.6 . & 53 \\
\hline & $6-10$ & 11 & 16.2 & 16 & 23.5 & 6 & 8.8 & 13 & 19.1 & 22 & 32.4 & 68 \\
\hline & $11-15$ & 12 & 15.2 & 10 & 12.7 & 3 & 3.8 & 27 & 34.2 & 27 & 34.2 & 79 \\
\hline \multirow{3}{*}{5} & $1-5$ & 12 & 22.7 & 26 & 49.1 & 0 & 11.3 & 3 & 5.7 & 0 & 11.3 & 53 \\
\hline & $6-10$ & 17 & 25.0 & 25 & 36.8 & 7 & 10.3 & 8 & 11.8 & $\overline{11}$ & 16.2 & 68 \\
\hline & 11-15 & 15 & 19.0 & 21 & 26.6 & 10 & 12.7 & 12 & 15.2 & 21 & 26.6 & 79 \\
\hline \multirow{3}{*}{6} & $1-5$ & 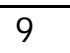 & 17.0 & 8 & 15.1 & 14 & 26.4 & 13 & 24.5 & & 17.0 & 53 \\
\hline & $6-10$ & 13 & 19.1 & 15 & 22.1 & 8 & 11.8 & 13 & 19.1 & 19 & 27.9 & 68 \\
\hline & 11-15 & 14 & 17.7 & 33 & 41.8 & 8 & 10.1 & 13 & 16.5 & 11 & 13.9 & 79 \\
\hline
\end{tabular}


2. Item 2: The three groups were in the side of disagreement scoring: group $2=55.90 \%$, group $1=52.8 \%$, and group $3=46.9 \%$.

3. Item 3: Groups 3 and 2 were in the side of agreement scoring: group $3=67.1 \%$, and group $2=48.6 \%$, while group 1 was on the side of disagreement scoring $=47.2 \%$.

4. Items 4: The three groups were on the side of disagreement scoring: group $3=68.4 \%$, group $2=51.5 \%$, and group $1=47.1 \%$.

5. Item 5: The three groups were on the side of agreement scoring: group $1=71.8 \%$, group $2=61.8 \%$, and group $3=45.6 \%$.

6. Item 6: groups 1 and 2 were on the side of disagreement scoring: group $2=47.0 \%$, and group $1=41.5 \%$, while group 3 was on the side of agreement with a $59.5 \%$.

Table 20 presents summary of the results of the analysis of variance relevant to the responses of the three groups for each of the six statements comprising the cognitive goals. 
Table (20)

Analysis of Variance among the effect of experience on the Perception of the Three Groups Toward Cognitive Goals

\begin{tabular}{|c|c|c|c|c|c|c|}
\hline \# & Source & Sum of Squares & $\mathrm{df}$ & Mean Square & $\mathrm{F}$ & Sig. \\
\hline \multirow{3}{*}{1} & Between & 6.000 & 2 & 3.000 & \multirow[t]{3}{*}{1.770} & \multirow[t]{3}{*}{0.173} \\
\hline & Within & 333.820 & 197 & 1.695 & & \\
\hline & Total & 339.820 & 199 & & & \\
\hline \multirow{3}{*}{2} & Between & 3.432 & 2 & 1.716 & \multirow[t]{3}{*}{0.863} & \multirow[t]{3}{*}{0.435} \\
\hline & Within & 404.443 & 197 & 2.053 & & \\
\hline & Total & 407.875 & 199 & & & \\
\hline \multirow{3}{*}{3} & Between & 17.572 & 2 & 8.786 & \multirow[t]{3}{*}{$4.526^{*}$} & \multirow[t]{3}{*}{0.012} \\
\hline & Within & 382.423 & 197 & 1.941 & & \\
\hline & Total & 399.995 & 199 & & & \\
\hline \multirow{3}{*}{4} & Between & 4.481 & 2 & 2.241 & \multirow[t]{3}{*}{1.077} & \multirow[t]{3}{*}{0.343} \\
\hline & Within & 409.899 & 197 & 2.081 & & \\
\hline & Total & 414.380 & 199 & & & \\
\hline \multirow{3}{*}{5} & Between & 16.990 & 2 & 8.459 & \multirow[t]{3}{*}{4.320} & \multirow[t]{3}{*}{0.015} \\
\hline & Within & 387.405 & 197 & 1.967 & & \\
\hline & Total & 404.395 & 199 & & & \\
\hline \multirow{3}{*}{6} & Between & 9.894 & 2 & 4.947 & \multirow[t]{3}{*}{2.535} & \multirow[t]{3}{*}{0.082} \\
\hline & Within & 384.501 & 197 & 1.952 & & \\
\hline & Total & 394.395 & 199 & & & \\
\hline
\end{tabular}

It can be seen that Table 20 showed that out of the six items of the cognitive domain, two items reached the level of significance: Item $3(p=0.012)$, and item $5(p=0.015)$. Multiple comparisons were calculated to determine which groups have means that are significantly different than the others. 
Multiple Comparisons (Gabriel) for Significant Statement in Cognitive Goals

\begin{tabular}{|c|c|c|c|c|}
\hline \# & Statement & Experience & $\begin{array}{l}\text { Mean } \\
\text { Diff. }\end{array}$ & Sig. \\
\hline \multirow[t]{3}{*}{3} & \multirow{3}{*}{$\begin{array}{l}\text { The physical education program helps students to } \\
\text { apply concepts and principles to the development of } \\
\text { motor skills. }\end{array}$} & $6-10$ & .21 & \\
\hline & & $11-15$ & $.70^{*}$ & .014 \\
\hline & & $6-10 \quad 11-15$ & .49 & \\
\hline \multirow[t]{3}{*}{5} & \multirow{3}{*}{$\begin{array}{l}\text { The physical education program helps students to } \\
\text { understand that physical activity provides the } \\
\text { opportunity for enjoyment, self-expression, and } \\
\text { communication. }\end{array}$} & $6-10$ & -.23 & \\
\hline & & $11-15$ & $-.70 *$ & .016 \\
\hline & & $6-10 \quad 11-15$ & -.46 & \\
\hline
\end{tabular}

The analysis of the multiple comparisons relevant to item 3 indicated that the mean difference $(0.70)$ between $1-5$ group $(M=3.09)$ and $11-15$ group ( $M=2.39)$ was significant at the 0.014 level.

Regarding item 5, the results of the multiple comparisons revealed that the mean difference $(-0.70)$ between $1-5$ group $(M=2.34)$ and the $11-15$ group $(M=3.04)$ was significant at the 0.016 level.

It may be concluded from the preceding results that the 11-15 group significantly agreed relevant to item 3 compared to the 1-5 group, and the latter group significantly agreed relevant to items 5 compared to the 11-15 group.

\section{Affective Responses and Experience}

Table 21 presents six statements comprising the goals of the affective domain in this study. Regarding each of the five points of the scale, the same table also shows frequencies and percentages of the responses for each of the three groups. 
Table 21

Years of Teaching Experience and Affective Goals Responses

\begin{tabular}{|c|c|c|c|c|c|c|c|c|c|c|c|c|}
\hline \multirow{2}{*}{ \# } & \multirow{2}{*}{ Exp. } & \multicolumn{10}{|c|}{ Frequencies \& \% } & \multirow{2}{*}{$\mathrm{N}$} \\
\hline & & 1 & $\%$ & 2 & $\%$ & 3 & $\%$ & 4 & $\%$ & 5 & $\%$ & \\
\hline \multirow{3}{*}{7} & $1-5$ & 12 & 22.6 & 16 & 30.2 & 8 & 15.1 & 8 & 15.1 & 9 & 17.0 & 53 \\
\hline & $6-10$ & 18 & 26.5 & 23 & 33.8 & 8 & 11.8 & 11 & 16.2 & 8 & 11.8 & 68 \\
\hline & 11-15 & 20 & 25.3 & 23 & 29.1 & 10 & 12.7 & 16 & 20.3 & 10 & 12.7 & 79 \\
\hline \multirow{3}{*}{8} & $1-5$ & 11 & 20.8 & 17 & 32.1 & 4 & 7.5 & 14 & 26.4 & 7 & 13.2 & 53 \\
\hline & $6-10$ & 16 & 23.5 & 13 & 19.1 & 3 & 4.4 & 20 & 29.4 & 16 & 23.5 & 68 \\
\hline & 11-15 & 18 & 22.8 & 18 & 22.8 & 9 & 11.4 & 19 & 24.1 & 15 & 19.0 & 79 \\
\hline \multirow{3}{*}{9} & $1-5$ & 10 & 18.9 & 13 & 24.5 & 6 & 11.3 & 11 & 20.8 & 13 & 24.5 & 53 \\
\hline & $6-10$ & 16 & 23.5 & 17 & 25.0 & 5 & 7.4 & 18 & 26.5 & 12 & 17.6 & 68 \\
\hline & $11-15$ & 13 & 16.5 & 18 & 22.8 & 12 & 15.2 & 20 & 25.3 & 16 & 20.3 & 79 \\
\hline \multirow{3}{*}{10} & $1-5$ & 15 & 28.3 & 12 & 22.6 & 5 & 9.4 & 11 & 20.8 & 10 & 18.9 & 53 \\
\hline & $6-10$ & 29 & 42.6 & 18 & 26.5 & 3 & 4.4 & 12 & 17.6 & 6 & 8.8 & 68 \\
\hline & $11-15$ & 24 & 30.4 & 22 & 27.8 & 2 & 2.5 & 19 & 24.1 & 12 & 15.2 & 79 \\
\hline \multirow{3}{*}{11} & $1-5$ & 13 & 24.5 & 17 & 32.1 & 7 & 13.2 & 13 & 24.5 & 3 & 5.7 & 53 \\
\hline & $6-10$ & 22 & 32.4 & 16 & 23.5 & 7 & 10.3 & 14 & 20.6 & 9 & 13.2 & 68 \\
\hline & $11-15$ & 22 & 27.8 & 23 & 29.1 & 9 & 11.4 & 16 & 20.3 & 9 & 11.4 & 79 \\
\hline \multirow{3}{*}{12} & $1-5$ & 9 & 17.0 & 16 & 30.2 & 7 & 13.2 & 16 & 30.2 & 5 & 9.4 & 53 \\
\hline & $6-10$ & 17 & 25.0 & 16 & 23.5 & 4 & 5.9 & 18 & 26.5 & 13 & 19.1 & 68 \\
\hline & $11-15$ & 15 & 19.0 & 23 & 29.1 & 11 & 13.9 & 17 & 21.5 & 13 & 16.5 & 79 \\
\hline
\end{tabular}

Results of the six statements comprising the affective goals of the KPEG (Table 21) indicated that responses of the agreement scales (Strongly Agree/ Agree) verses the disagreement scales (Strongly Disagree/ Disagree) might be summarized in descending order as follows:

1. Items 7: The three groups were on the side of agreement scoring: group $2=60.3 \%$, group $3=54.4 \%$, and group $1=52.8 \%$. 
2. Item 8: groups 1 and 3 were on the side of agreement scoring $52.9 \%$, and $45.6 \%$, respectively. Group 2 was on the side disagreement scoring $52.9 \%$.

3. Item 9: groups 3 and 1 were on the side of agreement scoring $45.6 \%$, and $45.3 \%$, respectively. Group 2 was on the side disagreement scoring $48.5 \%$.

4. Item 10: All groups were on the side of agreement scoring: group $2=$ $69.1 \%$, group $3=58.2 \%$, and group $1=50.9 \%$.

5. Items 11: The three groups were on the side of agreement scoring: group $3=56.9 \%$, Group $1=56.6 \%$, Group $2=55.9 \%$.

6. Item 12: All groups were on the side of agreement scoring: group $2=$ $48.5 \%$, Group 3= 48.1 \%, Group $1=47.2 \%$. However, the uncertain response values were higher for groups $3(13.9 \%)$, and group 1 (13.2).

Table 22 presents summary of the results of the analysis of variance relevant to the responses of the three groups for each of the six statements comprising the cognitive goals. 
Table 22

Analysis of Variance among the effect of experience on the Perception of the Three Groups Toward Affective Goals

\begin{tabular}{|c|c|c|c|c|c|c|}
\hline$\#$ & Source & Sum of Squares & $\overline{d f}$. & Mean Square & $\mathrm{F}$ & Sig. \\
\hline \multirow{3}{*}{7} & Between & 1.340 & 2 & .670 & \multirow[t]{3}{*}{0.350} & \multirow[t]{3}{*}{.705} \\
\hline & Within & 377.015 & 197 & 1.914 & & \\
\hline & Total & 378.355 & 199 & & & \\
\hline \multirow{3}{*}{8} & Between & 2.915 & 2 & 1.458 & \multirow[t]{3}{*}{0.668} & \multirow[t]{3}{*}{.514} \\
\hline & Within & 429.680 & 197 & 2.181 & & \\
\hline & Total & 432.595 & 199 & & & \\
\hline \multirow{3}{*}{9} & Between & 1.708 & 2 & .854 & \multirow[t]{3}{*}{0.405} & \multirow[t]{3}{*}{.667} \\
\hline & Within & 415.167 & 197 & 2.107 & & \\
\hline & Total & 416.875 & 199 & & & \\
\hline \multirow{3}{*}{10} & Between & 10.776 & 2 & 5.388 & \multirow[t]{3}{*}{2.487} & \multirow[t]{3}{*}{.086} \\
\hline & Within & 426.724 & 197 & 2.166 & & \\
\hline & Total & 437.500 & 199 & & & \\
\hline \multirow{3}{*}{11} & Between & 0.006 & 2 & 0.029 & \multirow[t]{3}{*}{0.015} & \multirow[t]{3}{*}{.985} \\
\hline & Within & 374.818 & 197 & 1.903 & & \\
\hline & Total & 374.875 & 199 & & & \\
\hline \multirow[t]{3}{*}{12} & Between & .123 & 2 & 0.061 & \multirow[t]{3}{*}{0.031} & \multirow[t]{3}{*}{.970} \\
\hline & Within & 390.997 & 197 & 1.985 & & \\
\hline & Total & 391.120 & 199 & & & \\
\hline
\end{tabular}

Table 22 indicated that none of the six items of the affective domain reached the 0.05 as a minimum level of significance in this study.

\section{Psychomotor Responses and Experience}

Table 23 presents six statements comprising the goals of the psychomotor domain in this study. Regarding each of the five points of the scale, the same 
table also shows frequencies and percentages of the responses for each of the three groups.

Table 23

Teaching Experience and Psychomotor Frequencies \& Percentages

\begin{tabular}{|c|c|c|c|c|c|c|c|c|c|c|c|c|}
\hline \multirow{2}{*}{ \# } & \multirow{2}{*}{ Exp. } & \multicolumn{10}{|c|}{ Frequencies \& \% } & \multirow{2}{*}{$\mathrm{N}$} \\
\hline & & 1 & $\%$ & 2 & $\%$ & $\overline{3}$ & $\%$ & 4 & $\%$ & 5 & $\%$ & \\
\hline \multirow{3}{*}{13} & $1-5$ & 13 & 24.5 & 14 & 26.4 & 6 & 11.3 & 12 & 22.6 & 8 & 15.1 & 53 \\
\hline & $6-10$ & 18 & 26.5 & 18 & 26.5 & 9 & 13.2 & 14 & 20.6 & 9 & 13.2 & 68 \\
\hline & $11-15$ & 25 & 31.6 & 23 & 29.1 & 6 & 7.6 & 14 & 17.7 & 11 & 13.9 & 79 \\
\hline \multirow{3}{*}{14} & $1-5$ & 15 & 28.3 & 23 & 43.4 & 8 & 15.1 & 5 & 9.4 & 2 & 3.8 & 53 \\
\hline & $6-10$ & 28 & 41.2 & 22 & 32.4 & 2 & 2.9 & 9 & 13.2 & 7 & 10.3 & 68 \\
\hline & $11-15$ & 33 & 41.8 & 26 & 32.9 & 8 & 10.1 & 7 & 8.9 & 5 & 6.3 & 79 \\
\hline \multirow{3}{*}{15} & $1-5$ & 13 & 24.5 & 11 & 20.8 & 5 & 9.4 & 9 & 17.0 & 15 & 28.3 & 53 \\
\hline & $6-10$ & 14 & 20.6 & 23 & 33.8 & 3 & 4.4 & 15 & 22.1 & 13 & 19.1 & 68 \\
\hline & $11-15$ & 17 & 21.5 & 21 & 26.6 & 3 & 3.8 & 20 & 25.3 & 18 & 22.8 & 79 \\
\hline \multirow{3}{*}{16} & $1-5$ & 11 & 20.8 & 10 & 18.9 & 6 & 11.3 & 13 & 24.5 & 13 & 24.5 & 53 \\
\hline & $6-10$ & 10 & 14.7 & 15 & 22.1 & 5 & 7.4 & 22 & 32.4 & 16 & 23.5 & 68 \\
\hline & $11-15$ & 17 & 21.5 & 19 & 24.1 & 6 & 7.6 & 19 & 24.1 & 18 & 22.8 & 79 \\
\hline \multirow{3}{*}{17} & $1-5$ & 4 & 7.5 & 14 & 26.4 & 7 & 13.2 & 15 & 28.3 & 13 & 24.5 & 53 \\
\hline & $6-10$ & 17 & 25.0 & 21 & 30.9 & 8 & 11.8 & 15 & 22.1 & 7 & 10.3 & 68 \\
\hline & $11-15$ & 14 & 17.7 & 27 & 34.2 & 6 & 7.6 & 21 & 26.6 & 11 & 13.9 & 79 \\
\hline \multirow{3}{*}{18} & $1-5$ & 8 & 15.1 & 11 & 20.8 & 10 & 18.9 & 17 & 32.1 & 7 & 13.2 & 53 \\
\hline & $6-10$ & 16 & 23.5 & 15 & 22.1 & 6 & 8.8 & 19 & 27.9 & 12 & 17.6 & 68 \\
\hline & $11-15$ & 17 & 21.5 & 23 & 29.1 & 3 & 3.8 & 18 & 22.8 & 18 & 22.8 & 79 \\
\hline
\end{tabular}

$1=$ Strongly agree $2=$ Agree $3=$ =ncertain $4=$ Disagree $5=$ Strongly disagree

Results of the six statements comprising the psychomotor goals of the KPEG (Table 23) indicated that responses of the agreement scales (Strongly Agree/ Agree) verses the disagreement scales (Strongly Disagree/ Disagree) might be summarized in descending order as follows: 
1. Items 13: The three groups were in the side of agreement scoring: group $3=60.7 \%$, group $2=53.0 \%$, and group $1=50.9 \%$.

2. Items 14: all groups were on the side of agreement scoring: group $3=$ $74.7 \%$, group 2= $73.6 \%$, and Group $1=71.7 \%$.

3. Item 15: group 2 was on the side of agreement scoring $54.4 \%$. Results of groups 1 and 3 were amazing. Each of these groups scored the same percentage value on the side of agreement and disagreement, $45.3 \%$ for group 1, and $48.1 \%$ for group 3. According to Table 23, scores along the five points of the scale were not identical.

4. Item 16: the three groups were on the side of disagreement scoring: group $2=55.9 \%$, group $1=49.0 \%$, and group $3=46.9 \%$. However, group 3 scored a very close value of agreement $(45.6 \%)$ to its value of disagreement.

5. Items 17: groups 2 and 3 were in the side of agreement scoring: 55.9 $\%, 51.9 \%$, respectively. On the other hand group 1 was on the side of disagreement scoring $52.8 \%$.

6. Item 18: groups 3 and 2 were in the side of agreement scoring: 50.6 $\%$, and $45.6 \%$, respectively. However, group 1 was in the side of disagreement scoring $45.3 \%$. 
Table 24 presents summary of the results of the analysis of variance relevant to the responses of the three groups for each of the six statements comprising the psychomotor goals.

\section{Table 24}

Analysis of Variance among the effect of experience on the Perception of the Three Groups toward Psychomotor Goals

\begin{tabular}{|c|c|c|c|c|c|c|}
\hline \# & Source & Sum of Squares & $\mathrm{df}$ & Mean Square & $\mathrm{F}$ & Sig. \\
\hline \multirow{3}{*}{13} & Between & 1.959 & 2 & 0.972 & \multirow[t]{3}{*}{0.478} & \multirow[t]{3}{*}{.621} \\
\hline & Within & 403.836 & 197 & 2.050 & & \\
\hline & Total & 405.795 & 199 & & & \\
\hline \multirow{3}{*}{14} & Between & .836 & 2 & 0.418 & \multirow[t]{3}{*}{0.275} & \multirow[t]{3}{*}{.760} \\
\hline & Within & 299.784 & 197 & 1.522 & & \\
\hline & Total & 300.620 & 199 & & & \\
\hline \multirow{3}{*}{15} & Between & 1.314 & 2 & 0.657 & \multirow[t]{3}{*}{0.283} & \multirow[t]{3}{*}{.754} \\
\hline & Within & 457.441 & 197 & 2.322 & & \\
\hline & Total & 458.755 & 199 & & & \\
\hline \multirow{3}{*}{16} & Between & 2.364 & 2 & 1.182 & \multirow[t]{3}{*}{0.539} & \multirow[t]{3}{*}{.584} \\
\hline & Within & 431.716 & 197 & 2.191 & & \\
\hline & Total & 434.080 & 199 & & & \\
\hline \multirow{3}{*}{17} & Between & 16.770 & 2 & 8.385 & \multirow[t]{3}{*}{ 4.609* } & \multirow[t]{3}{*}{.011} \\
\hline & Within & 358.425 & 197 & 1.819 & & \\
\hline & Total & 375.195 & 199 & & & \\
\hline \multirow{3}{*}{18} & Between & 0.606 & 2 & 0.303 & \multirow[t]{3}{*}{0.144} & \multirow[t]{3}{*}{.866} \\
\hline & Within & 414.349 & 197 & 2.103 & & \\
\hline & Total & 414.955 & 199 & & & \\
\hline
\end{tabular}

It can be seen from Table 24 that out of the six items of the psychomotor domain, only item 5 reached the level of significance $(p=0.011)$. Multiple comparisons were calculated to determine which groups had means that are significantly different than the others. 


\begin{tabular}{|llrrrc|}
\hline$\#$ & Statement & Experience & Mean Diff. & Sig. \\
\hline \multirow{2}{*}{17} & The physical education program helps students to & $1-5$ & $6-10$ & $-0.741^{*}$ & .009 \\
& apply concepts and principles to the development & & $11-15$ & -0.510 & \\
& of motor skills. & $6-10$ & $11-15$ & 0.231 & \\
\hline
\end{tabular}

Table 25

Years of Teaching Experience and Health-Related Fitness Frequencies \& \%

\begin{tabular}{|c|c|c|c|c|c|c|c|c|c|c|c|c|}
\hline \multirow{2}{*}{$\#$} & \multirow{2}{*}{ Exp. } & \multicolumn{10}{|c|}{ Frequencies \& \% } & \multirow{2}{*}{$\mathrm{N}$} \\
\hline & & 1 & $\%$ & 2 & $\%$ & 3 & $\%$ & 4 & $\%$ & 5 & $\%$ & \\
\hline \multirow{3}{*}{19} & $1-5$ & 12 & 22.6 & 12 & 22.6 & 5 & 9.4 & 13 & 24.5 & 11 & 20.8 & 53 \\
\hline & $6-10$ & 12 & 17.6 & 18 & 26.5 & 6 & 8.8 & 20 & 29.4 & 12 & 17.6 & 68 \\
\hline & $11-15$ & 21 & 26.6 & 21 & 26.6 & 8 & 10.1 & 15 & 19.2 & 14 & 17.7 & 79 \\
\hline \multirow{3}{*}{20} & $1-5$ & 12 & 22.6 & 13 & 24.5 & 14 & 7.5 & 10 & 18.9 & 14 & 26.4 & 53 \\
\hline & $6-10$ & 17 & 25.0 & 25 & 36.8 & 5 & 7.4 & 7 & 10.3 & 14 & 20.6 & 68 \\
\hline & $11-15$ & 21 & 26.6 & 35 & 44.3 & 4 & 5.1 & 9 & 11.4 & 10 & 12.7 & 79 \\
\hline \multirow{3}{*}{21} & $1-5$ & 4 & 7.5 & 7 & 13.2 & 6 & 11.3 & 21 & 39.6 & 15 & 28.3 & 53 \\
\hline & $6-10$ & 7 & 10.3 & 8 & 11.8 & 5 & 7.4 & 31 & 45.6 & 17 & 25.0 & 68 \\
\hline & $11-15$ & 11 & 13.9 & 9 & 14.4 & 5 & 6.3 & 27 & 34.2 & 27 & 34.2 & 79 \\
\hline \multirow{3}{*}{22} & $1-5$ & 4 & 7.5 & 9 & 17.0 & 6 & 11.3 & 10 & 18.9 & 24 & 45.3 & 53 \\
\hline & $6-10$ & 6 & 8.8 & 11 & 16.2 & 3 & 4.4 & 15 & 22.1 & 33 & 48.5 & 68 \\
\hline & $11-15$ & 5 & 6.3 & 8 & 10.1 & 8 & 10.1 & 14 & 17.7 & 44 & 15.7 & 79 \\
\hline \multirow{3}{*}{23} & $1-5$ & 9 & 17.0 & 13 & 24.5 & 2 & 3.8 & 20 & 37.7 & 9 & 17.0 & 53 \\
\hline & $6-10$ & 12 & 17.6 & 19 & 27.9 & 5 & 7.4 & 19 & 27.9 & 13 & 19.1 & 68 \\
\hline & 11-15 & 14 & 17.7 & 16 & 20.3 & 9 & 11.4 & 20 & 25.3 & 20 & 25.3 & 79 \\
\hline \multirow{3}{*}{24} & $1-5$ & 8 & 15.1 & 12 & 22.6 & 3 & 5.7 & 16 & 30.2 & 14 & 26.4 & 53 \\
\hline & $6-10$ & 10 & 14.7 & 17 & 25.0 & 5 & 7.4 & 24 & 35.3 & 12 & 17.6 & 68 \\
\hline & $11-15$ & 8 & 10.1 & 16 & 20.3 & 7 & 8.9 & 33 & 41.8 & 15 & 19.0 & 79 \\
\hline
\end{tabular}

$1=$ Strongly agree $2=$ Agree $3=$ Uncertain $4=$ Disagree $5=$ Strongly disagree

The analysis of the multiple comparisons relevant to item 17 indicated that the difference between the 1-5 group mean $(M=3.36)$ and the $6-10$ group mean (2.62) was 0.741 , reaching the 0.009 level of significance. 


\section{$\underline{\text { Health-Related Fitness and Experiences }}$}

Table 25 presents six statements comprising the goals of the healthrelated fitness domain in this study. Regarding each of the five points of the scale, the same table also shows frequencies and percentages of the responses for each of the three groups.

Results of the six statements comprising the health related fitness goals of the KPEG (Table 25) indicated that responses of the agreement scales (Strongly Agree/ Agree) verses the disagreement scales (Strongly Disagree/ Disagree) might be summarized in descending order as follows:

1. Item 19: Group three was on the side of agreement scoring $53.2 \%$. Frequencies of disagreement $(47.0 \%)$ and agreement $(44.1 \%)$ for group two were closer to each other. Frequencies of disagreement (45.3\%) and agreement (45.2\%) for group one were about identical.

2. Item 20: The three groups were on the side of agreement scoring: group $3=70.9 \%$, and group $2=61.8 \%$. Group 1 responses, more agreed $(47.1 \%)$ than disagreed $(45.3 \%)$.

3. Items 21: All groups were on the side of agreement scoring: group $2=$ $70.6 \%$, group 3=68.4 \%, and Group $1=67.9 \%$.

4. Item 22: All groups were on the side of disagreement scoring: group $3=73.4 \%$, group 3= $70.6 \%$, and Group $1=64.2 \%$.

5. Item 23: The three groups were on the side of disagreement scoring: group $1=54.7 \%$, group $3=50.6 \%$, and Group $2=47.0 \%$. 
6. Items 24: All groups were on the side of disagreement scoring: group

$3=60.8 \%$, group $1=56.6 \%$, and Group $2=52.9 \%$.

Table 26 summaries the results of the analysis of variance relevant to the responses of the three groups. Each of the six statements comprising the psychomotor goals was separately analyzed.

Table 26

Analysis of Variance among the effect of experience on the Perception of the Three Groups Toward Health-Related Fitness Goals

\begin{tabular}{|c|c|c|c|c|c|c|}
\hline \# & Source & Sum of Squares & $\mathrm{df}$ & Mean Square & $\mathrm{F}$ & Sig. \\
\hline \multirow{3}{*}{19} & Between & 3.336 & 2 & 1.668 & \multirow[t]{3}{*}{0.779} & \multirow[t]{3}{*}{.460} \\
\hline & Within & 421.859 & 197 & 2.141 & & \\
\hline & Total & 425.195 & 199 & & & \\
\hline \multirow{3}{*}{20} & Between & 12.449 & 2 & 6.225 & \multirow[t]{3}{*}{$2.967^{*}$} & \multirow[t]{3}{*}{.054} \\
\hline & Within & 413.346 & 197 & 2.098 & & \\
\hline & Total & 425.795 & 199 & & & \\
\hline \multirow{3}{*}{21} & Between & 0.085 & 2 & 0.042 & \multirow[t]{3}{*}{0.024} & \multirow[t]{3}{*}{.976} \\
\hline & Within & 343.710 & 197 & 1.745 & & \\
\hline & Total & 343.795 & 199 & & & \\
\hline \multirow{3}{*}{22} & Between & 3.095 & 2 & 1.530 & \multirow[t]{3}{*}{0.836} & \multirow[t]{3}{*}{.435} \\
\hline & Within & 360.496 & 197 & 1.830 & & \\
\hline & Total & 363.555 & 199 & & & \\
\hline \multirow{3}{*}{23} & Between & 1.099 & 2 & 0.549 & \multirow[t]{3}{*}{0.263} & \multirow[t]{3}{*}{$.76 \mathrm{~S}$} \\
\hline & Within & 410.776 & 197 & 2.085 & & \\
\hline & Total & 411.875 & 199 & & & \\
\hline \multirow{3}{*}{24} & Between & 1.954 & 2 & 0.977 & \multirow[t]{3}{*}{0.524} & \multirow[t]{3}{*}{.539} \\
\hline & Within & 367.226 & 197 & 1.864 & & \\
\hline & Total & 369.180 & 199 & & & \\
\hline
\end{tabular}


Results of Table 26 showed that out of the six items of the health-related fitness domain, only one item (\# 20) reached the level of significance ( $p=$ 0.054). Multiple comparisons were calculated to determine which groups had means that are significantly different than the others.

\begin{tabular}{|c|c|c|c|c|}
\hline$\#$ & Statement & Experience & Mean Diff. & Sig. \\
\hline \multirow{3}{*}{20} & \multirow{3}{*}{$\begin{array}{l}\text { Physical education program helps students assess, } \\
\text { achieve, and maintain physical fitness. }\end{array}$} & $6-10$ & -0.372 & \\
\hline & & $11-15$ & $-0.283^{*}$ & .045 \\
\hline & & $6-10 \quad 11-15$ & -0.255 & \\
\hline
\end{tabular}

The analysis of the multiple comparisons relevant to item 20 in the healthrelated fitness between each and other groups indicated that the difference between the $1-5$ group mean $(M=3.02)$ and the $11-15$ group mean (2.39) was 0.627 , reaching the 0.045 level of significance.

\section{Section Five}

\section{Discussion}

The major purpose of this study was to evaluate the present status of the secondary school physical education program in Kuwait. A survey was conducted using a developed questionnaire, Kuwaiti Physical Education Goals (KPEG) to determine how Kuwaiti physical education teachers perceive the domain goals of the physical education program.

A sample of 200 physical educators was asked to reflect their perceptions on 24 positive statements comprising four educational domains: cognitive, affective, psychomotor, and health-related fitness. The four domains were of an equal size, consisting of six items each. 
To answer the main question of this study, two related questions were investigated regarding differences in the perception of gender and years of experience toward the goals of the four domains. The sample was basically selected of two equal size groups $(n=100)$ from both sexes, and was internally divided into three groups according to their years of teaching experience (1-5, 610, 11-15 years).

Thus, the present study was designed to answer three related questions reflected the purpose of this study. To find answers to these questions, the discussion of the preceding results is organized in the same order.

\section{Research Question 1}

How do Kuwaiti physical education teachers perceive the domain goals of the physical education program?

According to the results of Table 4 , scores of the sample of the present study with respect to the total score of the KPEG, were more slightly toward the side of agreement than disagreement. Number of items scored under the average point (3) of the utilized scale was 15 (62.5\%), while 9 items (37.5\%) were scored over this level. The average of the total responses $(M=2.97)$ also indicated that responses were slightly under the average point of the scale (3).

The results of Table 5 assisted and provided more explanation relevant to the above-mentioned result. With $10 \%$ of uncertain responses, the total percentage of agreement was 46 (20.7\% Strongly agree \& $25.3 \%$ Agree), while 
the total percentage of disagreement was 44.1 (20.4\% Strongly disagree \& 23.7 $\%$ Disagree).

The preceding result indicated that the sample's responses were distributed with values nearly closer to the agreement points $(1 \& 2)$ and disagreement points $(4 \& 5)$ of the utilized scale. This result may be considered as an indication that the sample of this study responded to the questionnaire's items freely, fairly, and unbiased. Additionally, taking into account that the sample of the present study comprised both sexes, and three stages of teaching experience, the result may generally be considered as a positive reflection of the sample's perception toward the entire number of items of the KPEG.

Concerning the four domains, results of table 4 and 5 indicated that the sample of this study perceived positively the affective and psychomotor domains, but perceived negatively the cognitive and health-related fitness domains. Means of the psychomotor and affective domains were slightly under the average point of the utilized scale scoring 2.71 and, 2.76 , respectively. On the other hand, these values were 3.34 and 3.09 for the health-related fitness and cognitive domains, respectively (Table 4).

Regarding the positive and negative ratings of the four domains, results of Table 5 were in concordance with the previous arrangement of the four means. The participants of this study perceived the psychomotor domain at the top with $52.2 \%$ positive agreement ( $24.2 \%$ Strongly agree $\& 28.0 \%$ Agree), followed by the affective domain recording $51.8 \%$ (25.0\% Strongly agree $\& 26.8 \%$ Agree), 
then the health-related fitness domain with $46.0 \%$ positive agreement $(20.7 \%$ Strongly agree \& $25.3 \%$ Agree), and lastly the cognitive domain scoring $41.4 \%$ (17.6\% Strongly agree \& 23.8\% Agree).

In addition, the uncertain responses of the cognitive domain scored a higher percentage (13.1) in comparison to other domains: $8.9 \%$ for the psychomotor, $10 \%$ the affective and the same for the health-related fitness domains. This higher percentage may indicate that some of the sample participants did not have enough knowledge concerning the goals of the cognitive domain, in comparison to other domains.

However, findings pertaining to the results of the four domains (Table 4) revealed that the sample's means were in the positive side (agreement) for all domains, except for the cognitive domain. To arrange the sample's perceptions toward the four domains positively in descending order according to the corresponding mean values were as follows: psychomotor (2.71), affective domain (2.76), health-related fitness domain (2.97), and cognitive domain (3.09).

The preceding results differed slightly from the results obtained by The Educational Office of the Arab Golf Countries (1980), and the results found by Alsagheir (1993) in Saudi Arabia. Both studies found that the affective domain came first followed by the psychomotor domain. However, the present study did not differ from both studies regarding teachers' perception toward cognitive 
domain goals. This result may be an indication that Kuwaiti physical educators are paying more attention to teaching and performing motor skills.

Going further to obtain more detail on the teachers' perception toward the 24 statements of the KPEG, results of the Chi-Square indicated that 14 items had reached the levels of significance with an equal number ( 7 items) of agreement and disagreements items. Thus, ten items were non-significant. These nonsignificant items indicated that part of the sample perceived them positively, and about an equal part perceived them negatively.

The significant agreement statements comprised only one of the cognitive goals, and three for each of the affective and psychomotor goals. The cognitive goal indicated that the physical education program for secondary school provide students with "opportunity for enjoyment, self-expression, and communication $(\# 5, p<0.001) "$.

The significant affective goals indicated that the program helps students to "improve self-confidence ( $\# 7, p<0.001)$ ", and "appreciate the relationships with others (\#10 p<0.001)", and "cooperate with others to achieve common goals (\# 11, $p<0.001) "$.

The psychomotor goals that gained significant positive perception from the sample of the study indicated that the physical education program helps students to "move using concepts of body awareness, space awareness, and effort (\# 13, p < 0.001)", "demonstrate competence in a variety of manipulative, 
locomotors and non- locomotors skills performed individually and with others (\# $14, p<0.001)$ ", and "learn how to learn new skills (\# 17, $p<0.001$ )".

The seven significant goals perceived positively by the sample of this study may be viewed as inherited features in physical education activities as a result of practice, especially when the program contains group games and competitions.

The significant disagreement statements comprised three cognitive goals, and four health-related fitness goals. The cognitive goals indicated that the physical education program for secondary school helps students to "know the benefits, costs and obligations associated with regular participation in physical activity (\# 1, p <0.002)", "recognize the risk arid safety factors associated with regular participation in physical activity (\# 2, p <0.007)", and "know the rules, strategies and appropriate behaviors for selected physical activities $(\# 4, p<0.001)^{\prime \prime}$.

The health-related fitness four goals which gained significant disagreement indicated that the physical education program for secondary school helps students to "design safe, personal fitness programs in accordance with principles of training and conditioning (\# 21, $p<0.001$ )", "participate in health enhancing physical activity at least three times a week (\# 22, p <0.001)", "select and regularly participate in physical activities now and throughout their adult years (\# 23, p <0.047)", keep in good health and physical condition (\# 24, p <0.002)". 
The researcher partially agrees with of the significant disagreement of the sample regarding the cognitive domain. It is important to take into consideration when discussing the goals of this domain, the knowledge and ability of physical educators to realize such goals, the time available for this realization, the suitable teaching style, and the secondary school students as adolescent. Thus, the researcher agrees partially with this result.

A teacher's ability depends to a large extent on his/her experience in applying the goals of the cognitive domain in conjunction with particular situations. The situational cognition requires that the learning content be united with the use of that content. This may assist the students in comprehending the concepts within the complex environment.

The time available is not enough (two 45 min. per week) to apply such goals. Accordingly, the command style is a suitable style with short class time and large number of students. This style has a long history in the field of physical education, as mentioned by Mosston \& Ashworth (1986), and the most prevalent style of teaching used nowadays by physical educators and in teaching physical education in Kuwait. The command style in physical education is well known to have little impact on the goals of cognitive domain.

Knowing that physical activity can promote health is not enough. Students must be given opportunities to gain knowledge and skill needed to adopt active lifestyles. Thus, physical educators should teach students how to add the habit of physical activity into their daily lives by aligning instruction with the National 
Standards for Physical Education, and by providing content and learning experiences that develop the skills and desire to be active for life.

Statements that did not reach the significant level of agreement or disagreement were 10 statements. Two were found in the cognitive domain $(\# 2$, and 6), three in each of the affective (\# 8, 9, and 12) and psychomotor domain (\# 15, 16, and 18), and two in the health-related fitness domain (\# 19, and 20). The researcher will discuss these items after discussing the comparisons between the perception of both sexes, and among the three groups of teaching experience.

\section{Research Question 2}

Do female and male physical educators differ significantly in their perceptions relevant to the goals presented in the KPEG regarding: (a) cognitive, (b) affective, (c) psychomotor, and health-related fitness domains?

Before discussing differences between males and females physical educators perceptions in this study, it should be mentioned that the goals of the physical education program for males and female students are the same. The only difference is in the content.

Results of the comparison between the perception of the male and female group toward the 24 statements of the KPEG indicated eight significant gender effects were found for: cognitive domain (\# 4), affective domain (\# 10, 11, and 12), psychomotor domain (\# 13, 14 and 15), and health-related fitness domain 
(\# 19). Each of the male and female groups perceived significantly four items positively or negatively in comparison to one another.

The four significant goals perceived positively by the male group included items 11 and 12 (affective), 14 and 15 (psychomotor). Item 12 consisted of the role of exercise in healthful living $(P=0.055)$. The positive and significant responses recorded by the male group in comparison to the female group regarding this item did not arise from a vacuum. The appearance of secondary school male students as adolescents suggests that they appreciate the role of exercise. However the two 40 minutes weekly may help, but they do not constitute the major fact or factor that brings out this appearance. The developmental changes in the physical, physiological, and psychological are the basic factors. The male adolescent wants to prove and accept himself as a man. Thus, he wants to be strong, have big muscles, more masculinity, and wants this recognition from other males. He admires those of his own sex who have these qualities and strives to win the approval of these persons. On the other hand, the adolescent girl has her own developmental body style, which aids her to be accepted as a woman. Her body becomes heavier with new rounding contours at breast and hips giving her the femininity appearance. In addition, she does not like developing big muscles and extra strength, however she admires these features in man.

Items 11 and 14 are interrelated and constitute the corner stone in competitive sports. Competitive games enhance cooperation with others (\# 11, P 
$=0.011$, and require using a variety of manipulative, locomotors, and nonlocomotors skill (\# 14, $\mathrm{P}=0.015$ ), competence in many different forms of physical activity (\# 15, $P=0.045$ ). These results suggest that male physical educators maximize the role of competition in their classes in comparison to females.

The four significant items perceived positively by the female group included items $4,10,13$, and 19. However, each of these items belongs to different domain, they all could be explained from the point of view of sexoriented behavior. Females in general, and teenagers in particular and expressly in Kuwait, have life priorities different from males, and mostly, sports do not come first like males. Thus, teaching them the "rules, strategies and appropriate behaviors for selected physical activities (\# 4)" is very important. In comparison to males, most of females do not like to watch competitive sports; and in Kuwait they do not have permission to play outside home, except in schools. Thus, female physical educators have to teach their students these requirements to get adequate knowledge to enable them to play the required games. On the other hand, the negative perception of the male group to this item may be the result of students' understanding of most of these rules, except when they find controversial opinion between two competitive teams.

The importance of "keeping weight controlled (\# 19)" for females in general, and teen females in particular, might be the reason that influence the perception of the female group toward this goal. In addition to this reason, 
soccer in the boys' program has been replaced by modern dance in the females' program. This replacement may also influence the perception of the female group to record a positive significant difference in comparison to males regarding the influence of the physical education program in helping students "to move using concepts of body awareness, space awareness, effort, and relationship (\# 13)" (Griffin, 1983, 1985).

The last positive significant difference accounted for the perception of the female group in comparison to the male group was related to the affective domain. Teen males when competing consider themselves at work, they shout, using verbal harassment and physical contact, and sometimes quarrel with one another. On the other hand, most girls take competition as fun. Thus, the female group significantly agreed "the physical education program helps student appreciate the relationships with others that result from participation in physical activity (\# 10)".

\section{$\underline{\text { Research Question } 3}$}

Is there any significant difference among teachers' perceptions regarding number of years' teaching experience toward: (a) cognitive, (b) affective, (c) psychomotor, and health-related fitness domains?

The sample of the present study was internally divided into three groups representing number of years' teaching experience (1-5, 6-10, and 11-15 years). The three groups were found unequal in size and consisted of: group 1: 53 or $26.5 \%$ (19 females \& 34 males), group 2: 68 or $34.0 \%$ (36 females, and 34 males), and group 3: 79 or $39.5 \%$ (45 females \& 34 males). Mean and 
standard deviation of each group were as follows: group 1: $M=2.65$ and $S D=$ 1.17, group 2: $M=8.24$ and $S D=1.15$, group 3: $M=13.20$ and $S D=1.35$.

It can be seen from the sample's analysis that the percent of participants in this study increases as years of experience increased. This result might be related to different reasons. Physical education started in Kuwaiti schools in the fourth decade of the last century. It started as other subjects with physical educators from the Arab countries. Since that time, teaching of this subject depends on teacher from the Arab countries. One of Kuwaiti customs is that they do not forget those who help them, especially in the field of teaching. However, their salaries are more than they got in their countries. At present time, the new generation of Kuwaiti teachers replaces them gradually.

Another point is related to the small number of females $(n=19)$ in the $1-5$ group. Young Kuwaiti females usually get married, and they prefer to be housewives, or their husbands convince them to retire to take care of their future children.

Results of the comparison among the three stages of teaching experience groups indicated that significant differences were only found in four (\# 3, 5, 17, and 20) of the 24 items.

Items number 3 and 5 are cognitive goals indicating that the physical education program helps students to "apply concepts and principles to the development of motor skills (\# 3)", "understand that physical activity provides the opportunity for enjoyment, self-expression, and communication". Significant 
difference $(P=0.014)$ was found between $1-5$ and $11-15$ groups indicating that the perception of the 11-15 group was more positive in comparison to the 1-5 group. The opposite was found in there two groups regarding item 5, the 1-5 group perceived this statement significantly positive in comparison to group 11$15(p=0.017)$.

However, both statements are real goals that can be realized through physical education. Developing a motor skill is considered to be work. The only possible way for developing skill is through hard practice. Enjoyment, selfexpression, and communication through physical education do not require the participant to reach the perfection level in performing motor skills. Just playing within a group of friends helps to realize these goals.

The fact that both groups perceived a designated statement positively does not necessary mean that they were right in their perception. A possible explanation is that the most experienced group believed in the disciplinary approach in teaching physical education. This approach is considered to be activity-centered curriculum, and its major purpose is to achieve specific movement skills. The assumption of this approach is that students can achieve educational ends by doing what is dictated to them by the teacher. On the other hand the less experienced group believed in the recreational approach. This approach is considered to be joyful centered curriculum. Secondary schoolstudents as adolescents need both sides. 
To summarize, out of 24 goals comprising the KPEG, there were only seven that turned out to be significantly positive. However, positive or negative significant items between males and females were eight, and between stages of teaching experience were four. Therefore, the gender and experience significant items might influence the results of these items. Accordingly, only five items did not reach the significant level. These items were: \# 6 (Cognitive), \# 8, and 9 (Affective), and \# 16, and 18 (Psychomotor). From the results of these items, it may be concluded that a number of participants perceived them positively, and about an equal number perceived them negatively.

Finally, the styles of curriculum all have their strengths and weaknesses. It is true that the majority of the styles provide students experiences in preparation for present and future involvement in physical education. But, the style of the time in the secondary school in Kuwait is the disciplinary approach that dictates teachers to guide students in gaining perfection in many motor skills comprising many physical activities. The result of this study found this approach has influence in realizing quite a of the psychomotor and affective domain goals, and has a weak influence on realizing the cognitive and healthrelated fitness goals.

Considering the fact that the secondary school students are in the adolescence stage, secondary schools may be considered as the best period to educate a person for future life about physical activities and healthy living styles. 
Therefore, the researcher suggests the use of the social interaction curriculum. The emphasis of this curriculum as Portman \& Nelson (2001) described is on value clarification via small and large group interaction. This approach is guided by both affective and social objectives, which promote socialization. Through cooperation, competition, leadership activities, and sportsmanship, teachers control the students. A means-end orientation is usually in operation. Classes are organized for interaction. Students must demonstrate a sense of responsibility for themselves in relationship with others. Respect and fair play are criteria on which a portion of the student grade is based. Ends cannot always be determined in advance. In this approach, teacher's accountability is judged subjectively. 


\section{CHAPTER V}

\section{Summary, Findings, Conclusions, and Recommendations Introduction}

This chapter presents a brief summary of the study including the purpose, research questions, and summary of the findings, conclusions and recommendations.

\section{Research Summary}

Throughout history, physical activity has been considered an important component of the educational process and in diverse ways has been a significant element in all cultures. In its formal education institutional form, "physical education", it has enjoyed a continuing presence. Quality physical education programs taught by well-trained physical education specialists play a significant role in promoting the health of students and, ultimately, will adults.

Physical education in Kuwait is one of the subjects that is taught in public schools. Its general and official objectives are to grant optimal physical, mental, psychological, and social growth for the student. These objectives can be realized through paying attention to six areas: general health and posture, physical and motor fitness, physical preparation for defending homeland, learning and enhancing motor skills, and developing sportsmanship.

Students in the secondary schools have to attend two-class meetings per week with a total of 66 class hours for each grade level (based on thirty four 
week school year). Such classes are 40 minutes in length consisting of 20 to 25 students. Time in each class session (40 minutes) is divided into: (a) five minutes for putting on the sport uniform and roll call, ten minutes for warming up and fitness exercises, and (c) twenty minutes for playing the required sport activities, and (d) five minutes for cooling down and collecting the equipment.

Goals and programs of physical education in Kuwait are organized by the Ministry of Education for the development of students' abilities and their physical fitness. If this program is to be accepted as a worthwhile subject, it must demonstrate concrete outcomes that result from participating in physical education. Therefore, the present research examined the perception of physical educators of secondary schools toward the physical education program.

The major purpose of this study was to find out where we are now in realizing the educational goals of the secondary school physical education program in Kuwait. A survey was conducted using a questionnaire "Kuwaiti Physical Education Goals", briefly KPEG, to find answers to this inquiry. The study consisted of three major questions. These questions were:

1. How do Kuwaiti physical education teachers perceive the domain goals of the physical education program?

2. Do Female and male teachers differ significantly in their perceptions relevant to the goals of the: (a) cognitive, (b) affective, (c) psychomotor, and (d) health-related fitness domain? 
3. Is there any significant difference among teachers' perceptions in regard to the number of years of teaching experience toward: (a) cognitive, (b) affective, (c) psychomotor, and (d) health-related fitness domains?

In order to have a representative sample of the six Educational Provinces, a stratified random sampling technique was used to ensure that each individual in the defined population had an equal and independent chance of being selected as a member of the study (Best \& Kahn, 1998). Thus, each province was represented in the sample according to what it represented in number to the total male and female physical educators.

According to the secondary school physical education program in Kuwait, this study investigated the following domains' goals: (1) cognitive domain, (2) affective domain, (3) psychomotor domain, and (4) health-related fitness domain. To measure the importance of Kuwaiti Physical Education Goals (KPEPG), a questionnaire for measuring the importance of the program goals as well as each domain's goal was developed.

A five-category Likert scale was used for each item ( $1=$ strongly agree, $2=$ Agree, $3=$ Uncertain, $4=$ Disagree, $5=$ strongly disagree). Types of items in the KPEG included two sections. Section one sorted for the demographic information that included the participant's educational province, gender, and years of experience. Items on section two included a series of closed-ended statements designed to collect information about teachers' perceptions of the importance of 
selected physical education goals. These items covered all four aspects of physical education secondary school goals in Kuwait.

All data were coded for computer handling, and was analyzed using the program Statistical Package for the Social Sciences (SPSS). Types of analyses used to in this study were as follows:

1. Cronbach's alpha reliability test was used for items measuring the dependent variables.

2. Factor analysis was employed to examine the validity of the KPEG.

3. Descriptive statistics were reported for the variables of the study (frequencies, percentages, means, and standard deviations).

4. Chi-square-test was used to determine if the frequencies observed are different from the frequencies that would be expected by chance. This test was used to determine the significant level of agreement or disagreement of the sample toward each of the four domains as well as each of the six statement goals comprising that domain.

5. To compare males' and females' perceptions toward each domain and each goal, a t-test for "independent-samples" was used to determine if significant differences existed in responses between male and female participants in this study. The 0.05 level of significance was utilized as the lowest level of significant acceptance. 
6. To find out the effect of years' of teaching experience (1-5, 6-10, 11-15 years) upon the perception of each of the four domain's goals, one-way analysis of variance was employed. And, in case of significance at the 0.05 level, multiple comparisons (Gabriel) was employed.

\section{$\underline{\text { Research Findings }}$}

In light of the results of the present study, the findings were as follows:

1.The result reflected a slightly positive perception of the sample toward the entire number of items of the KPEG.

2.Responses were distributed in descending order along the five points of the utilized scale as follows: $25.3 \%$ Agree, $23.7 \%$ Disagree, $20.7 \%$ Strongly agree, $20.4 \%$ Strongly disagree, and 10\% Uncertain.

3.The participants of this study perceived positively the psychomotor domain $(M=2.71)$ at the top with $52.2 \%(24.2 \%$ Strongly agree \& $28.0 \%$ Agree), followed by the affective domain $(M=2.76)$ recording $51.8 \%$ (25.0\% Strongly agree \& $26.8 \%$ Agree), then the health-related fitness domain $(M=2.97)$ with $46.0 \%$ positive agreement (20.7\% Strongly agree \& $25.3 \%$ Agree), and lastly the cognitive domain ( $M=3.09$ ) scoring $41.4 \%$ (17.6\% Strongly agree $\& 23.8 \%$ Agree) 
4.Items that reached the levels of significance were 14 with an equal number (7 items) of agreement and disagreements items. Thus, ten items were non-significant.

5.The significant agreement items were one of the cognitive domain goals (\# 5), and three of each of the affective (\# 7,10 , and 11 ), and psychomotor goals (\# 13, 14, 17).

6.The significant disagreement items were three of the cognitive domain goals (\# 1, 2, and 4), and four of health related fitness goals (\# 21, 22, 23, and 24).

7.Ten items were found to be non-significant. These items were: two in the cognitive domain goals (\#2, and 6), three in each of the affective (\# 8, 9, and 12) and psychomotor domain (\# 15, 16, and 18), and two in the health-related fitness domain (\# 19, and 20).

8. Results of the comparison between the perception of male and female group toward the 24 statement of the KPEG indicated that 8 items were found to be significant. Items that perceived more positively by males were items 11 and 12 (affective), 14 and 15 (psychomotor). Items that were perceived more positively by females consisted of items 4 (Cognitive), 10 (Affective), 13 (Psychomotor), and 19 (Health-related fitness).

9.Comparisons relevant to years' teaching experience yielded a significant positive perception for group 11-15 in comparison to 1-5 
group regarding items 3 (Cognitive) and item 20 (Health-related fitness), for group 6-10 in comparison to 1-5 group relevant to item 17 (Psychomotor), and for group 1-5 in comparison to 11-15 group regarding item 5 (Cognitive).

\section{$\underline{\text { Research Conclusions }}$}

Based on the results of the present study, the following conclusions were derived:

1. The KPEG was found valid and affective in detecting valuable perceptions of the sample toward the physical education program for the secondary school. Responses were distributed about equally along the five points of the scale with only $10 \%$ of uncertainty.

2. The total perception of the sample toward the KPEG statements as perceived by the sample of the present study was slightly on the side of agreement.

3. Significant and non-significant results showed that seven items were positively significant, and seven items were negatively significant while ten items were non-significant. According to these results, it might be concluded that the perception of the physical education teachers in Kuwait toward physical education goals for secondary schools students needs to be elevated. 
4. The physical education program for secondary schools as perceived by a sample representing physical educators in Kuwait was found, to a suitable extent, to be effective in realizing the psychomotor and affective domain goals. The content and style of the physical education program and/or the command style as teaching style may influence this result.

5. The sample representing the physical educators in Kuwait did not match the cognitive and health-related fitness domain goals pertaining to the physical education program for secondary school students. The content and style of this and/or the command style as a teaching style may influence this result.

6. Comparisons between males and females indicated significant differences in their perceptions regarding eight of the 24 items (about 33\%). These items are very much related to the nature of the culture in Kuwait, and the needs of males and females secondary school students as adolescents.

7. Years of teaching experiences did not have a great influence on teachers' perception, as only four out the 24 items comprising the KPEG were found significant. 


\section{Recommendations and Implications of the Study}

In light of the results of this study, several recommendations can be made. These recommendations involve:

1. The disciplinary curriculum approach and the command style in teaching secondary school students should be changed to meet the needs of the adolescence period they are living, and to prepare them for participating now and through their adult years in physical activities. Thus, the researcher recommends the social interaction approach as suitable curriculum approach for secondary school students.

2. Changing the curriculum style to the social interaction approach would require enough equipment to meet the needs and desires of the students.

3. Secondary school physical educators in Kuwait may be in need of professional development to aid them in applying the concepts of the cognitive and health-related fitness domain to their students.

4. Developing the goals of the cognitive domain requires transforming the responsibility gradually throughout the three years of the secondary school from the teacher to the students. 
5. Secondary school physical educators should provide their students with written documents, statements, and tableau to enlighten, advise, and convince students about the needs and values of practicing heath-related fitness exercises.

6. Two 40 minutes classes per week is not enough for developing health-related fitness; thus, schools must open their doors after the educational day and in holydays to enable students to practice in homogenous groups heath-related fitness exercises.

7. Realizing and refining more physical educational goals require adding one more class session to be three instead of two per week.

8. Male physical educators should pay attention and apply adequate solutions for decreasing the level of tension associated with competitions, praising appropriate behaviors and sportsmanship.

9. Female physical educators should pay attention to increasing the level of competence in performing motor skills and physical activity.

10. No one can ignore the role of years' teaching experience, and no one can decrease the importance of new concepts and knowledge of young physical educators; thus, it is preferable 
that the staff of physical education in each school, as possible, comprises three generations of teaching experience.

11. Health education, including health related fitness, should be considered as a subject in the field of student's education, starting in elementary schools.

12. Further research on this topic might examine the physical education programs for junior high and elementary schools. 


\section{REFERENCES}

AAHPERD. ORG (1997). Health-related physical fitness test. Int.] In association with The Gale Group and LookSmart, 2001.

AAHPERD. ORG (2000). Curriculum Framework Health and Physical Education, Definition and Rational. Int.] in association with The Gale Group and LookSmart, 2001.

Alsagheir, A. (1993). Intermediate physical education goals evaluation from the teachers and supervisors point views. Unpublished master's thesis, King Saudi University, Riyadh, Saudi Arabia.

American J ournal of Public Health (1993). Social Issues as Public Health: Promise and Peril. Int.] in association with The Gale Group and LookSmart, 1998.

Arnold, P. J. (1991). Health promotion and the movement curriculum, Health Education Journal, 50 (3), 123-127.

Asci, H. (2001). The relationship of self-concept and perceived athletic competence to physical activity level and gender among early adolescents. Adolescence. Fall. Libra Publishers, Inc. Int.] in association with The Gale Group and LookSmart, 2002.

Bain. L. (1985). The hidden curriculum re-examined. Quest 37 (2), 145-153.

Beauchamp, G. A. (1969). A Curriculum Theory. Wilmette, Illinois: Kagg Press. 
Best, J., \& Khan, J. (1998). Research in Education. Boston: Allyn and Bacon.

Black, L. (1986). Physical education in New Zealand secondary schools. Int ] Research Report Series 36. Wellington: Department of Education, research and Statistics Division.

Bloom, B. (1956). Taxonomy of educational objectives Handbook 1: Cognitive domain. New York: Mckay.

Bucher, C. \& Wuest, D. (1987). Foundations of Physical Education and Sport. , St. Louis: Times Mirror.

Centers for Disease Control and Prevention (1996). Physical activity and health: A report of the surgeon general, Atlanta.

Chou, H. S. (1989). Perceived movement purposes among physical educators in Taiwan, Republic of China. (Doctoral dissertation, University of Georgia, 1989).

Coates, J. (1981). Technology assessment: The benefits, the costs, the consequences. The Futurist, 15. 225-231.

Corbin and Pate (1981). The physical fitness taxonomy. Lournal of Health, Physical Education, Recreation, and Dance. 55. 22-25. 
Dietz. W. H. \& Gortmaker, S. (1985). Do we fatten our children at the television set? Obesity and television viewing in children and adolescents. Pediatrics 75. $807-812$.

Educational Office of the Arab Gulf countries. (1980). Evaluation of the current physical education curriculum in the Arab Gulf Countries according to their goals setting. Riyadh, Saudi Arabia.

El-Naggar, A., Al-Nakeeb, Y., \& Al-Hazzaa, (1991). Physical education in the secondary school in Saudi Arabia. Lournal Saud University (3), 561-582.

Figley, G, E. (1984). Moral education through physical education. Quest. 36. 89 $-101$.

Flavel, J.H.F. (1977). Cognitive Development. Englewood Cliffs, NJ : Prentice-Hall.

Flintoff, A. (2000). Physical education. Equal opportunities and the national curriculum: crisis or challenge. Physical Education Review, 83 (2). 85-100.

Ford, M., Wentzel, K., \& Wood. D. (1989). Processes associated with integrative social competence: Emotional and contextual influences on adolescent social responsibility. Lournal of Adolescent Research. (4), 405-425.

Fry, M. (1999). Reading in physical education. ACHPER National Journal,_Spring. $9-12$. 
Graham, G. (1991). Result of motor skill testing. Lournal of Teaching in Physical Education (10). 353-374.

Griffey. D. (1987). Trouble for sure, a crisis - perhaps: Secondary school physical education today. Lournal of Health Physical Education. Recreation and Dance 58 (2), 20-21.

Griffin, S. (1983). Girls' participation patterns in a middle school team sports unit. Lournal of Teaching in Physical Education. 4, 30-38.

Griffin, S. (1985). Boys' participation in a middle school physical education team sport unit. Journal of Teaching in Physical Education. 4, 100 -110.

Harrison, J., Blackman, L., Buck, N., \& Pellett, T. (1996). Instructional strategies for secondary school physical education. Chicago: Brown \& Benchmark.

Haywood, K. M. (1991). The role of physical education in the development of active lifestyle. Research Quarterly for Exercise and Sport. (62). 151-156.

Hedlund, R. R. (1985). Kansa secondary school physical Education teachers' ranking of the goals of physical Education. Doctoral dissertation, Northern Illinois University. Dissertation Abstracts International. 46. 3584.

Hellison, D. (1985). Goals and Strategies for Teaching Physical education. Champaign, EL: Human Kinetics. 
Hlellison, D. (1993). Evaluating the affective domain in physical education: beyond measuring smiles. In J. E. Rink (Ed.), Reston: VA: National Association for Sport and Physical Education.

Hill, J. \& Trowbridge, F. (1998). Childhood obesity: Future directions and research priorities. Int. Pediatrics. 101, 570-574.

Hughes, William L, and Esther French. (1984). The administration of physical education for \& schools and colleges. New York: The Ronald Press Co.

Jensen, G. 0. (1975). The relationship of physical educational purposes and program implementation. Unpublished doctoral dissertation, University of Wisconsin, Madison. Dissertation Abstracts International, 36. 7929A.

Jerome, Q. \& Geraldine, H. (1996). African American students' perceptions of the values of basic physical education activity programs at historically black colleges and universities. Lournal of Teaching in Physical Education. 15, 188-204.

J ewell, J. F. (1995). Physical education teachers' perceptions of the goals of high school physical education. Unpublished doctoral dissertation, West Virginia University, Morgantown, West Virginia. Dissertation Abstracts International, 56. 3049.

Jewett, A. (1980). The status of physical education curriculum theory. Quest. $32(2) .163-173$. 
Jewett, A. (1994). Curriculum theory and research in sport pedagogy. Sport Science Review, 3 (1). 56-72.

J ewett, A., \& Mullen, M. (1977). Curriculum Design: Purpose and Processes in Physical Education: Teaching-learning. Washington: DC. AAHPER Publications.

Johnson, J.B.Thomas, R.G. (1992) Cognitive Theory-based teaching and learning in vocational education. Columbus, $\mathrm{OH}$; Center on Education and Training for Employment, Ohio State University.

J oyce, B., \& Weil, M. (1996). Models of Teaching. Boston: Allyn and Bacon.

Krawthwhol, D., Bloom B., and Masia, B. (1964). Taxonomy of Educational Objectives. HandbooklI: Affective Domain. New York: McKay.

Lambdin, D., \& Steinthardt, Ni. (1991). Elementary and secondary physical education teachers' perceptions of their goals. expertise. curriculum, and students' achievement. Lournal of Teaching in Physical Education. (11). $103-111$.

Lavie, C. Milani, R. Squires, W. (1993). Exercise and the heart: good, being, or evil? Cardiovasc. Dis. 91. 130-150.

Light, R., Singer, J., Willett, J. (1990). By design. Cambridge, MA: Harvard University Press. 
Luepker, R. (1999). How are physically active are American children and what can we do about it? Int.] The Gale Group and LookSmart.

Mack, G. (2001). Bridging the gab between medicine and fitness. Int.] Idea Personal Trainer.

Magill, R. \& Ash, M. (1979). Academic, psychosocial and motor research review. Scandinavian J ournal of Educational Research, 30 (4). 167-179.

Mark, S., Arkin, L. Kiefiuk, L. (2000). What fitness goals are you vowing to achieve? Int.] American Academy of Family Physicians in association with The Gale Group and LookSmart.

Martin, P. V. (1992). Educational value orientations and physical education goals. Unpublished doctoral dissertation, University of Georgia. Dissertation .Abstracts International, 53, 2291.

Medin D. (2000). Are their kinds of concepts? Int.] Annual Reviews of Psychology. , Inc. in association with The Gale Group and LookSmart.

Melograno, V. (1996). Designing the Physical Education Curriculum. Champaign, IL. : Human Kinetics.

Meyer, M. (1997). The new PE. (physical education changes) includes tips on encouraging physical fitness at home). Int.] The Gale Group and LookSmart. 
Ministry of Education, Kuwait, (2000). Handbook: Secondary School Physical Education Curriculum.

Mohr, D. (1971). Identifying the body of knowledge. Lournal of Health, Physical Education, Recreation and Dance. (42). 23-28.

Mosston, M. \& Ashworth, S. (1986). The Spectrum of Teaching Styles. Charles E. Merrill Publishing Co. Columbus, Ohio.

NASPE. (1992). Program guidelines and appraisal checklist for physical education, middle school.

NASPE. (2001). Shape of the nation report: Executive summary, 1-7. Research Quarterly for Exercise and Sport. 62 (2): 143-147.

National Center for Health Statistics (U.S.). Healthy people 2000.

National Institutes of Health Consensus Development Panel on the Health Implications of Obesity (1995). Health implications of obesity: National Institutes of Health consensus development conference statement. Int.] Lournal of the American Medical Association. (103): 1073-1077.

Newcomb, L. H. \& Treftz, M. K. (1987). Toward teaching at higher levels of cognition. NACTA Journal (31) : 145-152.

Nixon, J. \& Jewett (1984). Introduction to Physical Education. $9^{\text {th }}$ edition, Philadelphia: W. B. Saunders company. 
Noddings, N. (1992). The challenge to care in schools. New York: Teachers College Press.

Norman, D. (1980). Cognitive and education. In NJ: Enlbaum.

Novak, L. P., Hyatt, R. E., and Alexander, I. F. (1998). Body composition and physiologic function of athletes. Journal of the American Medical Association (205):764-770.

Ornstein, A., \& Hunkins, F. (1993). Curriculum foundations. principles. and theory. Boston: Allyn and Bacon.

Osterhof, A. (1994). Classroom application of educational measurement. New York: Macmillan.

Outcomes Committee. (1992). Outcomes of quality physical education programs. Reston, VA. AAHPERD.

Page, T.G. et al. (1980). International Dictionary of Education. Cambridge, MA. The MIT Press.

Parker, J. (1995). Teacher and student beliefs about physical education. Research Quarterly for Exercise and Sport. (66): 67-72.

Portman, P. and Nelson, L. (2001). Educational physical education: Findings solutions and meeting the challenges. Strategies. A Journal of Physical and Sport Educators. 15 (1), 20-27. 
Preboth, M. (2000). Physical education and fitness in schools. Int.] American Academy of Family Physicians in association with the Gale Group and LookSmart.

Riley, M. (1992). Review of Primary Care-Based Physical Activity Intervention Studies. Int.] Appleton \& Lange in association with The Gale Group and LookSmart.

Sadovsky, R. (2001). Promoting lifestyle physical activity and health. American Family Physician. Int.] American Academy of Family Physicians association with The Gale Group and LookSmart.

Schurr, E. (1985). Movement experiences. A humanistic approach. Prentice-Hall International, Inc.

Sefert, Kelvin L. (1991), Educational Psychology. Boston, MA: Houghton Mifflin Company.

Siedentop, D., Mand. C., \& Taggart. A. (1994). Physical Education: Teaching and Curriculum Strategies for grades 5-12. Palo Alto, CA: Mayfield.

Simons-Morton, B., Taylor, W. Snider, S. (1994). Observed levels of elementary and middle school children's physical activity during physical education classes. Prev. Med. (23): 437- 441. 
Sound, S., \& Everett. P. (1981). Physical education objectives as expressed as needs by Florida State University students. Lournal of Health. Physical Education. Recreation and Dance. 52(5), 15-17.

Speakman, M. A. (1987). A cross-cultural comparison of physical education purposes. Lournal of Teaching in Physical Education. (6): 252-258.

Stillwell, J. \& Willgoose, C. (1997). The physical education curriculum. Boston: Allyn and Bacon.

Stroot, S., \& Morton, P. (1989). Blueprints for learning. Physical Education (8): 213-222.

Target (2002). Fitness; New effort urges middle-schoolers to take 10,000 steps a day. Int.] American Academy of Family Physicians in association with The Gale Group and LookSmart.

Thomas, R.G. (1992). Cognitive theory - based teaching and learning in vocational education. Columbus, $\mathrm{OH}$ : Center on Education and Training for Employment, Ohio State University.

Van Dalen, B., \& Bennett, L. (1971). World history of physical education: Culture, philosophical comparative. New Jersey: Prentice Hall. 
Williams, J. (1984). Education through the physical. An anthology of contemporary readings. Howard and Aileen Lockhart, Eds. Dubuque: Win. C. Brown Company Publishers, 2nd Ed.

Woodford, R. (1979). The importance of the affective domain in the education of physical education. Quest, 31(2), 285-293.

Zeigler, E. (1988). History of physical education and sport. IL: Stipes Publishing. 


\section{APPENDIX A: DEMOGRAPHI C INFORMATION}




\section{DEMOGRAPHIC INFORMATION}

Participant Code:

\section{PART 1: FACULTY DEMOGRAPHICINFORMATION}

Directions: Please answer each question by either filling information required or selecting the category that best reflect your current situation.

1. Gender:

a) Male

b) Female

2. What is the name of the school at which you are currently teaching?

3. In which province are you currently teaching?

4. Years of teaching of teaching Physical Education

5. Qualifications:

a) Have bachelor's degree and above

b) Less than bachelor's degree

6. Are you familiar with goals of secondary schoools physical education in Kuwait?

a) Yes

b) No 


\section{APPENDI X B: SURVEY OF PHYSI CAL EDUCATION GOALS}




\section{SURVEY OF PHYSICAL EDUCATION GOALS}

Participant Code:

\section{PART 2: PHYSICAL EDUCATION GOALS}

Directions: The following are group of statements regarding the goals of Physical Education.

Please read the statements carefully, and check $(\sqrt{ })$ one to indicate to what extent you agree with these statements.

\begin{tabular}{|c|c|c|c|c|c|}
\hline Statement Goals & $\begin{array}{l}\text { Strongly } \\
\text { Disagree }\end{array}$ & Disagree & Uncertain & Agree & $\begin{array}{l}\text { Strongly } \\
\text { Agree }\end{array}$ \\
\hline $\begin{array}{l}\text { 1. Physical education program helps students know the } \\
\text { benefits, costs and obligations associated with regular } \\
\text { participation in physical activity }\end{array}$ & 1 & 2 & 3 & 4 & 5 \\
\hline $\begin{array}{l}\text { 2.Physical education program help students recognize the } \\
\text { risk and safety factors associated with regular participation } \\
\text { in physical activity. }\end{array}$ & 1 & 2 & 3 & 4 & 5 \\
\hline $\begin{array}{l}\text { 3.Physical education program help students apply concepts } \\
\text { and principles to the development of motor skill }\end{array}$ & 1 & 2 & 3 & 4 & 5 \\
\hline $\begin{array}{l}\text { 4.Physical education program helps students know the } \\
\text { rules, strategies and appropriate behaviors for selected } \\
\text { physical activities. }\end{array}$ & 1 & 2 & 3 & 4 & 5 \\
\hline $\begin{array}{l}\text { 5.Physical education program helps one to understand that } \\
\text { physical activity provides the opportunity for enjoyment, } \\
\text { self-expression, and communication. }\end{array}$ & 1 & 2 & 3 & 4 & 5 \\
\hline $\begin{array}{l}\text { 6.Physical education program helps students realize } \\
\text { activities that can continue outside of school. }\end{array}$ & 1 & 2 & 3 & 4 & 5 \\
\hline $\begin{array}{l}\text { 7. Physical education program helps students improve self- } \\
\text { confidence. }\end{array}$ & 1 & 2 & 3 & 4 & 5 \\
\hline $\begin{array}{l}\text { 8. Physical education program helps students release } \\
\text { tension and frustration. }\end{array}$ & 1 & 2 & 3 & 4 & 5 \\
\hline $\begin{array}{l}\text { 9. Physical education program helps students develop } \\
\text { emotional stability. }\end{array}$ & 1 & 2 & 3 & 4 & 5 \\
\hline $\begin{array}{l}\text { 10. Physical education program helps students appreciate } \\
\text { the relationships with others that result from participation } \\
\text { in physical activity. }\end{array}$ & 1 & 2 & 3 & 4 & 5 \\
\hline $\begin{array}{l}\text { 11. Physical education program helps students cooperate } \\
\text { with others to achieve common goals. }\end{array}$ & 1 & 2 & 3 & 4 & 5 \\
\hline $\begin{array}{l}\text { 12. Physical education program helps students appreciate } \\
\text { the role of exercise in healthful hiving. }\end{array}$ & 1 & 2 & 3 & 4 & 5 \\
\hline
\end{tabular}




\begin{tabular}{|c|c|c|c|c|c|}
\hline Statement goals & $\begin{array}{l}\text { Strongly } \\
\text { Disagree }\end{array}$ & Disagree & Uncertain & Agree & $\begin{array}{l}\text { Strongly } \\
\text { Agree }\end{array}$ \\
\hline $\begin{array}{l}\text { 13. Physical education program helps students move using } \\
\text { concept of body awareness, space awareness, effort, and } \\
\text { relationship. }\end{array}$ & 1 & 2 & 3 & 4 & 5 \\
\hline $\begin{array}{l}\text { 14. Physical education program helps students } \\
\text { demonstrate competence in a variety of manipulative, } \\
\text { locomotor and non-locomotor skills performed individually } \\
\text { and with others. }\end{array}$ & 1 & 2 & 3 & 4 & 5 \\
\hline $\begin{array}{l}\text { 15. Physical education program helps students } \\
\text { demonstrate competence in many different forms of } \\
\text { physical activity. }\end{array}$ & 1 & 2 & 3 & 4 & 5 \\
\hline $\begin{array}{l}\text { 16. Physical education program helps students } \\
\text { demonstrate proficiency program in few forms of physical } \\
\text { activity }\end{array}$ & 1 & 2 & 3 & 4 & 5 \\
\hline $\begin{array}{l}\text { 17. Physical education helps one to earn how to learn new } \\
\text { skills. }\end{array}$ & 1 & 2 & 3 & 4 & 5 \\
\hline $\begin{array}{l}\text { 18. Physical education program helps students develop } \\
\text { skills in various sports. }\end{array}$ & 1 & 2 & 3 & 4 & 5 \\
\hline $\begin{array}{l}\text { 19. Physical education program helps students keep weight } \\
\text { controlled. }\end{array}$ & 1 & 2 & 3 & 4 & 5 \\
\hline $\begin{array}{l}\text { 20. Physical education program helps students assess, } \\
\text { achieve, and maintain physical fitness. }\end{array}$ & 1 & 2 & 3 & 4 & 5 \\
\hline $\begin{array}{l}\text { 21. Physical education program helps students design safe, } \\
\text { personal fitness program in accordance with principles of } \\
\text { training and conditioning. }\end{array}$ & 1 & 2 & 3 & 4 & 5 \\
\hline $\begin{array}{l}\text { 22. Physical education program helps students participate } \\
\text { in health enhancing physical activity at least three times a } \\
\text { week. }\end{array}$ & 1 & 2 & $\sqrt{3}$ & 4 & 5 \\
\hline $\begin{array}{l}\text { 23. Physical education program helps students select and } \\
\text { regularly participate in physical activities now and } \\
\text { throughout their adult years. }\end{array}$ & 1 & 2 & 3 & 4 & 5 \\
\hline $\begin{array}{l}\text { 24. Physical education program helps students keep in } \\
\text { good health and physical condition. }\end{array}$ & 1 & 2 & 3 & 4 & 5 \\
\hline
\end{tabular}

*Please write any important goals that were not listed in the questionnaire. 


\section{APPENDIX C: RELATED RESEARCH CORRESPONDENCE}


Educational Theory \& Practice

\section{West Virginia University}

College of Human Resources and Education

PO Box 6122

Morgantown WV 26506-6122

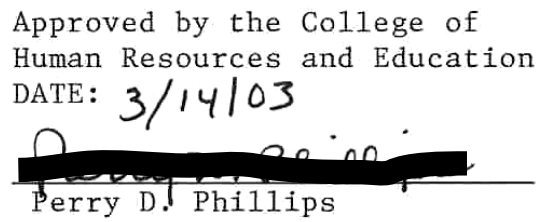

Dear Participant,

The purpose of this study is to investigate the present status of Teachers' Perceptions of the Goals of Secondary Schools Physical Education in State of Kuwait. The information gathered will be used for my doctoral dissertation.

Your participation is completely voluntary and you do not have to respond to every item or question. Please be assured that your responses will remain anonymous and confidentiality will be maintained.

If you should have any questions, please fell free to contact me at 216-5566 or email at obaid888@hotmail.com

Thank you in advance for your cooperation.

Sincerely,

Obaid Alshammari

$\frac{\text { Curriculum \& Instruction }}{304293-3441}$

Fax: 304 293-3802
Literacy Studies

$304293-4769$

Equal Opportunity / Affirmative Action Institution
Special Education 304 293-3450

Fax: 304 293-6834 


\section{Dear Teacher}

This research aims at knowing to what extent the physical education teachers perceive the objectives of physical education in the high secondary schools. It is a completion of the requirement of Ed.D dissertation in the Physical Education curriculum and methods of teaching. To conduct such a research a questionnaire to be answered by the concerned teachers is deemed necessary as far as they are concerned with the application of the school curriculum and realization of its goals. It is worth mentioning that all particulars enclosed herein will be dealt with confidentiality and will not be used in any field whatsoever other than the purposes of this research.

Thank you.

Sincerely,

Obaid Alshammari

The researcher 


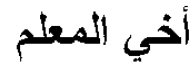 \\ ت ت مية و احتر ام}

يهذف هذا البحث إلى التعرف على مدى إدر الك معلمي التربية البدنبة لأهداف برنامج التربية البدنية للمرحلة الثانوية . يعتبر هذا البحث أستكمالا لمنطلبات درجة الدكتور اه في المناهج وطرق التّريس (تربيه بدنيه) حيث يتطلب ذلك إجر اء انتبانه يجبب عليها معلمي ومعلمات التربية البدنية بوصفه الأكثز ارثباطا بتتفيذ المنهج المدرسي. فهل تكرمت عزيزي المعلم بإعطائنا من وقتلك دقائق معدودة لتجيب عن أسئلة هذه الانتبانه ـ المهم أن تعبر عن ر أيك بصر احة هـ ملاحظة أن الببانات الكو اردة في الاستبانه سـوف تعامـل بنسرية تامـة ولن تسـتخدم إلا لأغر اض هذا البحث.

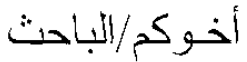

عبيـ محمد الثثمري
} 
$75 / 30 /$ EA0085698/01/5000

MINISTRY OF EDUCATION

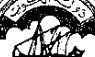

Educational Research and

Curricula Sector

Educational Research Administration

إدارة البحتوث التريوية

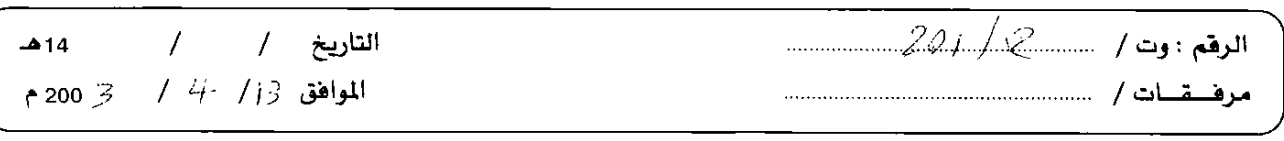

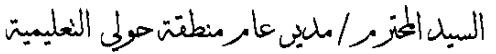 i

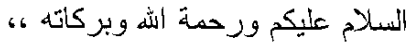

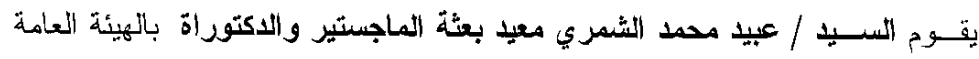

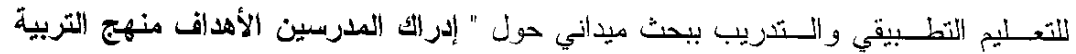

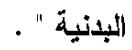

وبناء على طلبه برجى التكرم بتسهيل مهمــة النذكور أعـلاه بتطبيق بعض الأدوات البحثية

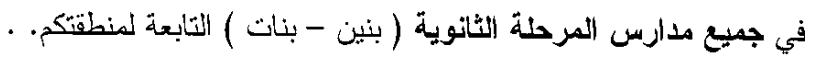

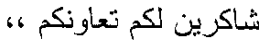

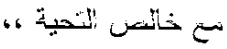

مساعلف مليق إدامة البحوث قالنطوي التربوي

سميحت البنديلنة

$+2$

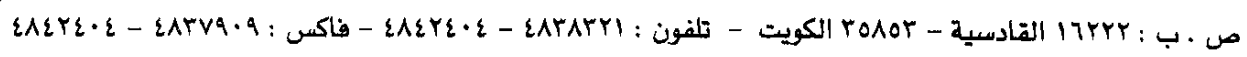
P.O.Box :16222 - QADSIAH - 35853- KUWAIT- Tel. : 4842404 - 4838321 - Fax : 4837909 - 4842404 


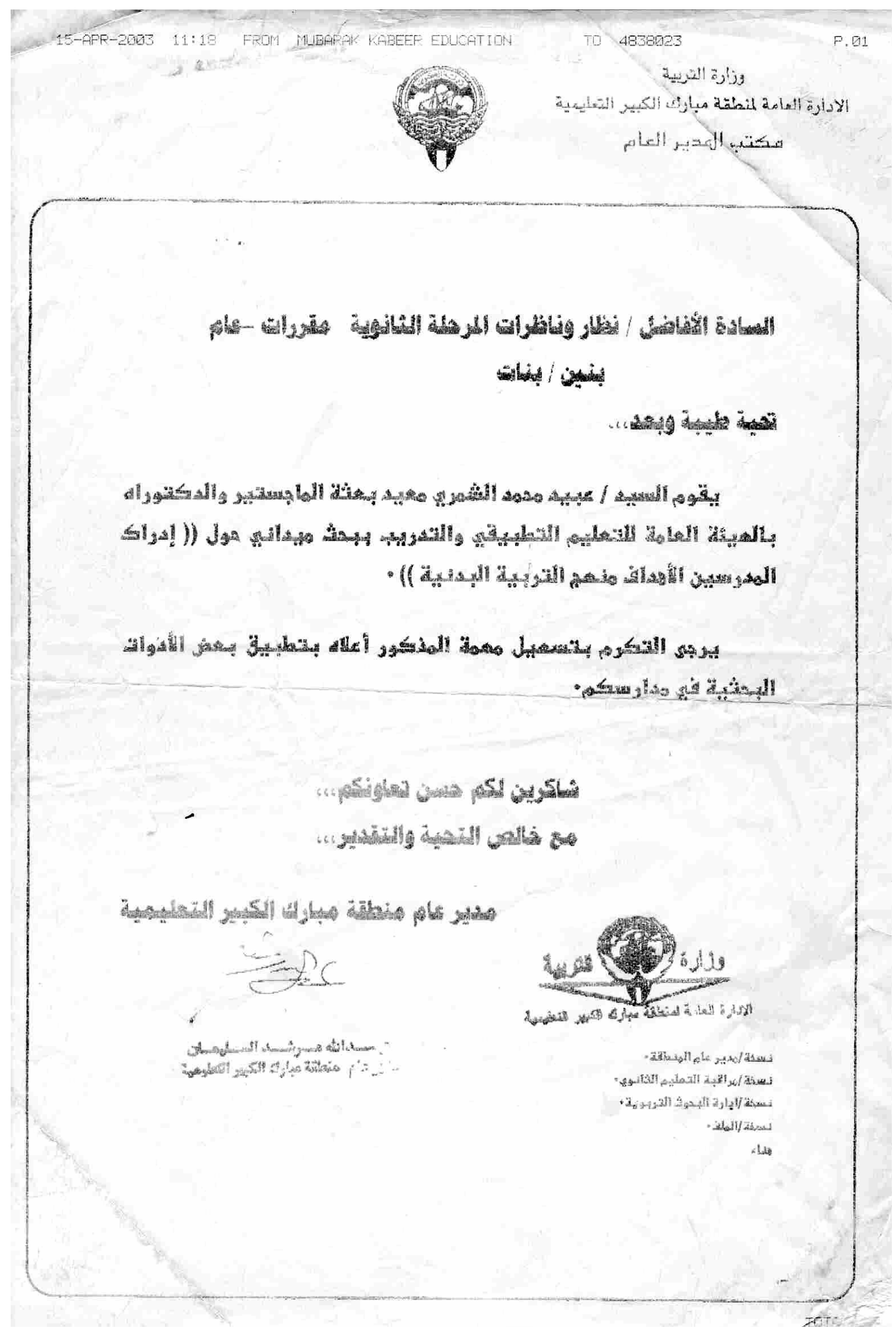




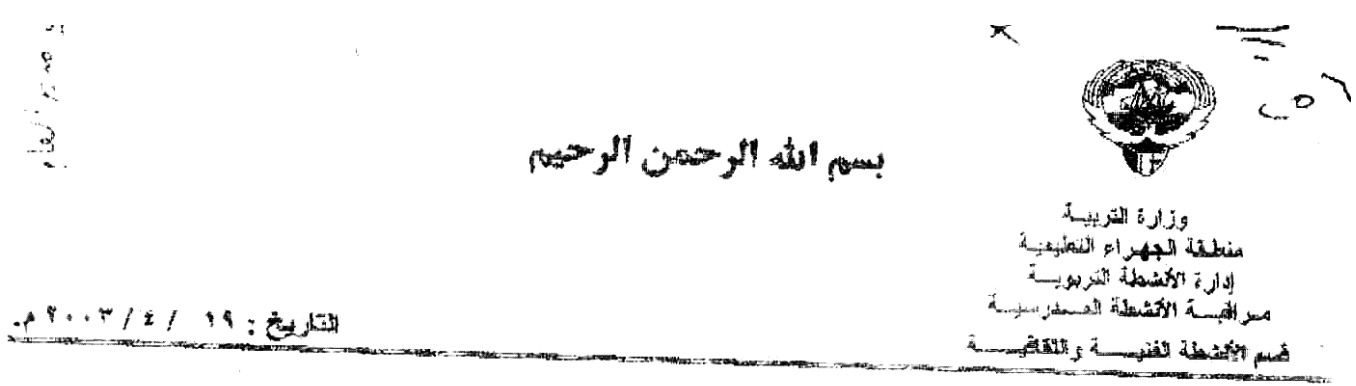

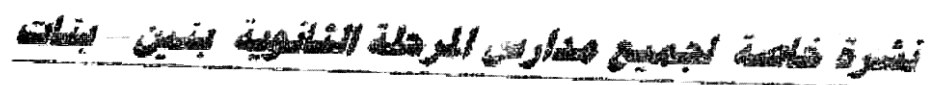

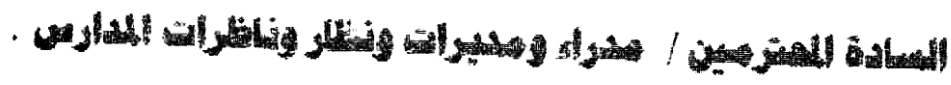

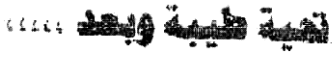

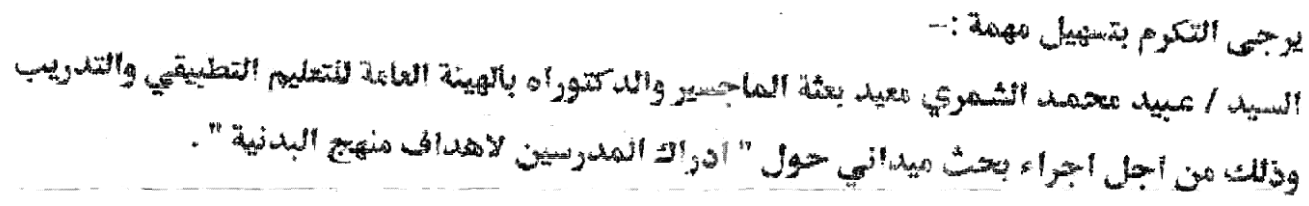

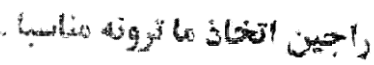

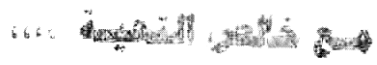

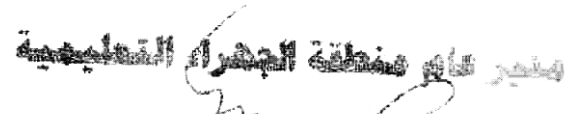

a w a d

A s.m a b
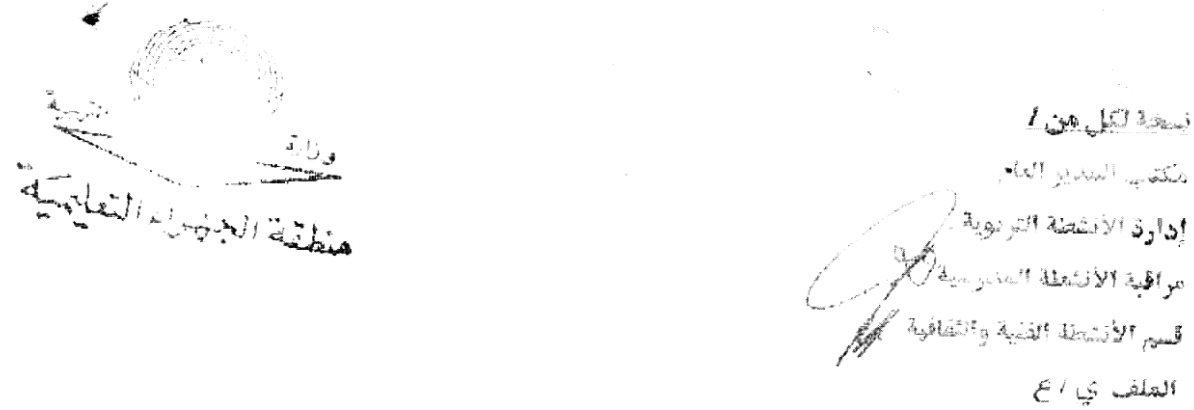
APPENDIX D: DEMOGRAPHI C I NFORMATI ON “ARABI C VERSI ON” 


\section{الجزء الاول: المعلومات الثخصيه}

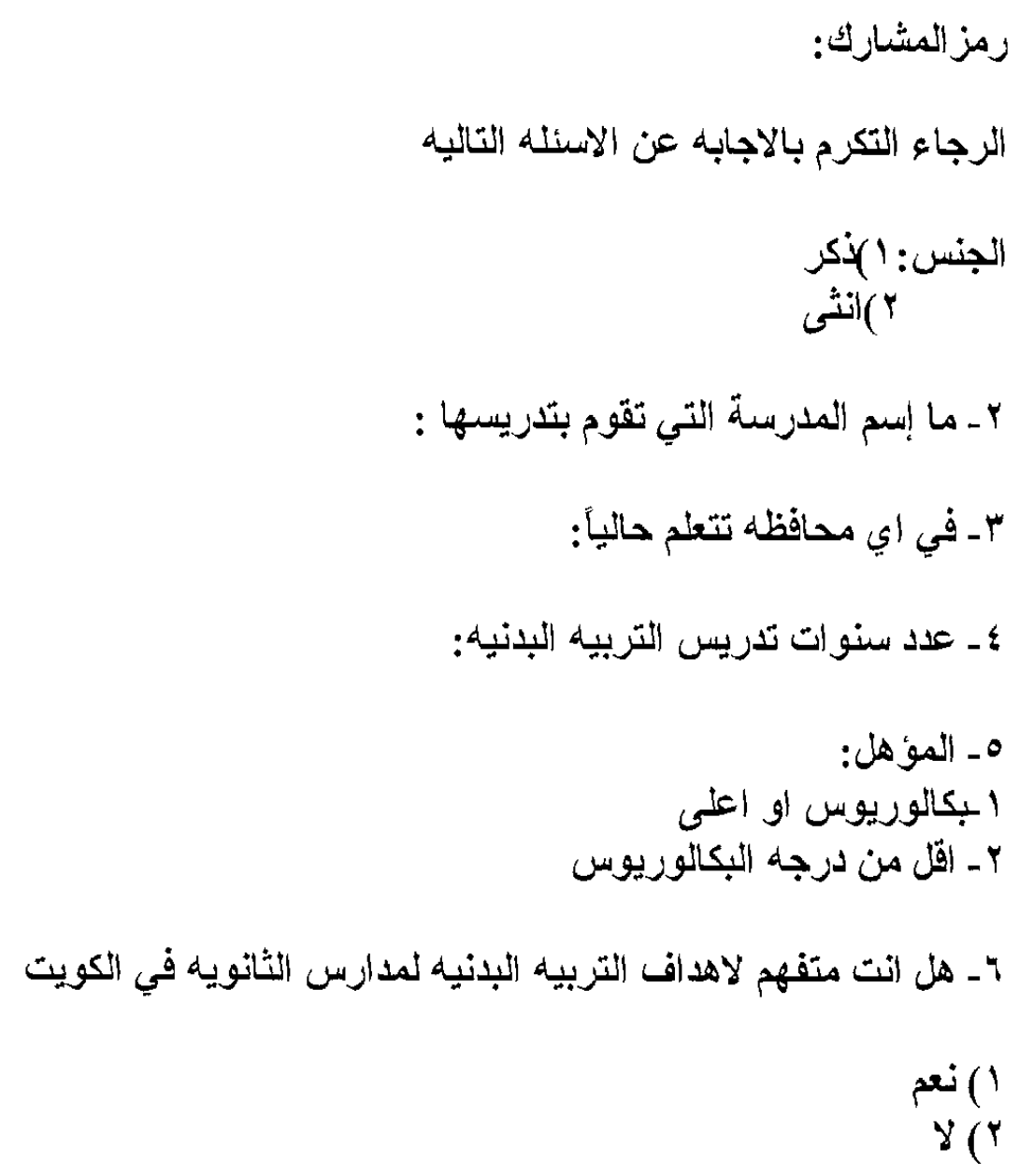


APPENDIX E: SURVEY OF PHYSI CAL EDUCATI ON GOALS “ARABIC VERSION" 


\section{استبيان عن اهداف التزبية الببنية}

رمز التمشارك

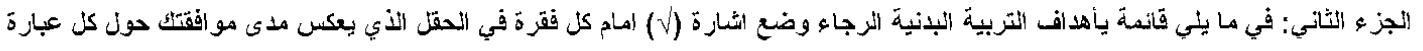

\begin{tabular}{|c|c|c|c|c|c|c|}
\hline أو افتق & أو أفق & غتأكد & مو افُق & مو أفّق & & الهنفف \\
\hline & & & & & 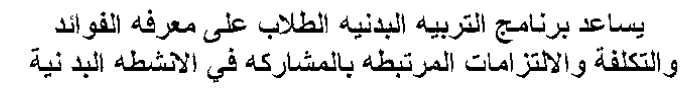 & 1 \\
\hline & & & & & 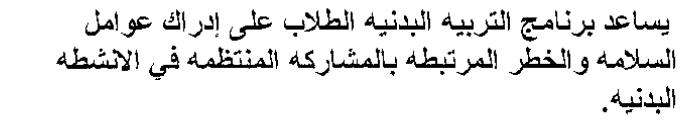 & 2 \\
\hline & & & & & 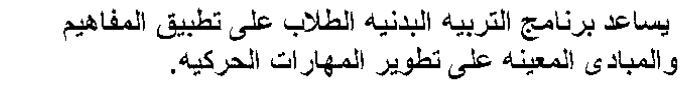 & 3 \\
\hline & & & & & 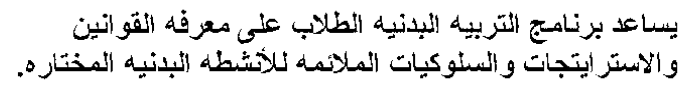 & 4 \\
\hline & & & & & 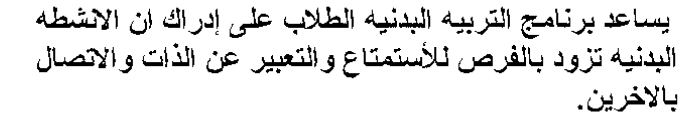 & 5 \\
\hline & & & & & 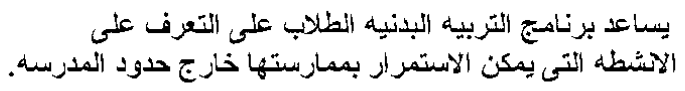 & 6 \\
\hline & & & & & يساعد برناميج التربيه البدنيه ألطلاب = & 7 \\
\hline & & & & & والاحباطد برنامه التربيه البانيه الطلاب على التخلص من التوتر & 8 \\
\hline & & & & & العاطفياعد برناميج التربيه البدنيه ألطلاب على تحقيق الاستقر ار & 9 \\
\hline & & & & & 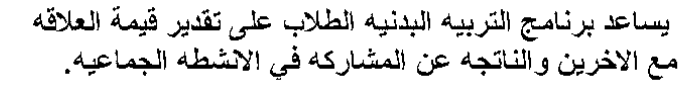 & 10 \\
\hline & & & & & 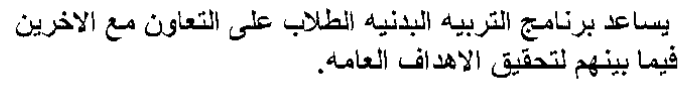 & 11 \\
\hline & & & & & 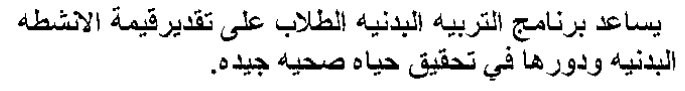 & 12 \\
\hline & & & & &  & 13 \\
\hline
\end{tabular}




\section{استبيان عن اهداف التزبية الببنية}

رمز التمشارك

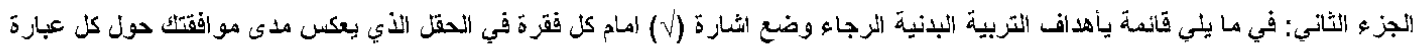

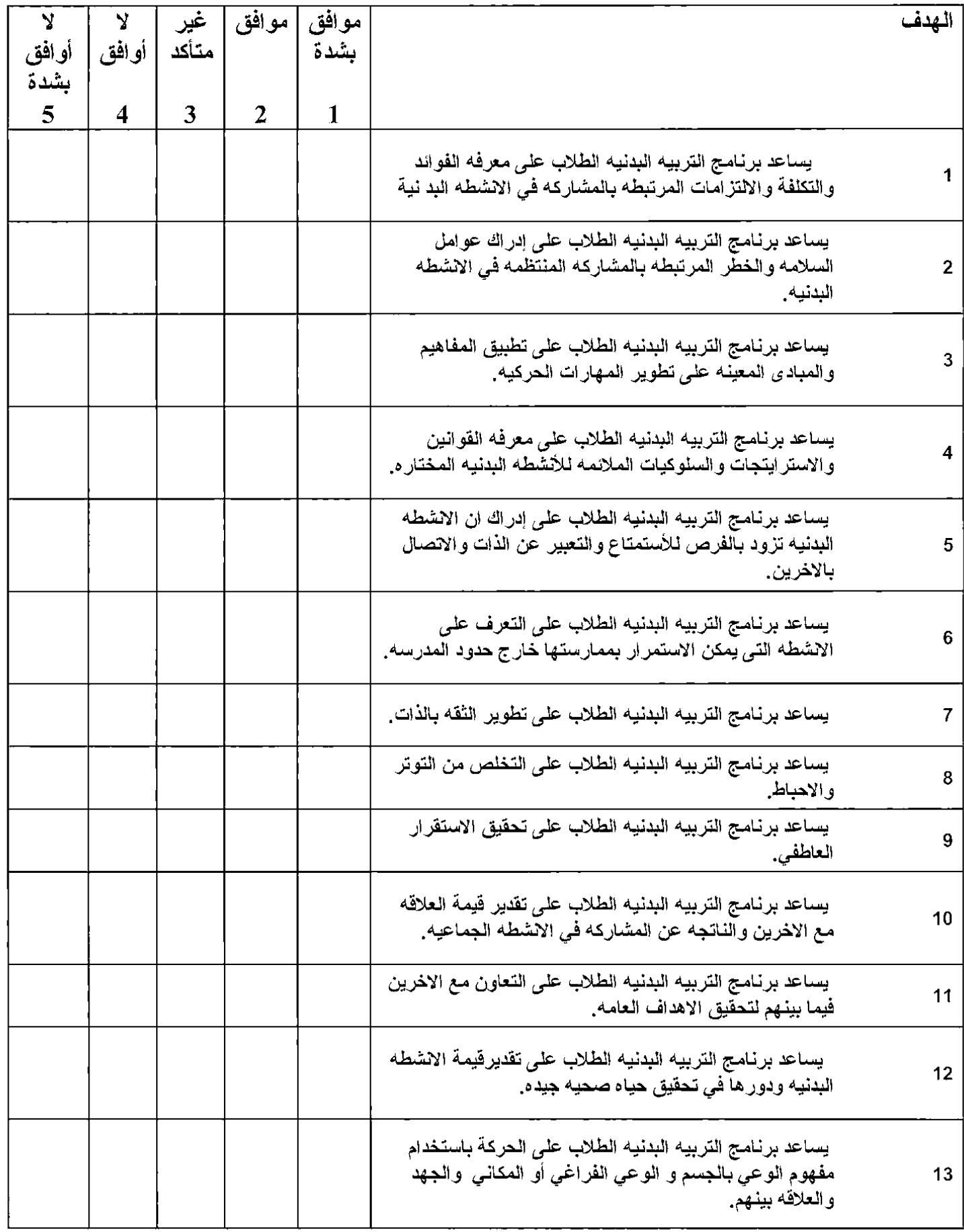




\section{CURRI CULUM VITAE}

Obaid Mohammad Al-Shammari

\section{Personal I nformation}

Date of birth: J anuary 19, 1965

Place of birth: Kuwait

\section{Education}

Ed.D. May 2004, West Virginia University, Morgantown, West Viriginia Major: Curriculum Instruction

Minor: Physical Education

Dissertation topic: Teachers' Perceptions of the Goals of Secondary Schools Physical Education in State of Kuwait

M.A. May 2002, West Virginia University, Morgantown, West Virginia Major: Secondary Education Minor: Physical Education

B.A. May 1996, Public Authority for Applied Education and Training Professional Experience

Teaching and I nstructional Support, teaching preliminary, intermediate, secondary levels, 1986-1996

Physical Education Supervision, 1996-2000

Member of J ournalist Association, 1998-current

Player in the Kuwaiti Soccer National Team, 1985-1996

Licensee in Soccer Training, 1998 